\title{
III. EXIL IN EUROPA: WIDERSTAND DURCH PLANUNG 1933-1937
}

\section{Europa im Bild: Europakonzepte der Emigration 1933-1937}

Fraglos belegen die Quellen schon für die ersten Jahre des Exils ein beachtliches Konvolut politischer Stellungnahmen zu Europa und zur europäischen Frage. Doch überwogen in dieser Zeit die politischen Einschätzungen des europäischen Status quo, denen häufig jede konzeptionell visionäre Komponente fehlte. Mithin ist der Europadiskurs im Sinne einer langfristigen Erörterung der zukünftigen Gestaltung des europäischen Kontinents nicht zu verwechseln mit dem allgemeinen Ruf nach einer „europäischen“ Gegenreaktion gegen Hitlers Revisions- und Annexionsforderungen. Denn damit war nicht mehr gemeint als die traditionelle Kooperation der europäischen Staaten als außenpolitisches Gebot der Stunde, nicht aber die strukturelle Verankerung einer solchen Kooperation in einem völkerrechtlich definierten europäischen Gefüge.

Selbstverständlich finden sich in den Quellen zahllose Beispiele für die wiederholte Forderung nach einer antifaschistischen Phalanx der europäischen Staaten, die sich insbesondere nach der Niederschlagung des österreichischen Arbeiteraufstandes im Februar 1934, nach der Saarabstimmung 1935 sowie nach dem Beginn des spanischen Bürgerkrieges 1936 in vehementen Aufrufen und apokalyptischen Warnungen entluden. Nur wenige Emigranten gingen aber soweit, über die Rückschlüsse aus der Tagespolitik hinaus strukturelle Veränderungen für ein Europa nach Hitler zu fordern. Dies lag zunächst an der weit verbreiteten Erwartung, das Hitler-Regime werde sich nicht lange halten können. Aus dieser Grunderwartung heraus resultierten die vorrangigen Bemühungen um die Organisation eines innerdeutschen Widerstandes, der zu gänzlich anderen, auf die innenpolitischen Entwicklungen konzentrierten Fragestellungen führte. Zudem fanden viele der von Hitler in den ersten Jahren nach seiner Machtübernahme durchgesetzten Revisionsforderungen auch in den Reihen der politischen Emigration Zustimmung. Nicht nur der emigrierte Nationalsozialist Otto Strasser oder der $\mathrm{Na}$ tionalkonservative Hermann Rauschning befürworteten das außenpolitische Ziel eines Großdeutschlands - auch der sudetendeutsche Sozialdemokrat Wenzel Jaksch oder der Leiter der Gruppe Sozialistische Nation, Karl Otto Paetel, konnten sich mit dieser Zielsetzung grundsätzlich identifizieren. Schließlich wurde der Ausbruch eines erneuten Krieges zwar häufig rhetorisch instrumentalisiert, doch nicht immer auch als reale Gefahr begriffen. Hier kommt wenigen Emigranten wie Leopold Schwarzschild, Eugen Brehm, Curt Geyer und Paul Hertz das Verdienst zu, schon in der ersten 
Phase des Exils die Kriegsgefahr konkretisiert und unablässig vor ihr gewarnt zu haben.

Die wenigen detaillierten Konzeptionen für eine europäische Neuordnung, die die Exilzeit zwischen 1933 und 1937 hervorbrachte, wurden selten zum Gegenstand einer ausführlichen Debatte und erst recht nicht eines gruppenübergreifenden Diskurses erhoben. In der gruppeninternen Auseinandersetzung stand in diesem frühen Stadium zumeist noch die Frage im Vordergrund, ob eine Neuordnungsdiskussion zu diesem Zeitpunkt überhaupt schon wünschenswert und sinnvoll sei, zumal die Ausgangsbedingungen des künftigen Europas nicht einmal schemenhaft bekannt seien. Folglich wuchsen viele europapolitische Stellungnahmen vor 1938 nicht über das Niveau tagespolitisch verkürzter Parolen hinaus oder erschöpften sich in nahezu schematischer Wiederholung Weimarer Positionen.

Kennzeichnend für die seltenen konzeptionell durchdachten Europavorschläge vor 1938 ist ihr Vertrauen in den gestalterischen Willen der europäischen Regierungen oder Völker sowie die Tatsache, daß die zugrunde gelegten Axiome selten an der aktuellen Realität überprüft wurden und somit einer flexiblen Handhabung nicht zugänglich waren. Es handelte sich zumeist um rigide Prinzipiensammlungen, mehr oder weniger starre Bilder eines gedachten Europas. Hierin liegt der strukturelle Unterschied zu vielen der ab 1938 entwickelten Europakonzeptionen, die der Dynamik eines vielschichtigen Diskurses ausgesetzt waren und durch die schnelle Abfolge der außenpolitischen Veränderungen notwendig einer ständigen Überarbeitung und Prüfung ihrer Realisierungschancen unterworfen waren. Erst nach der Annexion Österreichs und dem gruppenübergreifend als Schockereignis empfundenen Münchner Abkommen begann das politische Exil, die konzeptionelle Notwendigkeit einer institutionalisierten Föderation des europäischen Kontinents aus der außenpolitischen Aktualität abzuleiten und am realen Weltgeschehen zu messen, während viele der Europabilder der Jahre 1933 bis 1937 auf ideologische Plattitüden oder traditionelle Europapositionen in einem grundsätzlichen und damit vagen Sinne beschränkt blieben. Für die folgende Untersuchung der Europavorstellungen des politischen Exils wird diese wesentliche Unterscheidung zwischen der Statik der frühen Europabilder einerseits und der präzisierenden Dynamik des ab 1938 einsetzenden Europadiskurses andererseits vorausgesetzt. Dabei soll die Darstellung der frühen Exilphase zugleich der Präsentation der schon vor 1938 existenten politischen Gruppierungen, ihrer ideologischen Axiome und politischen Deduktionen dienen.

Dennoch käme es einer unzulässigen Verkürzung gleich, den europapolitischen Äußerungen des deutschen Exils vor 1938 jedwede Qualität abzusprechen oder gar ihre Existenz zu leugnen¹. Das hieße, die zahlreichen Quellen

1 So etwa PAUL, Zauberformel 1992, der insbesondere auf S. 264 - leider ohne Beleg behauptet: „Europa war in den Diskussionen des Exilvorstandes nicht mehr als ein geo- 
der Jahre 1933 bis 1937 trotz ihrer beachtlichen Quantität zu ignorieren und einige strukturelle Weichenstellungen in den Debatten dieser frühen Exilzeit auszublenden. Hierzu zählt wesentlich die Entdeckung des Widerstandspotentials der Europaidee, die konzeptionelle Ausformung eines Widerstandes durch Planung2.

\subsection{Kommunisten}

Zahlenmäßig eine der größten Gruppen des politischen Exils, spielten die Kommunisten für den Europadiskurs eine nur untergeordnete Rolle. In den Jahren von 1933 bis 1937 zeugen die kommunistischen Quellen von äußerster Zurückhaltung hinsichtlich europapolitischer oder gar visionärer Äußerungen. Im Grundsatz entsprach diese Haltung der Empfehlung Lenins, besser die Vereinigten sozialistischen Staaten der Welt auf den Weg zu bringen, als sich mit den Vereinigten Staaten von Europa aufzuhalten ${ }^{3}$. Erst nachdem der "Geist von Locarno" jedenfalls ihre politischen Gegner erfaßt hatte und die paneuropäische Bewegung des Grafen Coudenhove-Kalergi scheinbar unaufhaltsam an Einfluß gewann, gerieten die Kommunisten in Zugzwang. Im Plenum der Erweiterten Exekutive der Komintern wurde noch 1925 in Abwendung der bisherigen Sprachregelung die Losung der „Vereinigten Staaten des Sozialistischen Europas" aus taktischen Erwägungen ausgegeben. Dies stellte die europäischen Kommunisten vor das tagespolitische Problem, die neue Losung von der „bürgerlich-sozialdemokratischen Parole“ Paneuropas scharf abzugrenzen. John Pepper forderte daher in der Kommunistischen Internationale, unter Berufung auf ihren spezifisch sozialistischen Grundgehalt die Komintern-Losung als Gegenparole der europäischen kommunistischen Parteien im Kampf gegen den bürgerlichen Kapitalismus einzusetzen und den "pazifistischen Schwindelinhalt“ der Paneuropaidee zu zerschlagen ${ }^{4}$. Dies gelte umso mehr, als die Paneuropaidee in Form des Völkerbundes und des Vertrages von Locarno schon reale Formen angenommen habe, die beide gegen die Sowjetunion gerichtet seien ${ }^{5}$. Darüber hinaus

graphischer Begriff. [...] Von den linkssozialistischen Gruppen mit dezidiert marxistischer Ausrichtung nahm vor dem Zweiten Weltkrieg nur die Gruppe ,Neu Beginnen" zur Zukunft Deutschlands in einem neuen Europa Stellung."

2 Dies gilt auch für die Sopade, selbst wenn sie gegenüber allzu frühen programmatischen Debatten skeptisch blieb. Insoweit unterschätzt VoIGT, Idée européenne 1995, S. 65, die tatsächliche Quellenlage, wenn er behauptet: „Jusqu'au début de la guerre, la Sopade s'abstint dans ses manifestes de toute prise de position sur une fédération ou confédération européenne."

3 Vgl. LenIN, Sämtliche Werke, Bd. 18, 1929, S. 306-310.

${ }^{4}$ PEPPER, Die Vereinigten Staaten von Europa, in: KI VII. Jg. (1926), S. 209-223 (222f.).

${ }^{5}$ Die UdSSR trat erst am 18. 9. 1935 dem Völkerbund bei. An dem Vertragswerk von Locarno war sie nicht beteiligt gewesen. Zur frühen kommunistischen Auseinandersetzung mit dem Völkerbund vgl. auch: Dämmerung des Völkerbunds, in: KI VIII. Jg. (1927), S. 1781-1784. 
könne die Losung der Vereinigten Staaten des Sozialistischen Europas nur dann einen wahrhaft revolutionären, antikapitalistischen Sinn haben, wenn sie jede Kooperation mit kapitalistischen Kräften strikt ablehne und im engen Bündnis mit der Sowjetunion vertreten werde ${ }^{6}$. Ein halbes Jahr später fällte Sonter anläßlich des ersten Paneuropäischen Weltkongresses ein noch schärferes Urteil über die Paneuropa-Bewegung des „philosophisch angehauchten Grafen"7, der die Sowjetunion kategorisch ausschließen wolle und sich im übrigen in nebulösen, die amerikanischen Verhältnisse verherrlichenden Phrasen verliere. Höhnisch verwies Sonter auf die Hoffnung der Paneuropäer, schon durch den Fortfall der innereuropäischen Grenzen werde der Krieg aus Europa verbannt und setzte in Klammern hinzu: „Wir machen hier keine Witze, sondern geben ernsthaft die Ansicht der Paneuropäer wieder." 8

Im Exil besannen sich die Kommunisten wieder auf Lenins Rat, statt des Vereinigten Europas vorzugsweise die Vereinigten sozialistischen Staaten der Welt zu verwirklichen. Eine Kooperation mit kapitalistischen Mächten wurde kompromißlos abgelehnt, so daß vor der Implementierung der kommunistischen Revolution die Gründung eines Staatenbundes nicht in Betracht kam. In der Folge verhielten sich die deutschen Kommunisten hinsichtlich des Europadiskurses äußerst zurückhaltend und betonten stattdessen die beiden allgemeinen außenpolitischen Ziele: den Sturz Hitlers und den Kampf für den Weltfrieden. Insoweit ergab sich die Motivation zwanglos aus dem kommunistischen Dogma, während sich ein Nachdenken über eine mögliche Institutionalisierung dieses Weltfriedens mit Blick auf die ideologisch verankerte Führungsposition der UdSSR und die Existenz der Komintern erübrigte. Zwar war die KPD bei weitem kein monolithischer Block, doch setzten sich kritische, von der offiziellen Parteilinie abweichende Stimmen in der Regel dem Vorwurf des Trotzkismus und des Verrates aus. Unter den Parteikritikern wurde jedoch selten die europäische Frage erörtert, da der umfassendere Weltgeltungsanspruch der kommunistischen Revolution zumeist nicht in Frage gestellt wurde. Einer der prominentesten internen Kritiker war das ZK-Mitglied Willi Münzenberg, der jedoch 1937 nach schwerwiegenden Auseinandersetzungen mit Moskau seinem Parteiausschluß um ein halbes Jahr zuvor kam und sich mit europapolitischen Fragen erst seit der Gründung seiner Union franco-allemande intensiver beschäftigte?.

Die Quellen der exilierten Kommunisten aus den Jahren 1933-1945 prägen ein nahezu durchgängiges Schweigen zu internationalen Beziehungen, das

6 PEPPER, Die Vereinigten Staaten von Europa, in: KI VII. Jg. (1926), S. $222 \mathrm{f}$.

7 SONTER, Paneuropa, in: KI VII. Jg. (1926), S. 905-910 (905, 908); siehe des weiteren GÜNTHER, Randbemerkungen zum Paneuropa-Kongreß, in: KI VII. Jg. (1926), S. 209_ 223.

8 SONTER, „Paneuropa“, in: KI VII. Jg. (1926), S. 906.

9 Vgl. die Gründungserklärung der Deutsch-Französischen Union, in: Die Zukunft (28. 4. 1939), S. 1. 
nur hin und wieder einmal unterbrochen wird durch phrasenhafte Beteuerungen der freundschaftlichen Zusammenarbeit zwischen den Völkern und dem ebenso oberflächlichen Bekenntnis zur Erhaltung des Friedens ${ }^{10}$. Auch in der kommunistischen Exilpresse finden sich nur ganz vereinzelt Stellungnahmen zur Programmatik der internationalen Politik ${ }^{11}$. Erst 1944 widmeten sich einzelne Kommunisten der konkreten Nachkriegsplanung, wobei der Wiederaufbau Deutschlands im Mittelpunkt des Interesses stand, nicht aber die Zukunft des europäischen Kontinents.

In den ersten Jahren des Exils beschränkten sich die kommunistischen Verlautbarungen zur internationalen Politik in der Tat auf eher lapidare Feststellungen zur deutsch-sowjetischen Freundschaft und zum Weltfrieden. Die Resolution der Brüsseler Konferenz konstatierte lediglich: „Deutschland braucht Frieden und Zusammenarbeit mit den anderen Völkern, braucht vor allem eine Verständigung mit der Sowjetunion." 12 Dabei dürfte der kommunistische Ruf nach Frieden wohl primär als Forderung nach der Beibehaltung des Status quo verstanden werden ${ }^{13}$, mithin der Rückabwicklung der nationalsozialistischen Außen- und Verteidigungspolitik sowie der Rückkehr zu einer kollektiven Sicherheitspolitik ${ }^{14}$. Dies belegt auch ein Flugblatt der KPD-Auslandsleitung Paris, das für die illegale Verteilung in Deutschland bestimmt war und nicht mehr als die Rückkehr zum alten System des Europäischen Konzerts propagierte, diesmal jedoch unter sowjetischer Führung: „Der Brüsseler Kongreß hat sich für die Schiedsgerichtsbarkeit bei Konflikten, für die Sanktionen gegen den Angreifer im Geiste der Aufrechterhaltung der kollektiven Sicherheit ausgesprochen." 15 Zwar enthielt das Flugblatt auch ein schlagwortartiges Formalbekenntnis zur deutsch-französischen Versöhnung sowie zum Weltfrieden, doch wurde ohne weitere Vertiefung an das all solchen Bemühungen vorangehende Banner des Kommunismus erinnert, das unmißverständlich über der UdSSR wehe ${ }^{16}$. Folglich sei für das künftige Deutschland das „Freundschafts- und Wirtschaftsbündnis“ mit der Sowjetunion die zukunftsgestaltende Kraft, die den „großzügigsten Warenaustausch" ${ }^{17}$ zum beiderseitigen Vorteil biete. Aus dieser wirtschaftlichen Si-

10 Vgl. VOIGT (Hg.), Friedenssicherung 1988, S. 23; SYwOTTEK, Volksdemokratie 1971, S. 87, 95 .

11 Vgl. VoIGT (Hg.), Friedenssicherung 1988, S. 24.

12 Der neue Weg zum gemeinsamen Kampfe aller Werktätigen für den Sturz der HitlerDiktatur. Resolution der Brüsseler Parteikonferenz der KPD im Oktober 1935 (Tarnschrift: Wie unsere Kakteen richtig gepflegt werden müssen), S. 17.

13 So auch SYwOTTEK, Volksdemokratie 1971, S. 84.

14 Vgl. auch ibid. S. 75.

15 Vereinigt eure Kräfte gegen den Faschismus, den Urheber des Krieges. Flugblatt, o. O., o. D. [Paris, Frühjahr 1936], Faksimile, in: PikARSKI, Uebel (Hg.), Widerstandskampf der KPD 1978, Dok. Nr. 64.

16 Ibid.

17 Was würde ein Freundschaftsbündnis mit der Sowjetunion dem deutschen Volk nützen? Flugblatt des ZK der KPD, o. O., o. D. [Prag 1936], Faksimile, in: PIKARSKI, UEBEL (Hg.), Widerstandskampf der KPD 1978, Dok. Nr. 75. 
cherheit und der Frieden stiftenden Eigenart des kommunistischen Systems an sich würden sich dann zwangsläufig politische Stabilität und dauernder Frieden einstellen, zumal die UdSSR ein "Hort des Völkerfriedens" 18 sei. Dem Leser wurde versichert: „Die Sowjetunion ist groß und stark."19 Als Walter Ulbricht im Januar 1937 eine Radioansprache zum Spanischen Bürgerkrieg an „alle, die Ihr den Frieden und die Freiheit liebt", hielt, ließ er sich ungeachtet der internationalen Ausrichtung seines Themas zu keinerlei programmatischen Äußerungen verleiten. Seine diesbezüglichen Anmerkungen erschöpften sich in der bekannten, tagespolitisch ummantelten Überzeugung, daß die Niederlage Francos und Hitlers in Spanien und die Stärkung der nationalen Volksfronten "die entscheidende Aufgabe zur Erhaltung des Weltfriedens" sei20.

Die europapolitische Abstinenz der Kommunisten in den Jahren 1933 bis 1937 und darüber hinaus hat sowohl ideologische als auch von der Komintern vorgegebene parteitaktische Gründe. Im Vordergrund standen vier feste Bestandteile der kommunistischen Propaganda, die beispielhaft einem Manuskript Wilhelm Piecks aus dem Jahre 1937 entnommen werden können: Zunächst die Versicherung, daß allein die Sowjetunion in der Lage sei, den Frieden zu sichern; sodann die taktische Vorgabe der Komintern, sich an der Bildung einer deutschen Volksfront zu beteiligen; anschließend die regelmäBig wiederkehrende Kritik am Exilvorstand der SPD und schließlich die Hervorhebung der eigenen vermeintlichen Erfolge. In einem solchen Umfeld nehmen sich die Warnung vor dem drohenden Krieg und der Aufruf, „den Idealismus der Jugend mit dem Geist des Friedens, der Freiheit und des Fortschritts zu erfüllen" 21 , nahezu programmatisch aus. Grundsätzlich aber wurden Neuordnungsprogramme bewußt vermieden. Stattdessen wurden diejenigen Emigranten, die „sogar schon ganze Programme für die Tätigkeit des künftigen Staates ausgearbeitet" hätten, eher belächelt ${ }^{22}$.

\subsection{Sozialdemokraten}

Neben den Kommunisten waren die Sozialdemokraten die andere große Partei der untergegangenen Weimarer Republik, die wichtige Bestandteile ihres Organisationsapparates hatte retten können. In den Prager Jahren des Exils konnten die ins Ausland geflüchteten Sozialdemokraten einen regen Informationsaustausch mit ihren in Deutschland verbliebenen Genossen betrei-

18 Ibid.

19 Ibid.

20 Ulbricht, Wofür kämpft das spanische Volk? Wofür muß das deutsche werktätige Volk kämpfen? Rede des Genossen Walter Ulbricht vom ZK der KPD über den Sender Barcelona, o. D. [Januar 1937], BAB, RY 1/I, 2/8, Bl. 81.

21 Pieck, Neue Aufgaben der Partei, März 1937, BAB, RY 1/I, 2/707/52, Bl. 5.

22 Ders., Fragen der Volksfront in Deutschland. Klarheit tut not!, in: KI XVIII. Jg. (1937), S. 719-735 (725). 
ben. Dies brachte eine starke Fokussierung auf organisatorische Fragen mit sich, die den Parteivorstand neben der fortgesetzten Auseinandersetzung mit den Kommunisten und der aufkommenden linkssozialistischen Kritik am Führungsanspruch der Sopade hauptsächlich beschäftigte. In der Frage eines vereinigten Europas zog sich die Sopade bis 1940/41 im wesentlichen auf die Positionen ihres Heidelberger Parteiprogramms von 1925 zurück, in dem die SPD als erste Partei der Weimarer Republik das Fernziel der „Vereinigten Staaten von Europa“ artikuliert und sich ausdrücklich zu eigen gemacht hatte ${ }^{23}$. Dies entsprach dem traditionellen Selbstverständnis der SPD als internationalistischer Partei mit solidarischen Verbindungen zu gleichgesinnten Arbeiterparteien anderer Länder ${ }^{24}$. Vor diesem Hintergrund verwundert es nicht, daß die SPD in den Exiljahren deutlicher als andere Organisationen auf ihre in der Weimarer Zeit herausgearbeiteten europapolitischen Positionen zurückgriff. Deshalb ist für das Verständnis des im Exil präsentierten Europabildes der Sopade eine ausführlichere Auseinandersetzung mit den Weimarer Europabeiträgen der SPD unabdingbar.

\subsubsection{Ergebnisse der Weimarer Europadiskussion}

Auch die Europadebatten der Weimarer Sozialdemokraten fanden ihren Ausgangspunkt im Kampf gegen den Kapitalismus für Frieden und wirtschaftliche Gerechtigkeit, deren einzig denkbare Synthese im Sozialismus gesehen wurde. Als übergeordnetes Fernziel bedeutete der Sozialismus in der sozialdemokratischen Interpretation die einzig zuverlässige Sicherung des Friedens und zugleich die einzig gerechte Wirtschaftsordnung ${ }^{25}$. Der Bestand einer friedlichen Ordnung der Völker hänge wesentlich von der glaubhaften Gewähr wirtschaftlicher Gerechtigkeit $a b$, so daß beides untrennbar miteinander verbunden sei. Dagegen sei Krieg der „Ruin für jedermann“26.

Leitbild der sozialistischen Bewegung war der erklärtermaßen humanistisch motivierte proletarische Befreiungskampf, der nicht isoliert geführt werden könne, sondern nur als Befreiungskampf für die ganze Menschheit

${ }^{23}$ Heidelberger Programm der Vereinigten Sozialdemokratischen Partei Deutschlands, 14. 9. 1925, abgedruckt in: MOMMSEN (Hg.), Parteiprogramme 1960, S. 461-469 (468). 24 Vgl. VOIGT (Hg.), Friedenssicherung 1988, S. 31.

25 KAUTSKY, Grundsätzlicher Teil, in: Heidelberger Programm. Grundsätze und Forderungen [1925], S. 24: „Daher entspringt durch den Gegensatz zum Kapital aus dem internationalen Charakter der Produktion für die Proletarier in ihrem Klassenkampf die internationale Solidarität. Das zeigt sich nicht nur in ihren ökonomischen Kämpfen. Es bewirkt auch, daß sie eine eigene, der der Kapitalisten entgegengesetzte auswärtige Politik annehmen. Wie ihr Klassenkampf und schließlicher Sieg die Zivilisation rettet, so wird er auch zur festesten Schutzwehr des Weltfriedens. "

26 Ibid. S. 26: „Sie [d. i. die sozialistische Produktion, B. S.] wird aber sogar für viele, die jetzt von der Ausbeutung fremder Arbeit leben, eine Rettung werden durch Erhaltung des Weltfriedens, durch Ausschaltung jeder Möglichkeit von Kriegen, die heute den Ruin für jedermann bringen müssen, ausgenommen einige mehr oder weniger privilegierte Banditen.“ 
denkbar sei ${ }^{27}$. Denn erst mit der weltweiten Durchsetzung des Sozialismus „werden die einzelnen Nationen in einer klassenlosen Gesellschaft in wahrer Volksgemeinschaft nebeneinander leben und miteinander arbeiten, damit der Frieden der Welt durch Akte der Gewalt nie mehr gestört werden kann"28. Folglich wurde die Erhaltung der Kampffähigkeit gegen den Kapitalismus als täglich neu zu stellende Aufgabe des internationalen Sozialismus bezeichnet, um schließlich durch die internationale sozialistische Revolution die Zivilisation zu retten und den Weltfrieden zu schützen. Mit dem flächendeckenden Sieg des Sozialismus war die Vorstellung von einer Welt verbunden, die weder internationale Konflikte noch den Wettbewerb von Volkswirtschaften kennt.

Den richtigen Weg zur Verwirklichung des internationalen Sozialismus sah die Sozialdemokratie mehrheitlich nicht in einer schlagartigen sozialistischen Revolution, sondern in der Nutzung und langfristigen Umorientierung bestehender Strukturen und Institutionen in ihrem Sinne. Einmal etabliert, würde der Sozialismus aus sich heraus Frieden, Freiheit und Gerechtigkeit schaffen.

Für die Umorientierung der bestehenden Strukturen setzten die Sozialdemokraten in der außenpolitischen Theorie zwei institutionelle Hebel an: den Völkerbund und die Sozialistische Arbeiter-Internationale (SAI). Die SAI war das wirtschaftliche Instrument für eine Verstärkung der internationalen Solidarität und das Schwert im Kampf gegen den Kapitalismus. Ihr Hauptanliegen war die Förderung einer sozialistischen Weltwirtschaft als grenzüberschreitende Einigung der Völker. Um die internationale Solidarität zu stärken und die Plattform für eine sozialistische Arbeitsteilung der Völker zu schaffen, erkannten auch die Sozialdemokraten die Notwendigkeit einer europäischen Wirtschaftskooperation, die später von der systemimmanenten wirtschaftlichen Gerechtigkeit eines sozialistischen Europas als Teil einer sozialistischen Welt abgelöst werden sollte. Folgerichtig forderte Eduard Bernstein schon 1919 das Ende der „Schutzzöllnerei“29 und plädierte für einen „möglichst innige[n] Wirtschaftsverkehr der Völker"30.

Während die SAI über das Medium der Wirtschaftsstrukturen die Völker einigen sollte, kam dem Völkerbund nach sozialdemokratischer Lesart die Aufgabe der Friedenssicherung zwecks Einigung der Staaten zu. 1918 hatte Bernstein noch in Unkenntnis der Völkerbunds-Satzung die Idee eines wörtlich verstandenen Völkerbundes propagiert, dessen primäre Aufgabe die Ausarbeitung eines Allgemeingeltung beanspruchenden internationalen

27 Ibid: „Das Proletariat kann sich dauernd nur befreien, wenn es die ganze Menschheit befreit."

${ }^{28}$ Müller[-Franken], Internationale Politik, in: Heidelberger Programm. Grundsätze und Forderungen [1925], S. 59-63.

29 BERNSTEIN, Völkerbund oder Staatenbund 21919, S. 26.

30 Ibid. S. 29. 
Rechtes zur Sicherung des Friedens sein müsse ${ }^{31}$. Zu diesem frühen Zeitpunkt schon findet sich die Relativierung zweier wesentlicher Grundsätze der internationalen Beziehungen, deren nationale Ausrichtung jedem föderalistischen Ansatz diametral entgegen steht: das nationale Selbstbestimmungsrecht und das Prinzip der Nichteinmischung in die inneren Angelegenheiten eines anderen Staates. Der Grundsatz des nationalen Selbstbestimmungsrechts der Völker verdiene nur „im Rahmen des für alle gleichmäßig geltenden internationalen Rechts"32 Anerkennung, während das Prinzip der Nichteinmischung schon deshalb keine unbedingte Geltung beanspruchen könne, weil es ,in Widerspruch mit dem sozialistischen Grundsatz der Verbundenheit (Solidarität) der Völker “33 stehe. Dem zukünftigen Völkerbund müsse das Recht zugestanden werden, "für notwendig erkannte Eingriffe in die Selbstherrlichkeit der Staaten "34 allein anzuordnen und durchzuführen. Gerade diese starke Exekutivgewalt sollte dem bald darauf ins Leben gerufenen Völkerbund fehlen und der wichtigste Aspekt der international gesinnten Kritiker bleiben. So forderte Hermann Müller 1925 primär wirtschaftliche Sanktionsrechte für den Völkerbund, um den Bemühungen für die Sicherung des Friedens Nachdruck verleihen zu können ${ }^{35}$. Bernstein zufolge konnte der Völkerbund nur und erst dann Vollkommenheit erreichen, wenn der Bund der Staaten - die Bernstein als kapitalistisch und damit imperialistisch klassifizierte - sich zu einem wahren „Bund freier Republiken der Völker" auf sozialistischem Boden weiterentwickle ${ }^{36}$. Bernsteins Überlegungen von 1918 lieferten in vielerlei Hinsicht wichtige Vorgaben für die späteren Überzeugungen der SPD, die diese bis weit in die Emigration hinein nahezu unverändert beibehielt.

Bernsteins Forderung nach einem „für alle gleichmäßig geltenden internationalen Recht" griff das Görlitzer Programm vom 14. September 1921 wörtlich auf ${ }^{37}$ und verlangte neben dem internationalen Zusammenschluß der Arbeiterklasse den „Ausbau des Völkerbundes zu einer wahrhaften Arbeits-, Rechts- und Kulturgemeinschaft" ${ }^{\star 38}$.

Das Görlitzer Programm war erkennbar geprägt von der zeitgenössischen Kritik am Versailler Friedensvertrag und vermochte größere Leitlinien der sozialdemokratischen Außenpolitik kaum überzeugend zu vermitteln. Dennoch darf die zentrale Bedeutung des Gedankens eines für alle gleich gelten-

31 Vgl. ibid. S. 22.

32 Ibid.

33 Ibid. S. 21.

34 Ibid. S. 22.

35 Vgl. Muller[-Franken], Internationale Politik, in: Heidelberger Programm. Grundsätze und Forderungen [1925], S. 62.

36 BERNSTEIN, Völkerbund oder Staatenbund 21919, S. 27.

37 Vgl. den Abschnitt "Völkerbeziehungen und Internationale“ im Görlitzer Programm der Vereinigten Sozialdemokratischen Partei Deutschlands vom 14. 9. 1921, in: MOMMSEN (Hg.), Parteiprogramme 1960, S. 453-458 (458).

38 Ibid. 
den internationalen Rechts im Sinne eines „neuen Völkerrechts“39 nicht unterschätzt werden. Als zur damaligen Zeit visionär anmutendes Verlangen verstanden die Sozialdemokraten die Forderung nach einem allgemein verbindlichen Völkerrecht als zwischenstaatliches Pendant zur internationalen Solidarität der Völker und sahen darin ein wahrhaft sozialistisches Anliegen - wenngleich sie dieses Anliegen faktisch mit anderen, außerhalb des sozialistischen Lagers stehenden Intellektuellen teilten. In sinnvoller Ergänzung einer als notwendig erachteten internationalen Abrüstung sollte ein für alle gleiche Geltung beanspruchendes Völkerrecht die Funktion eines übergeordneten Wertmaßstabes einnehmen. Hermann Müller forderte sogar eine obligatorische Schiedsgerichtsbarkeit für „sogenannte Ehrenfragen oder sogenannte Lebensfragen der Nation " 40 und artikulierte damit eine auch innerhalb der Sozialdemokratie nicht mehrheitsfähige Ablehnung des Nichteinmischungsprinzips. Unter konsequenter Beachtung der „historischen Reihenfolge" - erst Umgestaltung der bürgerlichen in eine soziale Demokratie, dann erst Einführung des Sozialismus durch Mehrheitsbeschluß - riefen die Autoren des Heidelberger Programms nach einer "Demokratisierung des Völkerbundes und seine[r] Ausgestaltung zu einem wirksamen Instrument der Friedenspolitik“41. Gemeint war die Entwicklung eines VölkerbundsParlaments mit nationalen Delegationen, zusammengesetzt nach der Stärke der Parteien, als Kern eines späteren Weltparlaments ${ }^{42}$.

Vor dem Hintergrund der globalen Ausrichtung des sozialistischen Fernzieles konnte die Diskussion um ein sozialistisch geeintes Europa nur Teilaspekt einer umfassenderen Betrachtung sein. Die Heidelberger Formulierung, man setze sich ein „für die Bildung der Vereinigten Staaten von Europa, um damit zur Interessensolidarität der Völker aller Kontinente zu gelangen “43, legt die Auffassung nahe, Europa solle schließlich in der sozialistischen Weltgemeinschaft aufgehen und eben nicht als Regionalorganisation im Rahmen des Völkerbundes weiter bestehen bleiben. Dabei blieb der Aspekt der europäischen Werte- oder Kulturgemeinschaft zunächst nahezu unberücksichtigt. Bis in die späten Emigrationsjahre hinein blieb unklar, ob die deutsche Sozialdemokratie der europäischen Einigung per se einen Langzeitwert zuschrieb oder „Europa" nur als notwendigen Zwischenschritt auf dem Weg zu einer größeren, sozialistischen Weltgemeinschaft betrachtete.

$\mathrm{Da}$ die revisionistisch sozialistische Weltanschauung jedoch davon ausging, daß die als unerläßlich erachtete Übergangsphase vom Kapitalismus zum Sozialismus zwangsläufig auch ein retardierendes Moment in der Ent-

39 Müller[-Franken], Internationale Politik, in: Heidelberger Programm. Grundsätze und Forderungen, [1925], S. 61.

40 Ibid. S. 60.

41 Heidelberger Programm, in: W. MOMMSEN (Hg.), Parteiprogramme 1960, S. 469.

42 Vgl. Müllek[-Franken], Internationale Politik, in: Heidelberger Programm. Grundsätze und Forderungen [1925], S. 62.

43 Heidelberger Programm, in: W. MOMMSEN (Hg.), Parteiprogramme 1960, S. 468. 
wicklung vom Nationalstaat zur weltweiten sozialistischen Einheit der Völker nach sich ziehen würde, beschäftigte sich die SPD intensiver als viele linkssozialistische Gruppierungen mit der Ausgestaltung dieser unvermeidlichen Transformationsphase, deren Länge nicht einzuschätzen war. Darüber hinaus war die eurozentrische Weltsicht auch nach dem Ende des Ersten Weltkrieges in Europa unvermindert verbreitet. Trotz der gegenteiligen Erfahrungen während des Krieges wurden die europäischen Großmächte weiterhin als die entscheidenden Einflußfaktoren des Weltgeschehens betrachtet $^{44}$, wenngleich die USA und die Sowjetunion allmählich ins politische Blickfeld rückten. Tatsächlich sollte sich die Einsicht in den fundamentalen Bedeutungsverlust des europäischen Kontinents im Weltgefüge endgültig erst mit dem Abkommen von München und dem Verlauf des Zweiten Weltkrieges durchsetzen - denn diese Einsicht basierte notwendig auf der grundlegenden Erkenntnis der bipolaren Frontstellung zwischen Ost und West.

Immerhin hatten sich Hermann Müller und Rudolf Breitscheid schon in den 20er Jahren der vorgelagerten Frage gewidmet, wie „Europa“ räumlich zu definieren sei. Müller verfocht die Einbeziehung sowohl des „britischen Reichs“ 45 als auch der Sowjetunion in einen europäisch verstandenen Völkerbund ${ }^{46}$. Dabei enthielt er sich jeder Konkretisierung des Integrationsgrades und ließ offen, ob die Sowjetunion und Großbritannien nur in Form einer losen Wirtschaftskooperation oder als vollwertige Mitglieder eingebunden werden sollten. Es ist durchaus denkbar, daß diese Gedankenspiele auch als tagespolitische Spitze gegen die Paneuropa-Bewegung Graf CoudenhoveKalergis gedacht waren, der kategorisch Großbritannien und die Sowjetunion als außereuropäische Staaten ansah und daran im wesentlichen bis 1945 unverändert festhielt. Breitscheid plädierte 1926 für ein „freundschaftliches Verhältnis zu Rußland“ unter Ausschluß militärpolitischer Kooperationsformen ${ }^{47}$.

Für eine stärkere Beschäftigung mit dem Thema „Europa “ sprach aus sozialdemokratischer Sicht auch die doppelte Verwertbarkeit der europäischen Orientierung für die Außenpolitik und die Innenpolitik. Vor allem Rudolf Hilferding und Rudolf Breitscheid sahen hier die Chance, die Parameter der deutschen Außenpolitik zugunsten eines friedlichen Miteinander in Europa zu verändern und auf diese Weise ein eigenes außenpolitisches Profil zu ge-

${ }^{44}$ KAUTSKY, Grundsätzlicher Teil, in: Heidelberger Programm. Grundsätze und Forderungen 1925, S. 25: „Wir halten ein gedeihliches Wirken des Völkerbundes und die Erhaltung des Weltfriedens für möglich, weil wir erwarten, daß jetzt schon in den für die Weltpolitik in Europa entscheidenden Großmächten [eigene Hervorhebung, B. S.] das Proletariat und seine Partei, die Sozialdemokratie, genügend Einfluß gewinnt, um jede Politik zu verhindern, die eine Kriegsgefahr in sich birgt. “

${ }^{45} \mathrm{Vgl}$. Müller[-FrankeN], Internationale Politik, in: Heidelberger Programm. Grundsätze und Forderungen [1925], S. 63.

$46 \mathrm{Vgl}$. ibid.

47 BREITSCHEID, Das außenpolitische Programm der Sozialdemokratie, in: Europäische Gespräche, H. IV (April 1926), S. 169-175 (174). 
winnen. Zugleich bot sich das Plädoyer für eine Kooperation mit den westlichen Demokratien für die innenpolitische Verankerung des Republikanismus an ${ }^{48}$. Insbesondere Hilferding betonte die doppelte Dringlichkeit einer europäischen Einigung im Sinne wirtschaftlicher Notwendigkeit sowie der langfristigen Lösung der außenpolitischen Probleme in Europa. Damit schlug er bewußt den „Bogen zur Verständigungspolitik “49 und verband dieses Anliegen mit dem politischen Wunsch, einen erneuten Weltkrieg frühzeitig zu vermeiden: „Wir wollen eine Lösung des europäischen Staatenproblems, weil wir den Prozeß des Erwachens der geschichtslosen Nationen [gemeint sind die 1918 neu entstandenen europäischen Kleinstaaten, B. S.] allerdings bis zu einem gewissen Grade zu beeinflussen, zu überwachen und zu lenken haben, damit dieser Prozeß sich nicht wieder in einer katastrophalen, kriegerischen Weise vollziehe, die heute bei der Entwicklung der Kriegstechnik die ganze europäische Zivilisation dem Untergange aussetzen würde. “50 Vor diesem Hintergrund wurde aus den Reihen der Sozialdemokraten wiederholt die Forderung nach einem international garantierten Minderheitenschutz in Europa geäußert, der zumindest die Kulturautonomie nationaler Minderheiten umfassen müsse ${ }^{51}$.

Einen in mehrfacher Hinsicht beachtlichen Fortschritt in der Entwicklung eines spezifisch sozialdemokratischen Europaverständnisses brachten die zahlreichen Diskussionen um die Formulierung des Heidelberger Parteiprogramms von 1925, in dem die SPD nicht nur als erste und einzige Partei der Weimarer Republik, sondern auch als erste deutsche Partei überhaupt die „Vereinigten Staaten von Europa“ als politisches Fernziel postulierte ${ }^{52}$. Auffallend an der Heidelberger Formulierung ist die Betonung der als wirtschaftlich zwingend betrachteten Einheit Europas, die offenläßt, ob die Sozialdemokratie in diesem Ziel einen Wert an sich sah oder lediglich als notwendigen Zwischenschritt auf dem Weg zu einer sozialistischen Weltgemeinschaft ${ }^{53}$. In der Kommentierung wird Hermann Müller deutlicher: „Nur

48 Vgl. KRÜGER, Europäische Wirtschaftsgemeinschaft 1984, S. 155.

49 Ibid.

50 Hilferding, nach: Sozialdemokratischer Parteitag 1925 in Heidelberg. Protokoll 1925, S. 282.

51 So z. B. Müller[-Franken], Internationale Politik, in: Heidelberger Programm. Grundsätze und Forderungen [1925], S. 61; BREITSCHEID, Das außenpolitische Programm der Sozialdemokratie, in: Europäische Gespräche, H. IV (April 1926), S. 174. 52 Vgl. den Abschnitt „Internationale Politik“ im Heidelberger Programm der Vereinigten Sozialdemokratischen Partei Deutschlands vom 14.9. 1925, in: W. MOMMSEN (Hg.), Parteiprogramme 1960, S. 461-469 (468f.). Der Begriff der „Vereinigten Staaten von Europa" ist entgegen einer verbreiteten Ansicht weder auf Lenin noch auf Victor Hugo zurückzuführen, sondern wurde zuerst von Cattaneo, einem Weggefährten Mazzinis, im Jahre 1848 geprägt; vgl. dazu BÜLCK, Föderalismus 1964, S. 21, Anm. 51.

53 Heidelberger Programm, in: W. Mommsen (Hg.), Parteiprogramme 1960, S. 468: „Sie [d. i. die Sozialdemokratische Partei Deutschlands] tritt ein für die aus wirtschaftlichen Ursachen zwingend gewordene Schaffung [Hervorhebung d. Verf., B. S.] der 
durch solidarisches Zusammenwirken können die europäischen Staaten ihre Stellung auf dem Weltmarkt wieder verbessern und sich einen organisierten Bezug der Rohstoffe sichern." Obwohl Müller unterstrich, daß man sich - in Abgrenzung zu liberalen und konservativen Überzeugungen - keineswegs in eine verschärfte Wettbewerbsposition gegen die USA und andere Weltwirtschaftsmächte begeben wolle, erscheint es äußerst fraglich, wie ein solcher Ansatz nicht genau diese politische Frontstellung bewirken sollte. Viel eher muß Müllers Versuch als mißlungener Spagat zwischen der sozialistischen Ideologie und den Anforderungen einer Weltwirtschaftspolitik bezeichnet werden ${ }^{54}$.

Mit der SAI und dem Völkerbund hatte die Weimarer Sozialdemokratie ihre beiden Hauptmotive internationaler Politik, wirtschaftliche Gerechtigkeit und Friedenssicherung, institutionell zugeordnet, wobei beide Anliegen einer europäischen $Z$ wischenphase bedurften, bevor sie letztlich global hätten verwirklicht werden können. Im Einklang mit ihrem kämpferisch ideologischen Selbstverständnis hat die Sozialdemokratie die gezielte Abgrenzung gegenüber dem bürgerlichen Nationalitätenkonzept ${ }^{55}$ auf die europäische Ebene transferiert: Eine europäische Wirtschaftskooperation wurde bejaht als Befreiung der alle nationalen Ketten sprengenden Produktionskräfte durch eine möglichst weitgehende Internationalisierung im Sinne geographischer Arbeitsteilung. Auf Ablehnung stieß dagegen die Idee einer europäischen Wirtschaftsenklave als "Ausschlußmittel“ im wirtschaftlichen Konkurrenzkampf gegen die USA, die Sowjetunion oder Großbritannien ${ }^{56}$. In Ergänzung dazu wurde das politische Ziel der Friedenssicherung im Sinne einer internationalen Solidarität verstanden, die man als bewußten Gegenentwurf zum bürgerlich-kapitalistischen „Prinzip der Rivalität der Nationen “57 apostrophierte. Mithin war für die Sozialdemokraten die europäische Einigung ein Wert an sich, dem ein gewisser Selbstzweck inne wohnte. Zwar sollte dieser Selbstzweck erst Jahre später definiert und präzisiert werden, doch ist die politische Langzeitwirkung dieses frühen Europabewußtseins für die folgenden Jahre des Exils nicht zu leugnen. Noch am 13. Januar 1933

europäischen Wirtschaftseinheit, für die Bildung der Vereinigten Staaten von Europa, um damit zur Interessensolidarität der Völker aller Kontinente zu gelangen. “

${ }^{4}$ Die in den 20er Jahren populäre Tendenz zur wirtschaftlichen Abgrenzung gegenüber den USA wird auch bei Carlo Mierendorff deutlich; vgl. etwa MIERENDORFF, Besinnung auf Europa?, in: SozMon, 39. Jg., H. 1 (13. 1. 1933), S. 13-17, insb. S. 14.

55 Den Kampfcharakter der ideologischen Auseinandersetzung betont anschaulich Kautsky, Grundsätzlicher Teil, in: Heidelberger Programm. Grundsätze und Forderungen [1925], S. 24: „Aber die Kapitalisten ihrerseits bleiben auch nicht isoliert, schließen sich ebenfalls zusammen. Da heißt es, den Umfang der proletarischen Organisation immer mehr ausdehnen, um sich die Kampffähigkeit zu erhalten."

56 Hilferding, nach: Sozialdemokratischer Parteitag 1925 in Heidelberg. Protokoll 1925, S. 281 f. An dieser Stelle notierte das Protokoll den Zuruf "sehr wahr!“

57 Ibid. S. 281. Das Parteitagsprotokoll verzeichnet an dieser Stelle „lebhafte Zustimmung". 
rief Carlo Mierendorff den Lesern der Sozialistischen Monatshefte zu: „Deutschlands Arbeiterklasse hat die Mission, dem Vereinigten Europäischen Kontinent den Weg zu bereiten. " ${ }^{58}$ Mit seinem letzten Artikel vor dem Machtantritt der Nationalsozialisten wies Mierendorff, der selbst nicht emigrierte, dem intellektuellen Europadiskurs den Weg ins Exil. Die von ihm erwähnten Diskussionsansätze sollten für die Zeit des politischen Exils Programmcharakter erhalten:

„Die Vision des sozialistischen Europas, die uns vorschwebt, muß in dem neuen Jahr, das vor uns liegt, in schöpferischer Arbeit real geformt und gestaltet werden. Es handelt sich um die Organisation Europas aus überstaatlichem Denken, es handelt sich um die Überwindung jenes Nationalstaatenwahns, an dessen Forcierung die europäischen Völker heute zugrunde zu gehen drohen." 59

\subsubsection{Sozialdemokratische Europabilder 1933-1937}

Das neue Jahr 1933 vereitelte zunächst jeden Gedanken an eine „schöpferische Arbeit" für ein sozialistisches Europa. Durch den Machtantritt der Nationalsozialisten überrascht, hatte die SPD genug zu tun mit den existentiellen Fragen, denen sie sich unvermittelt gegenüber sah. Verdrängt durch die mit der Emigration verbundene neuartige Problematik sowie die Auseinandersetzung um die Grundentscheidung „Legalitätskurs oder Emigration?“, trat die innerparteiliche Europadiskussion zunächst in den Hintergrund. Erst 1935 sollte Rudolf Hilferding in der Zeitschrift für Sozialismus die von Mierendorff geforderte „schöpferische Arbeit“ an der Europavision der Sozialdemokraten wieder aufnehmen ${ }^{60}$ - nachdem der nach Prag emigrierte Teil des Parteivorstandes sich nicht nur der harten Kritik seitens der in Deutschland zurückgebliebenen Vorstandsmitglieder hatte stellen müssen, sondern auch mit den nicht minder heftigen Zweifeln am behaupteten Führungsanspruch der SPD seitens der linkssozialistischen Emigranten konfrontiert worden war.

Mit dem Prager Manifest wagte sich der Exilvorstand der SPD zum Erstaunen vieler Linkssozialisten auf den Pfad des revolutionären Sozialismus ${ }^{61}$. In der ursprünglichen Fassung war das Manifest im Prager Parteivorstand zunächst auf Ablehnung gestoßen. Erst in einer von Hilferding überarbeiteten Version fand die Denkschrift die Zustimmung des leitenden Parteigremiums, das am 20. Januar 1934 dieses organisationsgeschichtlich bedeutende Dokument mit dem aufrüttelnden Titel „Zerbrecht die Ketten“

58 Mierendorff, Besinnung auf Europa?, in: SozMon, 39. Jg., H. 1 (13. 1. 1933), S. 17.

59 Ibid. S. 16.

60 Vgl. KeRN [d. i. Hilferding], Das Ende der Völkerbundspolitik, in: ZfS, 2. Jg., H. $20 /$ 21 (Mai/Juni 1935), S. 625-637.

61 Vgl. Der Vorstand der Sozialdemokratischen Partei Deutschlands, Kampf und Ziel des revolutionären Sozialismus. Die Politik der Sozialdemokratischen Partei Deutschlands, in: NV, Nr. 33 (28. 1. 1934), S. 1 f.; auch abgedruckt in: Dowe, KlotZBaCH (Hg.), Programmatische Dokumente ${ }^{3} 1990$, S. 213-226. 
verabschiedete. Auf der Suche nach einer lebensnahen Auslegung der sozialistischen Ideologie in Anbetracht der neuen Situation des Exils propagierte das Prager Manifest die sozialistische Revolution und erklärte der Legalitätspolitik des in Berlin zurückgebliebenen Rumpf-Parteivorstandes eine unmißverständliche Absage. Die entscheidende Bedeutung des Dokumentes liegt jedoch in der Abkehr vom revisionistischen Dogma der historischen Reihenfolge und dem Bekenntnis zum revolutionären Politikansatz: Als "Träger der großen geschichtlichen Entwicklung" und "Erbe der unvergänglichen Überlieferungen der Renaissance und des Humanismus, der englischen und der Französischen Revolution" 62 komme der Sozialdemokratie die Aufgabe zu, die 1918 ausgebliebene sozialistische Revolution nunmehr herbeizuführen ${ }^{63}$. Schon bald aber kehrte die Sopade zum revisionistischen Verständnis zurück und befürwortete die historische Reihenfolge: erst der Ausbau einer mehrheitsfähigen Ausgangsposition innerhalb der bürgerlichen Demokratie, um dann aus der Regierungsverantwortung heraus die sozialistische Wende einzuführen. Auch wenn die Sopade erst mit Curt Geyers 1939 veröffentlichter Schrift „Die Partei der Freiheit" dem revolutionären Sozialismus des Prager Manifestes offiziell den Rücken kehrte, kam die Ablehnung jedes revolutionär-sozialistischen Ansatz schon 1935 in einem Artikel Hilferdings unverhohlen zum Ausdruck: „Eine positive Politik sozialistischer Parteien, die nicht den Problemen der Gegenwart sich entziehen wollen, indem sie romantischen Spekulationen über die Haltung im künftigen Kriege und dessen revolutionäre Folgen nachhängen, ist nur möglich, wenn sie sich von der Verfolgung solcher Ziele abwenden, die durch die historische Entwicklung sich als unerreichbar erwiesen haben." ${ }^{64}$ Das kurze dogmati-

62 Der Vorstand der Sozialdemokratischen Partei Deutschlands, Kampf und Ziel des revolutionären Sozialismus, in: NV, Nr. 33 (28. 1. 1934), S. 2. Die von BEHRING, Demokratische Außenpolitik 1999, S. 381 vorgenommene Verwendung dieses Zitates als Beleg für das sozialdemokratische Verständnis von Europa als „kulturelles Gebilde“ stellt das Zitat in einen mißverständlichen Sachzusammenhang: Nicht die "großen und unvergänglichen Ideen der Menschheit“, sondern „wir“, d.h. die Sozialdemokraten, waren nach dem Verständnis des Parteivorstandes die „Erben der unvergänglichen Überlieferungen der Renaissance und des Humanismus [... ". Von Europa ist nirgendwo im Prager Manifest auch nur andeutungsweise die Rede. Tatsächlich ging es den Verfassern des Manifestes zuallererst um die Umschreibung des sozialdemokratischen Selbstverständnisses als Grundlage der künftigen Exilarbeit. Die Erwähnung der „Menschheit" weist an dieser Stelle lediglich auf die freiheitlich-humanistischen Wurzeln der Sozialdemokratie, nicht aber Europas hin.

${ }^{63}$ Der Vorstand der Sozialdemokratischen Partei Deutschlands, Kampf und Ziel des revolutionären Sozialismus, in: NV, Nr. 33 (28. 1. 1934), S. 1.

64 KERN [d. i. Hilferding], Das Ende der Völkerbundspolitik, in: ZfS, 2. Jg., H. 20/21 (Mai/Juni 1935), S. 637. Diese Formulierung griff Geyer in seinem ersten Grundsatzbeitrag nahezu wörtlich auf, indem er vorbrachte, „daß es illusionär und romantisch ist, wenn man sich engstirnig an die Verfolgung von Zielen bindet, die bei der gegenwärtigen Lage nicht erreichbar sind [...]“; KLINGER [d. i. Geyer], Völkerbund gegen Faschismus. Die Internationale und die europäische Demokratie, in: NV, Nr. 123 (20. 10. 1935), S. 1 f. (1). 
sche Intermezzo der Sopade im ersten Jahr des Exils veranschaulicht die ideologische Verunsicherung der Sozialdemokratie durch Hitlers Machtergreifung und den Schock der "dritten Emigration“65.

Diese Verunsicherung äußerte sich in der Europadebatte zunächst durch sozialdemokratische Abstinenz. Doch war der Sopade von vornherein bewußt, welch einen großen Vorsprung vor allen anderen politischen Gruppierungen ihr das Heidelberger Programm von 1925 verschafft hatte ${ }^{66}$. Dies umso mehr, als das Heidelberger Europabekenntnis nicht nur die aktive Unterstützung sozialdemokratischer Persönlichkeiten wie die von Karl Kautsky und dem mehrmaligen Reichskanzler und Außenminister Hermann Müller gefunden hatte, sondern schon seit 1925 auch die beiden intellektuellen Ikonen des späteren sozialdemokratischen Exils sich der Losung der Vereinigten Staaten von Europa nachhaltig angenommen hatten: der spätere Fraktionsvorsitzende Rudolf Breitscheid und der mit ihm befreundete außenpolitische Berichterstatter des Heidelberger Parteitags Rudolf Hilferding. Mit Breitscheid und Hilferding war somit eine personelle Kontinuität sozialdemokratischen Europabewußteins von der Weimarer Zeit bis in die Zeit des Exils hinein gegeben. Während Breitscheid nach 1933 allerdings nur noch gelegentlich in außenpolitische Debatten eingriff, meldete sich der Finanzexperte Hilferding bis zu seinem mysteriösen Tod 1941 häufiger und mit großem Einfluß zu Wort. Dabei löste er sich zögerlich, aber stetig von Illusionen und bemühte sich erkennbar um eine Weiterentwicklung und Aktualisierung der in Weimar gewonnenen Erkenntnisse. So beruhen noch die auf der Vorstandssitzung vom 29. Januar 1940 vorgetragenen „Anmerkungen des Genossen Dr. Rudolf Hilferding über die Frage der Kriegsziele und über das Problem der Vereinigten Staaten von Europa “ in wesentlichen Grundzügen auf den Heidelberger Überlegungen. Und doch kennzeichnen sie eine mit Hilferding personifizierte Entwicklung der sozialdemokratischen Auffassung von Europa, die zwischen 1925 und 1940 eine gewisse Entideologisierung erfuhr, die mit einer sachlichen Spezifizierung einher ging. Dies schmälert nicht die Grundtendenz, daß die Sopade länger als andere Exilgruppen an ihren Weimarer Ideen festgehalten hat ${ }^{67}$.

Rudolf Hilferding: kollektive Friedenssicherung Hilferding war es auch, der im Frühsommer 1935 für die Sopade den Diskussionsfaden um die zukünftige Gestaltung des europäischen Kontinents wieder aufnahm - nachdem schon 1933 die von der Sozialdemokratie abgespaltenen Revolutionären

65 STAMPFER, Die dritte Emigration. Ein Beitrag zu ihrer Geschichte, in: MATTHIAS (Hg.), Mit dem Gesicht nach Deutschland 1968, S. 63-171.

66 Hilferding formulierte im Protokoll des Heidelberger Parteitages: „Diese Formulierung unterscheidet unsere Konzeption wiederum grundlegend von allen bürgerlichen Reden über die Vereinigten Staaten Europas."; Sozialdemokratischer Parteitag 1925 in Heidelberg. Protokoll 1925, S. 281.

67 Zustimmend VoIGT (Hg.), Friedenssicherung 1988, S. 32. 
Sozialisten Deutschlands (RSD) und im folgenden Jahr auch der Internationale Sozialistische Kampfbund (ISK) die ersten Beiträge zur Europadebatte des Exils geleistet hatten ${ }^{68}$. In seinem Artikel über „Das Ende der Völkerbundspolitik" 69 propagierte Hilferding die Errichtung eines europäischen Systems der kollektiven Friedenssicherung. Mit diesem Schlagwort der Weimarer Europadebatte ließ Hilferding einen Kontrapunkt sozialdemokratischer Beiträge zur Europadebatte im Exil erklingen. Die anhaltende Hoffnung auf einen verbesserten Völkerbund als internationales System langfristiger Friedenssicherung wurde jedoch mit dem Austritt Deutschlands aus dem Völkerbund 1933, dem Japan 1934 folgen sollte, zunehmend getrübt. Ungeachtet dieser „Kollektivschuld“ Großbritanniens, Frankreichs und der USA $^{70}$ sah Hilferding in Großbritannien unverändert den entscheidenden Schiedsrichter des europäischen Friedens. Dieser sei aus seiner Rolle gefallen, indem er bereitwillig die deutsche Aufrüstung zugelassen und Deutschland mit dem bilateralen Flottenabkommen gestärkt habe. Damit sei der Idee der kollektiven Friedenssicherung vorerst der Rücken zugekehrt und der Völkerbund als effizienter Mittler auf dem internationalen Parkett erneut der Boden unter den Füßen entzogen worden ${ }^{71}$. Hilferding zollte dem alten Rechtsgrundsatz pacta sunt servanda zwar Respekt ${ }^{72}$, erkannte jedoch klar, daß die faschistischen Regime damit nicht zu befrieden seien: „Noch wird der Illusion nachgejagt, die angreifenden Mächte durch Verträge binden zu können, statt sie durch überlegene Macht zum Frieden zu zwingen"73. Beachtenswert ist Hilferdings undogmatische Sichtweise, die ihn im Gegensatz zu vielen Linkssozialisten veranlaßte, den engeren Rahmen der auf die internationale Arbeiterklasse beschränkten Solidarität zu sprengen und einer Kooperation der "beiden großen Demokratien“ England und Frankreich das Wort zu reden.

Curt Geyer: „europäische Demokratie“ und „neues europäisches Gleichgewicht" Für die Sopade der ersten Exiljahre waren neben Hilferding vor allem die beiden Chefredakteure des Neuen Vorwärts Curt Geyer und Fried-

68 Den wohl ersten sozialistischen Beitrag zur Europadiskussion des Exils leistete der Revolutionäre Sozialist Alexander SCHIFRIN, Hitler-Deutschland und Europa, in: Sozialistische Revolution (später: ZfS, ) 1. Jg., Nr. 1 (Oktober 1933), S. 24-30. Acht Monate später meldete sich Schifrin erneut europapolitisch zu Wort: Ders., Die Konsequenzen des revolutionären Programms, in: ZfS, 1. Jg., Nr. 9 (Juni 1934), S. 281-293. Der ISK beschäftigte sich schon im April 1934 mit den Anforderungen an eine internationale Polizei; vgl. Gérard, Protokoll der Aussprache vom 2. April 1934 abends. Thema: Internationale Polizei, AsD, Bestand IJB/ISK, Box 8, S. 1.

${ }^{69}$ KERN [d. i. Hilferding], Das Ende der Völkerbundspolitik, in: ZfS, 2. Jg., H. 20/21

(Mai/Juni 1935), S. 625-637.

70 Ibid. S. 630.

71 Ibid.

72 Ibid. S. 632.

73 Ibid. S. 636. 
rich Stampfer die unangefochtenen Verfasser ihrer außenpolitischen Leitlinien ${ }^{74}$, denen Gregor Bienstock anfangs sekundierte. Geyer kommentierte unter dem Pseudonym Max Klinger mehrere Jahre hindurch in der Parteizeitschrift der Sopade die internationale Entwicklung und prägte entscheidend die sozialdemokratische Haltung zur internationalen Politik der Jahre 1933 bis 1937. Wie Hilferding nahm auch Geyer das deutsch-britische Flottenabkommen zum Anlaß, um erstmals seit Beginn des Exils grundsätzlich zur außenpolitischen Situation Stellung zu nehmen ${ }^{75}$. Weniger moralisierend als Hilferding beurteilte Geyer die englische Politik als "realistisch“ und kritisierte eher die deutsche Haltung ob ihrer Anknüpfung an die Tirpitz'sche Flottenpolitik. Doch findet sich auch bei Geyer das Grundvertrauen in Englands Resistenzwillen im Ernstfall. Schon im Dezember 1935 verdeutlichte Geyer, daß er Großbritannien mehr Sympathien entgegenbrachte als Hilferding und stilisierte die britische Demokratie zum Vorbild für ein Deutschland nach Hitler: „Wenn man uns fragt nach drei Jahren Hitlerdespotie: ,Was soll nach Hitler kommen?" - so antworten wir: ,Seht nach England! Blickt auf die lebendige Demokratie in England, das ist das Vorbild. Das soll nach Hitler kommen! " 76

In seinen außenpolitischen Leitartikeln für den Neuen Vorwärts prägte Curt Geyer zwei für die frühe Phase der sozialdemokratischen Europadebatte zentrale Begriffe: die "europäische Demokratie" und das "neue europäische Gleichgewicht".

Im Oktober 1935 skizzierte Geyer erstmals die „europäische Demokratie“ als Gegenentwurf gegen den europäischen Faschismus 77 . Darunter verstand er eine auf die britische und französische Demokratie gestützte „antifaschi-

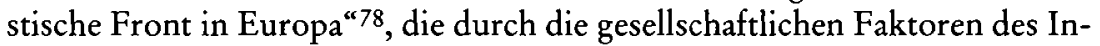
ternationalen Gewerkschaftsbundes (IGB) und der Sozialistischen ArbeiterInternationale (SAI) als „Kräfte der europäischen Demokratie“79 ergänzt werde. In dieser Aufgabenstellung spiegelte sich der für das politische Exil typische Doppelkampf gegen den Faschismus und zugleich für die Demo-

74 Zunächst leitete Stampfer die Redaktion des NV, bis ihn Geyer 1935 ablöste.

75 KLINGER [d. i. Geyer], Flottenbau und Flottenabkommen, in: NV, Nr. 107 (30.6. 1935), Beilage, S. 1 f. (1).

76 [GEYER], Die große Lehre der Demokratie. Europa am Ende des Jahres 1935, in: NV, Nr. 133 (29.12. 1935), S. 1. Der ungezeichnete Leitartikel stammt mit an Sicherheit grenzender Wahrscheinlichkeit von Curt Geyer, der als Chefredakteur des $N V$ gewöhnlich an dieser exponierten Stelle die internationale Politik kommentierte. Zudem sprechen Duktus und politische Positionierung für Geyers Urheberschaft. Im Rückblick auf das Jahr 1935 äußert Geyer die Hoffnung auf ein konzertiertes Vorgehen der europäischen Demokratien gegen den Nationalsozialismus; ibid.: „Das englische Volk hat sich um die Sache des Friedens in Europa und um die Sache der Demokratie verdient gemacht."

77 KLINGER [d. i. Geyer], Völkerbund gegen Faschismus, in: NV, Nr. 123 (20. 10. 1935), S. $1 \mathrm{f}$.

78 Ibid. S. 2.

79 Ibid. S. 1. 
kratie wider. Voraussetzung der europäischen Demokratie als kontinentales Zukunftsmodell war Geyer zufolge die unbedingte Treue zur Satzung des Völkerbundes, der zu einem „kraftvollen, zur Verteidigung des Rechts und der kollektiven Sicherheit mit allen Mitteln entschlossenen"80 Institut weiterentwickelt werden müsse. Denn die Demokratie sei eine geistige Grundhaltung, die als Antithese zu Faschismus und Gewalt das „Lebenselement des Völkerbundes" darstelle ${ }^{81}$.

Das zweite Geyer'sche Schlagwort zur Zukunft Europas ist das des neuen europäischen Gleichgewichts. Es entstammt ebenfalls einem Leitartikel im Neuen Vorwärts, der im Jahre 1937 unter dem bezeichnenden Titel "Deutschland und Europa" veröffentlicht wurde 82 und greift zurück auf einen politischen Leitbegriff des 18 . Jahrhunderts ${ }^{83}$. Einige Jahre später sollte die Forderung nach einem stabilen europäischen Gleichgewicht von Erich Ollenhauer wieder aufgenommen werden ${ }^{84}$. Im Gegensatz zur allgemeinen Kritik an der „Kleinstaaterei“ als eines der Hauptübel der europäischen Misere befürwortete Geyer die Gründung europäischer Kleinstaaten, die durch einen reformierten Völkerbund ergänzt werden müsse. Diese „fortschrittliche und demokratische Auffassung des europäischen Gleichgewichts" ${ }^{455}$, wie sie seit dem Ende des Ersten Weltkrieges entwickelt worden sei, müsse erhalten bleiben und vor einem Rückfall in „die Machtmetaphysik von Großmächten" 86 bewahrt werden. Auch auf der nationalen Ebene deutscher $\mathrm{Au}$ Benpolitik sollte sich das neue europäische Gleichgewicht auswirken. Geyer forderte die Aufgabe der traditionellen Machtpolitik in ihrer imperialistisch übersteigerten Version einer territorial expandierenden Weltmachtpolitik: "Damit ist die demokratische Alternative der deutschen Außenpolitik im Einklang mit den Ideen, die der Gleichgewichtsordnung Europas auf der Basis des Völkerbundes zugrunde lagen." Mit diesem programmatischen Beitrag faßte Geyer zusammen, was 1937 im Parteivorstand der Sopade mehrheitsfähige außenpolitische Position war:

- eine europäische Föderation als demokratische Alternative zu Hitlers revisionistischer Lebensraumpolitik,

${ }^{80}$ [GEYER], Die große Lehre der Demokratie, in: NV, Nr. 133 (29. 12. 1935), S. 1.

81 KLINGER [d. i. Geyer], Völkerbund gegen Faschismus, in: NV, Nr. 123 (20. 10.1935), S. 1.

82 DERS., Deutschland und Europa. Grundfragen der deutschen Politik, in: NV, Nr. 220 (29. 8. 1937), Beilage, S. 1 f. (1).

${ }^{83}$ Zum europäischen Gleichgewichtsdenken seit dem 16. Jahrhundert vgl. FENSKE, Gleichgewicht, Balance, in: BRUNNER, CONZE, KOSELlECK (Hg.), Geschichtliche Grundbegriffe, 2, S. 959-996.

${ }^{84}$ Vgl. PV [Ollenhauer] an Sander, 13. 7. 1939, AsD, Bestand PV-Emigration Sopade, M. 111.

${ }^{85}$ KLINGER [d. i. Geyer], Deutschland und Europa, in: NV, Nr. 220 (29. 8. 1937), Beilage, S. 1.

${ }^{86}$ Ibid. S. 2. Geyer verstand diese Machtmetapysik als momentan noch dominierendes historisches Gesetz, dessen Überwindung Voraussetzung sei für „sozialistische Verwirklichungen“; ibid. 
- die harmonische Einordnung Deutschlands in das europäische Staatensystem,

- ein starker Völkerbund mit Exekutivvollmachten als Ausdruck und Garant internationalen Rechts und Friedens.

Geyers programmatische Beiträge deckten sich im wesentlichen mit den Erkenntnissen der Weimarer Sozialdemokratie. Das Motiv der europäischen Demokratie beruhte vorrangig auf dem Aspekt der kollektiven Friedenssicherung und der Durchsetzung international gültiger Rechtsmaßstäbe, während für den institutionellen Rahmen weiterhin der Völkerbund in einer modifizierten Verfassung bevorzugt wurde. Der Gesichtspunkt der europäischen Position in der Welt findet sich in Geyers Beitrag hingegen nicht. Die USA wurden kaum erwähnt, vielmehr nahm Geyer einen noch deutlich europazentrierten Standpunkt ein.

Im Gegensatz dazu findet sich bei Hilferding eine stärkere Berücksichtigung der USA und der Sowjetunion bei der Betrachtung der europäischen Frage. Gerade dieses Versäumnis legte er Großbritannien zur Last, nämlich keine effektive Kooperation mit den USA, der Sowjetunion und Frankreich gesucht zu haben ${ }^{87}$.

Auffallend ist jedoch, daß die ökonomische Dimension zunächst nahezu unerwähnt blieb. Erst später sollte eine Rückbesinnung auf dieses zweite Europamotiv der Weimarer SPD neben der Friedenssicherung einsetzen. Hierfür sind im wesentlichen drei Gründe zu benennen: Erstens war Geyer, anders als Hilferding, kein Ökonom. Zweitens gab die aktuelle Situation der Jahre 1933 bis 1937 kaum Anlaß, über eine europäische Wirtschaftsföderation nachzudenken. Vielmehr konnte die rasche Überwindung des europäischen Faschismus nur politisch vollbracht werden. Und drittens stand in den ersten Exiljahren die ideologische Positionierung im Beziehungsgeflecht der politischen Emigration im Vordergrund. Insbesondere zur Erreichung dieses letzten Zieles waren die Schlüsselbegriffe der "europäischen Demokratie“ und der „kollektiven Friedenssicherung" geeigneter als die gruppenübergreifend unstreitigen Vorteile einer europäischen Wirtschaftsföderation.

Friedrich Stampfer: „europäische Föderation“ Auch Friedrich Stampfer unterstrich als Mitglied des Parteivorstandes der Sopade die Bedeutung des föderativen Europagedankens als demokratischen Gegenentwurf zu Hitlers Hegemonialpolitik. Stampfer, Mitglied der von Richard Coudenhove-Kalergi gegründeten Paneuropa-Union, zeichnete sich während der gesamten Zeit des Exils mit steigender Vehemenz als aktiver Europäer aus. In einem vermutlich von Stampfer verfaßten scharfsinnigen Artikel aus dem Jahre 1936 formulierte er seine europapolitische Grundanschauung ${ }^{88}$. Dort warnte

${ }^{87}$ Vgl. KeRN [d. i. Hilferding], Das Ende der Völkerbundspolitik, in: ZfS, 2. Jg., H. $20 /$ 21 (Mai/Juni 1935), S. 634.

88 [STAMPFER], Sein wahres Ziel. Vorherrschaft in Europa, in: NV, Nr. 144 (15. 3. 1936), S. 1 f. Von den wenigen außenpolitischen Autoren der Sopade, die im $N V$ veröffentlich- 
er eindringlich vor einer „Organisierung Europas unter dem Diktat Hitlers" 89 und warb für eine "wahrhaft europäische Föderation [...] im Geiste der Demokratie, im Geiste der Gleichheit", die das Prinzip staatlicher Souveränität hinter den identitätsstiftenden Merkmalen des freien Europas zurücktreten lasse. Identitätsstiftende Wirkung sprach er insbesondere der „Gleichheit der Kulturauffassung, der Freiheit der wirtschaftlichen Beziehungen und der Gemeinsamkeit der Rechtsauffassungen " $\mathrm{zu}^{90}$. Gegen den überhitzten Nationalismus des Hitler-Regimes helfe allein die dauerhafte Einrichtung starker Institutionen des Völkerrechts ${ }^{91}$. Damit griff Stampfer Geyers Idee der europäischen Demokratie auf. Als Chefredakteur der in New York herausgegebenen Neuen Volkszeitung sollte er ab 1940/41 wortgewaltig diese europäische Demokratie mit pragmatischen Überlegungen zu einer mehrheitsfähigen Leitfunktion Frankreichs auf dem Weg zu einer zukunftsfähigen Europaföderation verknüpfen ${ }^{92}$.

Gregor Bienstock: „Europa und die Weltpolitik" Gregor Bienstocks im Jahre 1936 erschienenes Buch „Europa und die Weltpolitik“ stellt ein weiteres wichtiges Werk der frühen Europadebatte in sozialdemokratischen Exilkreisen dar. Im Gegensatz zu wiederholt vorgebrachten Behauptungen ${ }^{93}$ hatte diese Veröffentlichung ihren Ursprung aber keineswegs im Zentrum der Sozialdemokratie. Vielmehr machte sich die Sopade einige hellsichtige Schlußfolgerungen Bienstocks erst nach 1940 zu eigen, ohne sich dabei auf Bienstock zu berufen.

Aus einer schonungslosen Selbstkritik und der frühzeitigen Erkenntnis heraus, daß „Europa [...] heute nicht nur an seiner eigenen Zerrissenheit zugrunde [gehe], sondern auch an seiner weltpolitischen Isolierung ${ }^{\alpha 94}$, bemühte sich Bienstock von Beginn an um eine globale Sichtweise. Das „System Europa" sei wechselseitig verwoben mit anderen politischen Systemen der Welt, etwa dem des mittleren Orients oder dem "pazifischen Ozeankreis “95, insbesondere aber der Einflußzone „der Europäer am anderen Ufer

ten - Geyer, Stampfer, Hilferding - kommt nach Stil und Duktus des Artikels nur Stampfer als Verfasser in Betracht. Übereinstimmend BEHRING, Demokratische AuBenpolitik 1999, S. 382, ohne Nennung von Gründen.

89 [STAMPFER], Sein wahres Ziel, in: NV, Nr. 144 (15. 3. 1936), S. 2.

90 Ibid.

91 Ibid.

92 Insbesondere STAMPFER, Die anderen Drei. Europas Rettung: Eine europäische Föderation - Die Mission Frankreichs, in: NVZ, 12. Jg., Nr. 49 (4. 12. 1943), S. 1; DERS., Für die Vereinigten Staaten von Europa: Vive la France!, in: NVZ, 13. Jg., Nr. 2 (8. 1. 1944), S. 1; DERS., Gruß nach Frankreich. Die europäische Mission der französischen Sozialisten, in: NVZ, 13. Jg., Nr. 34 (19. 8. 1944), S. 1, sowie DeRS., Gute Nachbar-Politik in Europa: De Gaulle am Kreuzweg, in: NVZ, 13. Jg., Nr. 44 (28. 10. 1944), S. 1. 93 So z. B. VOIGT (Hg.), Friedenssicherung 1988, S. 34.

94 BIENSTOCK, Kontinentalpolitik oder Weltpolitik?, in: ZfS, 2. Jg., H. 22/23 (Juli/August 1935), S. 697-703 (702).

95 BIENSTOCK, Europa und die Weltpolitik 1936, S. 41. 
des Atlantik “96. Aus dieser globalen Interdependenz der politischen Systeme folgerte Bienstock, daß „heute kaum noch von einer isolierten europäischen Politik“ geredet werden könne" ${ }^{97}$. Vielmehr könne man „keine konstruktive europäische Politik durchführen [...], ohne den amerikanischen Faktor in die Rechnung einzustellen"98. Und auch die auf den Kontinent beschränkte europäische Politik werde wesentlich beeinflußt durch die „am wenigsten europäisch orientierte[n] Staate[n] Europas" - Großbritannien und die Sowjetunion". Damit rückte Bienstock auf den ersten Blick den geographischen Umrissen des paneuropäischen Modells näher. Doch zog er nicht Coudenhove-Kalergis Schluß, Rußland und England von Europa fernzuhalten, sondern plädierte gerade wegen des weltpolitischen Gewichts dieser beiden Machtfaktoren für deren europäische Einbindung. Dabei präzisierte er einige Axiome sozialistischer Weltsicht, die selten in solcher Klarheit ausgesprochen wurden und doch von tragender Bedeutung für das Verständnis sozialdemokratischer und sozialistischer Europadebatten sind: „Die sozialistische Bewegung, die doch im wesentlichen eine europäische Angelegenheit ist, kann besonders in ihrer heutigen Lage keine Verantwortung für die Gestaltung der Weltpolitik übernehmen." 100 Die europäischen Sozialisten müßten bereit sein, sich allen feindlichen Kräften entgegenzuwerfen.

Der Sozialismus als wesentlich europäisches Phänomen entsprach dem Verständnis des Völkerbundes als wesentlich europäischer Institution. Bienstock bot resümierend eine der seltenen quellengestützten Definitionen des Begriffs „Europa“, auf den die sozialistischen Ideale projiziert werden und der auf diese Weise das politische Fernziel einer „europäischen Föderation unter sozialistischer Führung “101 anschaulich umschreibt: „Für uns Europäer, ich meine natürlich Europäer nicht im geographischen Sinne, sondern umfasse mit diesem Begriff jene nicht sehr zahlreiche, aber auch nicht unbedeutende Schicht von Menschen, für die die geistige Kultur höher steht als die materielle, für die ,Europa' gleichbedeutend ist mit politischer Freiheit, sozialer Gerechtigkeit und alten Kulturtraditionen, für uns, Demokraten und Sozialisten, ist der Krieg überhaupt kein Ausweg." 102

96 Ibid. S. 79.

97 Ibid. S. 41.

98 Ibid. S. 80. Ähnlich hatte BIENSTOCK, Kontinentalpolitik oder Weltpolitik?, in: ZfS, 2. Jg., H. 22/23 (Juli/August 1935), S. 701 argumentiert: „Alles, was man auf dem Kontinent England vorwirft, könnte London mit ebensoviel und mehr Berechtigung Washington vorwerfen. England könnte mit Amerikas Hilfe für die Befriedung Europas und der Welt alles tun, ohne Amerika gar nichts oder jedenfalls sehr wenig."

99 BieNSTOCK, Europa und die Weltpolitik 1936, S. 39.

100 Ibid. S. 78.

101 BIENSTOCK, Kontinentalpolitik oder Weltpolitik?, in: ZfS, 2. Jg., H. 22/23 (Juli/August 1935), S. 700.

102 BIENSTOCK, Europa und die Weltpolitik 1936, S. 79. 


\subsection{Revolutionäre Sozialisten Deutschlands (RSD)}

Ungeachtet der verhältnismäßig geringen Zahl der politisch aktiven Emigranten ${ }^{103}$ fächert sich die sozialdemokratische Emigration in verschiedene Gruppen, deren Anzahl mit der Dauer des Exils stetig zunahm und die mehrere, häufig konkurrierende Denkmodelle entwickelten. Hilferding, Geyer und Stampfer repräsentieren dabei lediglich den Exilvorstand der SPD bis zu dessen räumlicher Trennung nach der Besetzung Frankreichs durch die deutsche Wehrmacht. Ein wesentlicher Grund für die im Laufe des Exils zu beobachtende Zersplitterung der Sozialdemokratie in Gruppen und Grüppchen ist in dem Individualisierungsprozeß zu sehen, dem insbesondere die exilierten Parteiorganisationen ausgesetzt waren. Ohne den Rückhalt breiter Wählerschichten reduzierte sich der Einflußbereich der Parteien auf die verhältnismäßig wenigen emigrierten Persönlichkeiten, die sich weiterhin am politischen Leben beteiligten. Dadurch erfuhr der politische Diskurs zwangsläufig eine eher theoretische Orientierung, denn die Zielsetzung war nun weniger die Beeinflussung und Mobilisierung der Arbeitermassen als vielmehr die intellektuelle Überzeugungskraft von Argument und Gegenargument. Durch die Konzentration auf wenige selbständig denkende Köpfe mit jeweils eigenen Ideen, politischen Grundüberzeugungen und persönlichen Motiven wurde der Blick für individuelle Nuancen und Einzelfallbetrachtungen geschärft. Dieses soziale Phänomen des Individualisierungsprozesses gewann an Bedeutung, je länger die organisatorische und biographische Ausnahmesituation des Exils mit von Grund auf ausgewechselten Zielgruppen anhielt. Individualisten wie Gerhard Kreyssig taten sich ohnehin schwer, ihren politischen Freiraum zugunsten einer bestimmten parteipolitischen Richtung einzuengen ${ }^{104}$.

Erste Abspaltungen vom Exilvorstand der SPD gehen auf das erste Jahr des Exils zurück, als die Gruppe ORG/Neu Beginnen unter Beteiligung

103 Der emigrierte Sozialdemokrat Karl Höltermann schildert in einem Brief an „Lieber T." vom 4. 6. 1937, AsD, NL Höltermann, M. 1 die Doppelmoral und das mangelnde Engagement: „Wie viele kommen aus dem Reich hierher und ,lehnen selbstverständlich die Nazi ab" - aber der Gedanke, daß Verantwortlichkeit für das gesamte Tun des Reiches nur durch erfolgreiche Gegentat abgewendet werden kann, kommt nur ganz wenigen Leuten. Diese guten Deutschen machen immer irgend jemand verantwortlich, nie sich und ihre eigene Untätigkeit. Die ganz Schlauen helfen sich in der Regel noch immer mit dem saudummen Gequatsche über die ,Fehler der Sozialdemokraten und Gewerkschaften'. Am meisten tun es Leute, die entweder selbst nie einen Finger gerührt haben oder gar selbst stets zu den Gegnern gehörten."

104 In einem Antwortschreiben an Wilhelm Sander vom 4. 5. 1945, AsD, NL Kreyssig, Mappe 60 fand Kreyssig für seine abstinente Haltung klare Worte: „Es wird Dir auch nicht entgangen sein, daß ich seit rund zwei Jahren kaum eine der Zusammenkünfte besucht habe. Aus mehreren Gründen [...] war ich schon in Frankreich dagegen, Emigrantenvereine zu organisieren - nicht zuletzt, weil positive Arbeit m. M. besser ohne sie geleistet werden kann. Ich betrachte mich deshalb auch an keine Beschlüsse gebunden, die der ,Londoner Ausschuß der SPD' faßt." 
namhafter Sopade-Grenzsekretäre wie Waldemar von Knoeringen, Erwin Schoettle und Franz Bögler sowie des Vorstandsmitglieds Paul Hertz schrittweise ihren Anspruch als eigenständige Exilgruppe offenlegte. Häufig versammelten sozialdemokratische Persönlichkeiten gleichgesinnte Genossen um sich und dokumentierten so ihre Opposition zu einzelnen Überzeugungen oder Reaktionen des Sopade-Parteivorstandes. So entstand in Frankreich 1938 die Landesgruppe deutscher Sozialdemokraten in Frankreich um Max Braun und in Großbritannien eine Gruppe von Parlamentariern um den sozialdemokratischen Politiker Karl Höltermann. Die Zersplitterung der exilierten Sozialdemokratie erreichte schließlich einen Höhepunkt, als im Rahmen der Fight for Freedom-Affäre Anfang 1942 eine der Schlüsselfiguren der Sopade, Curt Geyer, mit der Partei brach ${ }^{105}$ und 1945 die in die USA geflüchteten Vorstandsmitglieder Wilhelm Sollmann, Marie Juchacz und Georg Dietrich unter Verweis auf das zeitlich überholte demokratische Mandat aus dem Vorstand ausschieden ${ }^{106}$.

In der Folge des Individualisierungsprozesses und der damit einhergehenden Zersplitterung des sozialistischen Exils stieß der Parteivorstand der SPD von Anfang an auf erhebliche Akzeptanzschwierigkeiten. Dies umso mehr, als er sich selbst als organisatorischer und programmatischer "Treuhänder" der deutschen Sozialdemokratie mit Alleinvertretungsanspruch betrachtete $^{107}$. Gerade dieses Selbstverständnis barg hinreichend Konfliktpotential für die Auseinandersetzungen zwischen der Sopade und anderen sozialdemokratischen und linkssozialistischen Gruppen des politischen Exils. Daraus resultierte eine deutliche Konzentration auf die Verteidigung des Alleinvertretungsanspruchs - sowohl gegenüber den abgespaltenen Gruppierungen als auch gegenüber der KPD, mit der die Sozialdemokratie traditionell um die Führungsposition in der Arbeiterschaft rang. Im Kern ging es um die $\mathrm{Da}$ seinsberechtigung der Sopade und die Legitimation ihres politischen Mandats im Exil. Wie schwierig diese Aufgabe war, zeigt ein Brief des Vorstandsmitglieds Wilhelm Sollmann an das Vorstandsmitglied Paul Hertz vom November 1937, in dem Sollmann der Sopade-Prominenz jegliche intellektuelle Führungskompetenz absprach: „Keiner der im Parteivorstand tätigen Personen gestehe ich in Zukunft das Recht zu, mit einem politischen Urteil aufzutreten, das Autorität beansprucht. Breitscheids Bankrott ist vollständig. Hilferding ist jammervoll passiv. Seine Artikel sind provinziell und unbeachtlich. Die anderen? Schwamm drüber! "108 Sollmann, der nie zu Vorstandssitzungen hinzugezogen wurde, kommt zu einer vernichtenden Einschätzung:

105 Vgl. die Dokumentation des Konfliktes bei EIBER, Union 1998, Dok. Nr. $58 \mathrm{ff}$.

106 Gemeinsames Schreiben von Aufhäuser, Dietrich, Hertz und Juchacz an Vogel, in: MatTHias (Hg.), Mit dem Gesicht nach Deutschland 1968, Dok. Nr. 175, S. 698-700. $107 \mathrm{Vgl}$. Ollenhauers Ausführungen in Auseinandersetzung mit Aufhäuser in der Vorstandssitzung vom 22. 6. 1934, in: BuCHHOLZ, RoTHER (Bearb.), Parteivorstand 1995, Dok. Nr. 15.

108 Sollmann an Hertz, 4. 11. 1937, IISG, NL Hertz, S7/8, Mappe B, Nr. 37. 
„Traurig, wie das Erbe der großartigsten politischen Bewegung, die es je in der Welt gegeben hat, von kleinen Seelen verwüstet wird. "109 Mißtrauen und Geringschätzung prägte auch das Urteil der Sopade über die konkurrierenden sozialistischen Exilgruppen. So ärgerte sich Erich Ollenhauer in einer Gesprächsnotiz über die „rein kommunistische[n] Fraktionskampfmanieren und Tschekkamethoden" der Gruppe Neu Beginnen und forderte seinen Gesprächspartner zur Spionage und Denunziation auf ${ }^{110}$.

Auch die Revolutionären Sozialisten Deutschlands (RSD) gingen aus einer Abspaltung von der Sozialdemokratie hervor, sollten jedoch schon Mitte 1937 wieder zur Sopade zurückkehren. In der ideologischen Auseinandersetzung mit dem Prager Manifest der Sopade hatten sich die Vorstandsmitglieder Siegfried Aufhäuser und Karl Böchel vehement gegen das ihrer Ansicht nach nicht hinreichend revolutionäre Manifest ausgesprochen und ihre grundsätzliche Kritik in der Zeitschrift für Sozialismus im Herbst 1934 veröffentlicht ${ }^{111}$. Damit war der „Arbeitskreis Revolutionärer Sozialisten“" geboren, der sich als „überparteiliche Arbeitsgemeinschaft" verstand und sich primär der Schaffung einer sozialistischen Einheitsfront widmen wollte. Kennzeichnend für die „Plattform" der RSD ist die Befürwortung eines revolutionären Sozialismus, der auf die $Z$ wischenetappe einer Beteiligung an bürgerlichen Demokratien verzichtet und im Gegensatz zur Mehrheit der Sopade die Klassendiktatur des Proletariats als Endziel definiert ${ }^{112}$. Den rein intellektuellen Widerstand ablehnend, propagierten die Revolutionären Sozialisten den Widerstand des Exils als aktiven Machtkampf gegen die Reaktion: „Nicht indem wir die Paragraphen der neuen Verfassung ausklügeln, sondern indem wir die Macht der Reaktion brechen und die Macht der arbeitenden Klassen stabilisieren, werden wir die neue Freiheit sichern. "113

\section{Ibid.}

110 Ollenhauer, Gesprächsnotiz über eine Unterhaltung mit Fuchs vom 23. 7. 1938, ANF, F7 14716. Der Verdacht des Parteivorstands, bei der Gruppe Neu Beginnen handle es sich um ein Trojanisches Pferd der Kommunisten oder zumindest um die Demontage des Exilvorstandes betreibende Linkssozialisten, wird in Ollenhauers weiteren Aufzeichnungen sichtbar, ibid.: „Fuchs erklärt sich bereit, die ihm aus eigenem Erlebnis bekannten Tatsachen und Personalkenntnisse niederzulegen, damit sie einem beschränkten Kreis wie dem P. V. [Parteivorstand, B. S.] zur Verfügung stehen."

111 Arbeitskreis Revolutionärer Sozialisten, Der Weg zum sozialistischen Deutschland. Eine Plattform für die Einheitsfront, in: ZfS, 1. Jg., H. 12/13 (September/Oktober 1934), S. 375-409.

112 SCHIFrIN, Die Konsequenzen des revolutionären Programms, in: ZfS, 1. Jg., Nr. 9 (Juni 1934), S. 281-293 (283). Hinsichtlich der Absage an das sozialdemokratische Dogma der historischen Reihenfolge stimmte Schifrin ausdrücklich dem sozialistisch revolutionären Programm des „Prager Manifestes“ vom Januar 1934 zu. Bemerkenswert ist auch die Distanzierung der RSD von dem sozialistischen Mythos der „Massen gegen Hitler" und das ungeschminkte Eingeständnis, daß die deutsche Arbeiterschaft zur "Reservearmee der faschistisch-kapitalistischen Reaktion“ geworden sei; vgl. Arbeitskreis Revolutionärer Sozialisten, Der Weg zum sozialistischen Deutschland, in: ZfS, 1. Jg., H. 12/13 (September/Oktober 1934), S. 376.

113 Kommt nach Hitler das Chaos?, in: SozAk (Januar 1936). Der Artikel setzt sich kri- 
Auf dieser ideologischen Basis entwickelte der altlinke Theoretiker Alexander Schifrin, Mitverfasser der RSD-Plattform von 1934, die europäische Vision der Revolutionären Sozialisten und veröffentlichte in der Sozialistischen Aktion einige brillante und weitblickende Analysen der politischen Situation in Europa. In zahlreichen Beiträgen setzte sich Schifrin bis zu seiner Emigration in die USA - wo er sich dann auf militärpolitische Analysen konzentrieren sollte - mit der Gefahr einer "Faschisierung Mitteleuropas“ auseinander und sah darin einen Meilenstein auf dem Weg zur „Entfachung eines europäischen Krieges" ${ }^{114}$. Diese frühe Erkenntnis präzisierte er in seinem 1938 erschienenen Werk „Sozialismus, Krieg und Europa“: „Europa hat die Wahl zwischen Krieg und Frieden. [...] Der Frieden wird die Lösungen langsamer bringen, sie werden widerspruchsvoller sein, aber nicht durch den Blutpreis von Millionen Menschenleben bezahlt werden. "115 Hauptmotiv des vormaligen Mitarbeiters von Hilferding war die Verknüpfung des Fernzieles einer sozialistischen Revolution mit dem politischen Nahziel der Kriegsverhinderung und Friedenssicherung. In seinen europapolitischen Schriften widmete sich Schifrin vor allem zwei Aspekten: der Garantenfunktion einer deutschen sozialistischen Revolution für den europäischen Frieden und der Bildung einer „europäischen Volksfront“ zur Bekämpfung des Faschismus.

Alexander Schifrin: die deutsche Revolution als Garant des europäischen Friedens Mit einem Artikel für die Zeitschrift Sozialistische Revolution, der Vorläuferin der Zeitschrift für Sozialismus, meldete sich Schifrin schon im Oktober 1933 zur Frage der europäischen Zukunft zu Wort und eröffnete damit die allgemeine Exildebatte um eine Neuordnung Europas ${ }^{116}$. Er verfocht das Ideal eines sozialistischen Europas, das weder aus einer einseitigen Westorientierung noch aus einer Anlehnung an die Sowjetunion geboren werden könne. Vielmehr müsse das neue Europa aus seiner Mitte heraus entstehen. Dieser europäische Entwicklungsprozeß gliederte sich für Schifrin in drei revolutionäre Phasen. Zunächst müsse im Herzen Europas eine doppelte Revolution stattfinden: erst eine antifaschistische Revolution, die das nationalsozialistische Regime zu beseitigen habe, und anschließend eine proletarische Revolution, um dem Sozialismus in Deutschland zum Durchbruch zu

tisch mit den Bemühungen des Lutetia-Kreises um einen Verfassungsentwurf für Deutschland auseinander, denen zwei Vorschläge von Georg Bernhard und Leopold Schwarzschild zugrunde lagen.

114 SCHIFRIN, Hitler-Deutschland und Europa, in: Sozialistische Revolution. Monatsschrift für die Probleme des Sozialismus (später: ZfS), 1. Jg., Nr. 1 (Oktober 1933), S. 24-30 (25).

115 WeRnER [d. i. Schifrin], Sozialismus, Krieg und Europa 1938, S. 87.

116 SCHIFrin, Hitler-Deutschland und Europa, in: Sozialistische Revolution, 1. Jg., Nr. 1 (Oktober 1933), S. 24-30, passim. Leider geht Behring in seiner Studie über die außenpolitischen Vorstellungen deutscher Sozialdemokraten im Exil überhaupt nicht auf Schifrins Beiträge ein. 
verhelfen. Mit der proletarischen Revolution in Deutschland werde zwangsläufig eine dritte Phase eingeleitet, die den Triumphzug des Sozialismus nun auf der europäischen Ebene fortsetzen werde. Dabei erkannte der revolutionär-sozialistische Theoretiker eine Interdependenz zwischen der nationalen und der europäischen Handlungsebene. Europa sei auf ein sozialistisches und damit per se friedliches Deutschland angewiesen, zugleich aber könne die deutsche Revolution auch nur „als Garant des europäischen Friedens siegen ${ }^{* 117}$.

In Schifrins Vorstellung des zukünftigen Europas spiegelt sich der allgemeine sozialistische Traum eines sozialistischen Deutschlands als Motor eines sozialistischen Europas wider. Umstritten war lediglich, ob dieses neue Europa von vornherein sozialistisch zu sein habe oder übergangsweise eine Kooperation mit bürgerlich-kapitalistischen Mächten vertretbar sei. Für die Revolutionären Sozialisten Deutschlands kam eine Zusammenarbeit mit reaktionären Kräften überwiegend nicht in Betracht. Ihr europapolitischer Vordenker Schifrin aber orientierte sich eher an den tatsächlichen Gegebenheiten. Zwar hielt auch er selbst nach der Wiedereingliederung der RSD in die Sopade im Jahre 1937 an der Grundauffassung des revolutionären Sozialismus fest ${ }^{118}$, doch betrachtete er auf der europäischen Ebene eine zeitweilige „Rückendeckung [des sozialistischen Deutschlands] durch den demokratischen Westen " für unvermeidlich ${ }^{119}$. Damit redete Schifrin keineswegs einer Westorientierung das Wort, sondern betonte lediglich die strategische Notwendigkeit einer temporären Kooperation mit nichtsozialistischen Staaten, um eine letztlich unabhängige sozialistische Umwälzung aus der europäischen Mitte heraus zu ermöglichen. Auch eine enge Anlehnung an die UdSSR lehnte er mit deutlicheren Worten als andere Revolutionäre Sozialisten $a b^{120}$, wenngleich er in der stetigen Zusammenarbeit mit dem sozialistischen Vorzeigestaat einen wichtigen Parameter sozialistischer Außenpolitik sah ${ }^{121}$. Entscheidend für Deutschland und Europa sei Deutschlands "große europäische Sendung als Vermittlerin zwischen Ost und West" ${ }^{122}$. Schifrin kam zu dem Schluß, daß Mitteleuropa zwar grundsätzlich der „vorbe-

117 Ibid. S. 30.

118 Vgl. Werner [d. i. Schifrin], Sozialismus, Krieg und Europa 1938, passim.

119 SCHIFRIN, Hitler-Deutschland und Europa, in: Sozialistische Revolution, 1. Jg., Nr. 1 (Oktober 1933), S. 29.

120 DERS., Konsequenzen, in: ZfS, 1. Jg., Nr. 9 (Juni 1934), S. 288: Ablehnung der bolschewistischen Diktatur und des Sowjetsystems als „Pseudonym einer Diktatur der Partei über das Proletariat, einer Diktatur des Apparats über die Partei und einer Diktatur des,Führers“ über den Apparat“.

121 Vgl. ibid. S. $290 \mathrm{f}$.

122 WERNER [d. i. Schifrin], Sozialismus, Krieg und Europa 1938, S. 128. Schifrin greift hier auf eine Formel des sudetendeutschen Sozialdemokraten Wenzel JAKSCH zurück, der im Jahre 1936 ein Buch mit dem Titel „Volk und Arbeiter. Deutschlands europäische Sendung" veröffentlicht hatte. Dort verfocht Jaksch allerdings im Gegensatz zu Schifrins Ansatz ein Großdeutschland unter Einschluß Österreichs und des Sudetenlandes, das als friedlicher Koloß Europa aus seiner Mitte heraus regieren solle. 
stimmte Partner für alle zwischenregionalen Ententen innerhalb einer europäischen Föderation" sei123, die momentane Situation jedoch erfordere, daß Frankreich die europäische Aufgabe kommissarisch übernehme ${ }^{124}$. Für den Augenblick sei Mitteleuropa ein fundamentaler "Sprengkörper" 125 , der vorläufig „die große Zukunft des deutschen Sozialismus" überlagere ${ }^{126}$.

Europäische Volksfront zur Bekämpfung des Faschismus Aus der Verknüpfung der deutschen Frage mit der europäischen Frage unter dem gemeinsamen Dach der sozialistischen Revolutionsideologie folgte für Schifrin denknotwendig eine weitere Aufgabe: die Schaffung einer „europäischen Volksfront" 127 , um dem Faschismus wirksam entgegentreten zu können. Kenntnisreich hatte er schon Ende 1933 die Gefahren eines „faschistisch-revisionistischen Staatenblocks" 128 analysiert. Die implizite europäische Krise berge zwei Hauptstoßrichtungen der deutschen Außenpolitik: gegen die Sowjetunion und gegen Frankreich. Schifrin war einer der wenigen Emigranten, die zu einem solch frühen Zeitpunkt schon die ideologischen Komponenten des Nationalsozialismus erkannten, und ordnete sie überzeugend den beiden Hauptstoßrichtungen zu. Die Spitze gegen die Sowjetunion entspreche der Lebensraumideologie und der ,antikommunistische[n] Sendung "129, während Frankreich als Sinnbild der Erbfeindschaft gelte und für die verachteten Ideen der Französischen Revolution einzustehen habe. Damit hatte Schifrin die Grundkonstellation des deutschen Zweifrontenkrieges vorhergesagt und in ihrer ideologischen Dimension durchschaut. Den übrigen Staaten des Kontinents zwinge die Ausweitung des europäischen Faschismus unweigerlich einen „Kampf um Europa“ 130 auf, der unbedingt als ein Kampf um den europäischen Frieden geführt werden müsse mit dem Ziel, einen Krieg möglichst zu vermeiden. Seiner Grundhaltung verlieh Schifrin mit der Losung "Liquidierung des Krieges durch die Revolution"131 eine pazifistische Prägung, die er jedoch durch die bedingte Befürwortung

123 Ibid. S. 149.

124 SCHIFRIN, Frankreich und Europa, in: Die Neue Weltbühne, XXXIV. Jg., Nr. 3 (20. 1. 1938), S. 68-72 (71).

125 WERNER [d. i. A. Schifrin], Sozialismus, Krieg und Europa 1938, S. 149.

126 SCHIFrIN, Frankreich und Europa, in: Die Neue Weltbühne, XXXIV. Jg., Nr. 3 (20. 1. 1938), S. 71.

127 WeRnER [d. i. A. Schifrin], Sozialismus, Krieg und Europa 1938, S. 111.

128 SCHIFrin, Hitler-Deutschland und Europa, in: Sozialistische Revolution, 1. Jg., Nr. 1 (Oktober 1933), S. 25.

129 Ibid. S. 26.

130 Ibid.

131 Ibid. S. 29. Zur grundsätzlichen Beurteilung von Krieg als Mittel der Politik im sozialistischen Denken und die harten Auseinandersetzungen um die Stellung zum Krieg in jener Zeit vgl. LANGKAU-ALEX, „Der Kampf für die Demokratie und den Frieden“ 1992. 
des Krieges zur Durchsetzung der antifaschistischen Revolution relativierte ${ }^{132}$.

Um den Faschismus wirksam bekämpfen zu können, forderte Schifrin einen sozialistischen Gegenentwurf zum faschistischen Europa. Er ging davon aus, daß Ausgangspunkt aller diesbezüglichen Überlegungen „die sozialistische und die europäische Lösung der deutschen Frage ${ }^{\text {"133 }} \mathrm{zu}$ sein habe. Konkret schlug Schifrin vor, der von ihm geforderten „europäischen Volksfront" auf einer sozialistischen Entente Frankreichs und Großbritanniens mit der Sowjetunion aufzubauen ${ }^{134}$, die in engster Kooperation mit den „Kräfte[n] der mitteleuropäischen und der italienischen Revolution [sowie den] Arbeiter- und Bauernbewegungen Ost- und Südosteuropas "135 zusammenarbeiten müsse. Innerhalb der zentralen Entente müsse Frankreich als "Organisator Europas" fungieren, während Großbritannien und die UdSSR als geographisch „periphere Großmächte“ nur eingeschränkt Einfluß ausüben könnten ${ }^{136}$. Gerade mit Frankreich aber müsse sich ein sozialistisches Deutschland um eine „bleibende Verständigung [...] im Rahmen europäischer Einigungspolitik" 137 bemühen. Schifrin war erkennbar unschlüssig über die Zusammensetzung des europäischen Machtzentrums. Forderte er einerseits die erwähnte Entente zwischen London, Paris und Moskau, so setzte er sich andererseits für die deutsch-französische und die deutsch-russische Kooperation als den beiden Hauptpfeilern Europas ein und sah an wieder anderer Stelle die Zukunft Europas in einem Vierergespann aus dem demokratischen Sozialismus des Westens, der Sowjetunion, der mitteleuropäischen und italienischen Revolution sowie den Arbeiter- und Bauernbewegungen Ost- und Südosteuropas ${ }^{138}$.

Alexander Schifrin, der sich zwar an exponierter Stelle, neben Aufhäuser aber nahezu als einziger Revolutionärer Sozialist am frühen Europadiskurs beteiligte, resümierte 1938: „Die sozialistische Organisation Europas wird nur eine gesamteuropäische sozialistische Föderation sein können: nicht eine beschränkte Regelung für Westeuropa und nicht das abgekapselte Kontinentaleuropa. Die Verbindung mit England wird dem sozialistischen Kontinen-

132 SCHIFrin, Hitler-Deutschland und Europa, in: Sozialistische Revolution, 1. Jg., Nr. 1 (Oktober 1933), S. 29: „Der Krieg kann dem Sturz der faschistischen Diktatur in Deutschland vorangehen, aber er darf nicht dem Sturz der Diktatur folgen."

133 SCHIFrIN, Konsequenzen, in: ZfS, 1. Jg., Nr. 9 (Juni 1934), S. 291. Vier Jahre später prophezeite Schifrin: „Nach dem Zusammenbruch des Nationalsozialismus wird diese [deutsche] Frage in einer Krise ohnegleichen aufgerollt werden, und ohne ihre Lösung wird es keine Lösung des europäischen Problems geben."; WeRner [d. i. Schifrin], Sozialismus, Krieg und Europa 1938, S. 117.

134 WERNER [d. i. Schifrin], ibid. S. 108-110.

135 Ibid. S. 82.

136 SCHIFRIN, Frankreich und Europa, in: Die Neue Weltbühne, XXXIV. Jg., Nr. 3 (20. 1. 1938), S. 68.

137 DeRS., Konsequenzen, in: ZfS, 1. Jg., Nr. 9 (Juni 1934), S. 291.

138 WERnER [d. i. Schifrin], Sozialismus, Krieg und Europa 1938, S. 82. 
taleuropa den Zugang zu vier Kontinenten öffnen, die Verbindung mit der Sowjetunion den Weg ins Innere Asiens. Innerhalb Kontinentaleuropas wird das sozialistische Deutschland, das zugleich mit Frankreich, Zwischeneuropa und der Sowjetunion zusammenarbeitet, das organische Ineinandergreifen der entscheidenden Zonen der europäischen Föderation sichern. "139 Damit distanzierte sich der revolutionäre Sozialist deutlich von der Paneuropa-Idee Coudenhove-Kalergis, der sowohl Großbritannien als auch die Sowjetunion von einer europäischen Föderation auszuschließen beabsichtigte und jedenfalls hinsichtlich des antikommunistischen Motivs auf die tatkräftige Unterstützung des Sozialdemokraten Friedrich Stampfer zählen konnte.

Siegfried Aufhäuser: „Donau-Locarno" Aus dem Kreise der Revolutionären Sozialisten wurden die europapolitischen Ausführungen Schifrins durch Siegfried Aufhäuser um eine wirtschaftliche Komponente ergänzt. Aufhäuser warnte im Juni 1936 vor einer nationalsozialistischen Großraumwirtschaft in Südosteuropa und stellte als Gegenentwurf ein „Donau-Locarno“ zur Diskussion ${ }^{140}$. Dabei dachte der 1935 aus der Sopade ausgeschlossene Gewerkschaftsfunktionär an eine wirtschaftliche Föderation der Donauländer Tschechoslowakei, Jugoslawien, Rumänien, Österreich, Ungarn „und vielleicht auch Bulgarien" 141 . Nur auf dem Wege einer Wirtschaftsgemeinschaft könne die drohende Abhängigkeit des Donauraumes von der deutschen Wirtschaft verhindert und die dahinter stehenden "politischen Gefahren für den europäischen Frieden" abgewehrt werden ${ }^{142}$.

In den Jahren der Existenz des Arbeitskreises Revolutionärer Sozialisten zwischen 1933 und 1937 findet sich kein einziger detaillierter Plan der RSD zum Neuaufbau Europas. Vielmehr verstanden die beiden Vordenker Siegfried Aufhäuser und vor allem Alexander Schifrin Europa primär als Kontinentaldefinition, als einen geographischen und geostrategischen Begriff für ein Territorium, das sich dem wachsenden Einfluß des Faschismus entgegenstellen müsse. Dennoch darf nicht übersehen werden, daß die Utopie einer sozialistischen Revolution auf der nationalen, europäischen und schließlich globalen Ebene sowie der damit verbundenen Hoffnung auf eine Föderation aller sozialistischen Länder die Grundlage des revolutionär-sozialistischen Europabildes als Teilelement notwendig in sich barg ${ }^{143}$. Doch bleibt unverändert festzuhalten, daß der Kampf gegen Hitler in diesen ersten Exiljahren

139 Ibid. S. 156.

140 AufHÄUSER, Mitteleuropa, in: Die Neue Weltbühne, XXXII.Jg., Nr. 26 (25. 6. 1936), S. 797-801 (798).

141 Ibid. S. 798.

142 Ibid. S. 799.

143 Insofern kann die Aussage BeHRINGs, Demokratische Außenpolitik 1999, S. 444, Anm. 7 zur Gruppe Neu Beginnen, schon 1934 hätten wesentliche Bestandteile der spezifisch linkssozialistischen Europavorstellungen "gleichsam in der Luft" gelegen, auf die Revolutionären Sozialisten ausgedehnt werden. 
ganz im Vordergrund stand - ein Kampf, dessen Erfolgschancen weniger in einer institutionell verankerten europäischen Einigung, sondern eher in einzelnen oder konzertierten Aktionen gegen das Hitler-Regime gesehen wurden. Folglich konzentrierten sich die Europabeiträge der RSD auf den antifaschistischen Kampf als Hauptmotiv für ein geeintes Europa. Überlegungen zur künftigen Position Europas im weltpolitischen und weltwirtschaftlichen Gesamtgefüge kamen dabei ebenso selten zur Sprache wie Äußerungen zur Institutionalisierung einer europäischen Föderation, ihres Kompetenzenkataloges oder der inneren Struktur. Bis 1938 sahen sich die Vertreter der linken Sozialdemokratie kaum veranlaßt, solche Fragen eingehend zu erörtern. Europa wurde nicht als eigenständiges Ziel des exilierten Widerstandes betrachtet, sondern trat als Motiv völlig hinter die Überwindung des europäischen Faschismus und die sozialistische Revolution zurück. Ein konzeptionelles Verständnis der Widerstandsarbeit als Forum zukunftsorientierter Neuordnungsplanungen sollte erst durch das Münchner Abkommen und den HitlerStalin-Pakt die entscheidenden Impulse erhalten.

\subsection{Sozialistische Arbeiter-Partei (SAP)}

Unter den linkssozialistischen Gruppierungen des Exils verfolgte die Sozialistische Arbeiter-Partei Deutschlands (SAPD) die dogmatisch unnachgiebigste Linie. Die nach dem Scheitern der Koalitionsregierung unter Hermann Müller 1931 von der SPD abgespaltene Organisation zählte zu ihren Mitgliedern Persönlichkeiten des späteren politischen Exils wie Willy Brandt, August und Irmgard Enderle, Stefan Szende sowie die ehemaligen KPO-Mitglieder Paul Frölich und Jacob Walcher. Frölich und Walcher errichteten nach 1933 in Paris die politisch äußerst aktive "Auslands-Gruppe P“, die sich bis Kriegsbeginn bemühte, den innerdeutschen Widerstand anzuleiten und aus dem Ausland zu koordinieren. Infolge einer parteiinternen Grundsatzdiskussion über die parteipolitischen und dogmatischen Konsequenzen des deutsch-sowjetischen Nichtangriffspaktes vom 23. August 1939, der das Selbstverständnis der SAP erschütterte, zerfiel die Partei in mehrere Grüppchen Intellektueller ${ }^{144}$. In Skandinavien trafen sich Brandt, Szende und das Ehepaar Enderle, während Walcher und Frölich nach der deutschen Besetzung Frankreichs in die USA weiterflüchteten. Der politischen Arbeit der nach Großbritannien geflüchteten SAP-Mitglieder kommt für den Europadiskurs nur geringe Bedeutung zu. Dies gilt erst recht seit dem Eintritt in die 1941 gegründete Union deutscher sozialistischer Organisationen in Großbritannien. Dagegen gelang es dem 1933 aus der SAP ausgetretenen August Siemsen, mit der Bewegung „Das Andere Deutschland“ in Argentinien ein Zentrum politischer Aktivität zu errichten.

144 Zur Organisationsgeschichte der SAP(D) vgl. BREMER, SAP 1978; Drechsler, SAP 1965; FOITZIK, Zwischen den Fronten 1986. 
Die SAP verstand sich selbst als Sammelbecken linkssozialistischer Gruppierungen und Abspaltungen von der SPD. Als Hauptanliegen galt ihr die Schaffung einer Einheitsfront der sozialistischen Arbeiterbewegung gegen den Nationalsozialismus. Im revolutionär-sozialistischen Eifer rief der junge Willy Brandt 1936 aus: „Wir müssen verstehen, die Einheit zu unserer Parole zu machen - gegen die tatsächlichen reformistischen Spalter [Hervorhebung im Original, B. S.]“145. Damit wehrte sich der 22jährige im Namen seiner Partei gegen den Spaltervorwurf der „reformistischen“ Sopade.

Im Gegensatz zu ihrem Anspruch, ein Sammelbecken der Linkssozialisten zu werden, stand die dogmatische Selbstwahrnehmung der SAP als Bannerträger eines orthodox verstandenen Marxismus, den es "nach mehreren Fronten zugleich zu verteidigen" 146 gelte. Aus dieser Grundhaltung resultierte eine Fokussierung auf die sozialistische Weltrevolution, die mit der deutschen Revolution und in engstem Schulterschluß mit der Sowjetunion beginnen werde. Damit reduzierte sich die außenpolitische Sicht der zahlenmäßig stärksten der linkssozialistischen Gruppen auf den global-revolutionären Aspekt einer „revolutionären sozialistischen Macht, die vom Rhein bis Wladiwostok reichen würde, zu der Japan und riesige Teile Asiens zu zählen wären"147. Mit einem solchen Ansatz erübrigte sich jede Überlegung zu einem eigenständigen europäischen Machtblock. Abseits der offiziellen Verlautbarungen der Pariser Auslandszentrale der SAP jedoch äußerten sich Willy Brandt und der schon 1933 ausgetretene Mitgründer der SAP, August Siemsen, oftmals kritisch zur Parteilinie. Während sich Brandt aus Norwegen anfangs vor allem um eine differenzierte Betrachtung des Weltmachtfaktors Sowjetunion bemühte, trat August Siemsen als einziges Mitglied des Sympathisantenkreises der SAP schon in den Jahren bis 1938 mit der Forderung nach einem europäischen Staatenbund in Erscheinung. Ihm sollte erst im Oktober 1938 der Pazifist, Volkssozialist und SAPler Eugen Brehm mit seinen pointierten „Bemerkungen zur Außenpolitik“ und anderen Beiträgen zur Seite stehen. Ab 1940 trat auch Willy Brandt, teilweise in Kooperation mit Stefan Szende und dem Ehepaar Enderle, gezielt in den Europadiskurs des Exils ein. Dagegen zogen sich die beiden Parteifunktionäre Jacob Walcher und Paul Frölich nach ihrer Flucht in die USA völlig aus der Exilpolitik zurück. Die damit einhergehende faktische Zersplitterung der SAP führte dazu, daß politische Positionierungen nach 1939/40 kaum mehr im Namen der SAP veröffentlicht wurden und die unvermindert aktiven Persönlichkeiten wie Brandt und Siemsen sich von der ursprünglichen dogmatisch marxistischen Parteilinie weit entfernten. Nicht nur der 1933 ausgetretene Siemsen, sondern auch das Parteimitglied Brandt verstanden sich nicht mehr als Repräsentanten der SAP, sondern als Sozialisten im Kampf um die Einheit der

145 BRANDT, Bemerkungen zum Einheitsfrontproblem, in: MT, 1. Jg., Nr. 5 (Oktober 1936), S. 25-31 (31).

146 Ibid. S. 26.

147 Walcher an Antonius [d. i. Enderle], 15. 6. 1934, AsD, SAP-Archiv, M. 224. 
sozialistischen Bewegung. Aus diesem veränderten Selbstverständnis folgte gerade bei Brandt eine früh einsetzende pragmatische Sichtweise, die ihn schon 1940 die Schaffung eines geeinten Europas als unabdingbare Voraussetzung jeder dauerhaften Friedenssicherung erkennen ließ ${ }^{148}$.

Um die geistige Entwicklung renommierter SAP-Mitglieder nachvollziehen zu können, ist es notwendig, sich die ideologischen Ursprünge ins $\mathrm{Ge}-$ dächtnis zu rufen. Das Fundament der Parteiideologie war durch das orthodoxe Verständnis der marxistischen Theorie vorgegeben und kam in den vier Dogmen des Anti-Imperialismus, Antikapitalismus, Antifaschismus und Antibellizismus zum Ausdruck. Die SAP-Auslandszentrale um Walcher und Frölich sah in Faschismus und Kapitalismus zwei äquivalente Ausprägungen des Imperialismus, die es gleichermaßen zu bekämpfen gelte ${ }^{149}$. Daher war man im Gegensatz zur Sopade und einigen anderen Linkssozialisten nicht bereit, mit den kapitalistischen Demokratien des Westens zusammenzuarbeiten, selbst wenn diese Zusammenarbeit auf eine Übergangszeit beschränkt sein sollte. Stattdessen focht die SAP kompromißlos für die unmittelbare Errichtung einer „Föderation der sozialistischen Sowjetrepubliken der Welt" 150 . Nach Auffassung der Auslandsleitung konnte ein solches Ziel nur durch eine möglichst enge Anlehnung an die Sowjetunion erreicht werden, die durch eine "Verflechtung des deutsch-russischen Wirtschaftslebens" gestützt werden sollte ${ }^{151}$. Die führenden Dogmatiker der SAP verkündeten die Verteidigung der Sowjetunion als die wichtigste Aufgabe des internationalen Proletariats und gaben die Losung aus: „Die Sowjetunion [führt] einen Verteidigungskrieg selbst dann, wenn sie politisch und militärisch die Initiative zum Kriege ergreifen sollte. ${ }^{152}$ Diese starr dogmatische Grundhaltung sollte die SAP nach dem Schock des Hitler-Stalin-Paktes in eine letztlich vernichtende Krise stürzen.

Anders als die Pariser Auslandszentrale seiner Partei sprach sich Willy Brandt schon früh für eine kritischere Haltung gegenüber der Sowjetunion aus und warnte nachdrücklich vor einer Unterordnung der internationalen

148 BRANDT, Stormaktenes krigsmål og det nye Europa, Oslo 1940, deutscher Teilabdruck in: VOIGT (Hg.), Friedenssicherung 1988, S. 56-70.

149 Auslandszentrale der SAP, Die gemeinsamen Grundlagen der Kriegsdiskussion, in: MT, 1. Jg., Nr. 1 (Anfang November 1935), S. 3-5 (4): „Ein Krieg zwischen, demokratischen "Großmächten und faschistischen Ländern ist nur möglich, weil auf beiden Seiten um imperialistische Ziele gekämpft wird. “; Zur Abgrenzung des linkssozialistischen vom kommunistischen Antifaschismus-Verständnis vgl. LANGKAU-ALEX, Zweimal Antifaschismus - zweierlei Antifaschismus? 2002.

150 Resolution zur Kriegsdiskussion, angenommen am 28. 12. 1935 von der AuslandsGruppe P der SAP, in: MT, 1. Jg., Nr. 2 (Februar 1936), S. 12-15 (13). Die Paginierung dieser MT-Ausgabe ist für die Seiten 13 und 14 vertauscht, so daß gilt: „S. $14^{4}=$ S. 13 und „S. 13“" = S. 14.

151 SAPD (Hg.), Was kommt nach Hitler? Probleme der deutschen Revolution [1937], S. 43.

152 Resolution zur Kriegsdiskussion, in: MT, 1. Jg., Nr. 2 (Februar 1936), S. 12 f. 
Arbeiterbewegung unter die sowjetische Außenpolitik ${ }^{153}$. Dennoch zeigte auch er sich ein Jahr vor den ersten Moskauer Schauprozessen überzeugt, daß die Sowjetunion im Augenblick "nichts als den Frieden“" wolle ${ }^{154}$. Für den späteren Sekretär und Initiator des Stockholmer Arbeitskreises Internationaler Sozialisten bedeutete der Kampf um den Frieden die wichtigste Grundlage für die sozialistische Revolutionsbewegung ${ }^{155}$. Die Bewahrung des Friedens sollte vor allem nicht dem Völkerbund anvertraut werden, dem Brandt von Grund auf mißtraute ${ }^{156}$. Statt dessen plädierte er vehement für die Einberufung eines breitangelegten Antikriegskongresses, dem auch Vertreter der II. und III. Internationale angehören sollten, und beteiligte sich auf einer Sitzung des Internationalen Büros für revolutionäre sozialistische Einheit führend an der Ausarbeitung von Leitlinien eines solchen Kongresses ${ }^{157}$. Brandt ließ sich ungeachtet seiner Ablehnung des bestehenden Völkerbundes von der Idee eines kollektiven Friedenssicherungssystems leiten, die er später konkretisieren sollte. Doch war schon 1936 erkennbar, daß er zwischen dem außenpolitischen Ansatz eines kollektiven Sicherheitssystems einerseits und dem Völkerbund als dessen konkreter Erscheinungsform andererseits zu unterscheiden wußte ${ }^{158}$.

Wie schon erwähnt, war August Siemsen der einzige emigrierte SAP-Sympathisant, der nicht erst der aufrüttelnden Schockwirkung des deutsch-sowjetischen Nichtangriffspaktes bedurfte, um sich mit der Zukunft Europas auseinanderzusetzen. Siemsens Motiv für einen europäischen Staatenbund lag jedoch weniger in einem ausgeprägten Europabewußtsein als vielmehr in seiner harten Ablehnung des preußischen Staates und der damit assoziierten

153 W. B[randt], Revolutionäre Realpolitik - in der Kriegsfrage vor allem, in: MT, 1. Jg., Nr. 3 (Juli 1936), S. 13-18 (15).

154 Ibid.

155 Ibid. S. 16: „Durch eine vervielfachte internationale Friedensbewegung müssen wir die Kräfte des Fortschritts stärken."

156 Sitzung des Internationalen Büros für revolutionär-sozialistische Einheit vom 8.-10. Mai [1936] in Paris, Protokoll, S. 5, AsD, SAP-Archiv, M. 36: überarbeitete Vorschläge Willy Brandts für die Resolution eines künftigen Antikriegskongresses, Punkt 3: „Kein Vertrauen dem Völkerbund und irgendwelcher kapitalistischer Regierung.“ An dieser Sitzung nahmen neben Vertretern der sozialistischen Parteien Schwedens und Italiens sowie der britischen ILP auch drei SAP-Mitglieder teil, unter anderem der unter dem Decknamen „Antonius" erwähnte August Enderle, der sich jedoch nicht zu Wort meldete. Brandt dagegen war als Vertreter des Internationalen Büros revolutionärer Jugendorganisationen ein aktiver Mitgestalter dieser Sitzung und wurde schließlich sowohl mit der Ausarbeitung der Leitlinien des Antikriegskongresses als auch einer gemeinsamen Resolution zur Frage der Einheitsbewegung beauftragt; vgl. ibid. S. 5 und S. 8.

157 Ibid.

158 So verzichtete Brandt in der erwähnten Sitzung des Internationalen Büros für revolutionär-sozialistische Einheit darauf, den von ihm erarbeiteten Sechs-Punkte-Katalog um eine von ILP-Mitglied Stephen Campbell vorgeschlagene Stellungnahme gegen jedes kollektive Friedenssicherheitssystem zu ergänzen; vgl. ibid. 
politisch-gesellschaftlichen Wertorientierung begründet. In seiner aus Gründen der persönlichen Sicherheit von seiner Schwester, der engagierten Sozialistin Anna Siemsen, herausgegebenen Schrift „Preußen, die Gefahr Europas" vertrat er die Auffassung, daß die preußischen Grundwerte und Traditionen vom Nationalsozialismus „ins Unerträgliche übersteigert “159 worden seien und eine Vergiftung des deutschen Volkes bewirkt hätten. Siemsen sah im Untergang des Dritten Reiches die Chance, Preußen als den Brandherd dieser Entwicklung endgültig auszulöschen und das befreite Volk „aus dem alten preußischen in ein neues europäisches Deutschland" 160 hinüberzuführen. In Übereinstimmung mit nahezu allen deutschen Sozialisten maß auch Siemsen der sozialistischen Revolution in Deutschland eine bestimmungsgemäße Initialfunktion für die Schaffung eines sozialistischen Europas zu: „Dieses kommende sozialistische Deutschland wird [...] Kitt sein für die Vereinigten Staaten von Europa. "161 Wirtschaftlich lag für ihn auf der Hand, daß die Entwicklung der Weltwirtschaft „gebieterisch“ ein einheitliches Europa verlange, ohne dies jedoch weiter auszuführen 162 .

In einem vereinten Europa erkannte August Siemsen die historische Chance, die internationalen Beziehungen auf eine völlig neue Grundlage zu stellen. Für diese Funktion kam nach Siemsen die absolut gesetzte Staatssouveränität nicht in Betracht, da mit dem jedes Völkerrecht zum Scheitern verurteilenden Nichteinmischungsprinzip eine wirkliche Friedenssicherung unmöglich sei ${ }^{163}$. Hier ist der ideologische Zusammenhang in Siemsens $\mathrm{Ge}$ dankengebäude zu beachten. In Erweiterung der sozialistischen These vom Faschismus als barbarische Steigerung des Kapitalismus stellte er die „Verpreußung " 164 Europas als typische Folge des kapitalistischen Souveränitätsprinzips dar. Die äquivalente Gegenkraft war für ihn die Arbeiterschaft, die als der gestaltende Gesellschaftsfaktor der Zukunft Frieden und Menschlichkeit in einem sozialistischen Europa schaffen werde ${ }^{165}$. Siemsen zufolge repräsentierten die illegalen Gruppen der deutschen Arbeiterschaft das neue, europäische Deutschland der Zukunft ${ }^{166}$.

Mit der antipreußischen Komponente trug Siemsen weniger im Interesse der SAP als eher im eigenen Namen mit dem Antipreußentum einen neuen Aspekt in den frühen Europadiskurs ein. Die wesentlichen sozialistischen Motive für eine europäische Föderation zusammenfassend, konstatierte

159 Siemsen (Hg.), Preußen. Die Gefahr Europas 1937, S. 200. Die Gleichsetzung von Preußentum und Nationalsozialismus wurde im deutschen Exil vielfach kolportiert, vgl. z.B. Wirth, Gedanken über die Neuordnung Deutschlands nach Hitler, 26. 11. 1939, BAK, NL Wirth, N 1342, Bd. 123.

160 SiEMSEN (Hg.), Preußen. Die Gefahr Europas 1937, S. 200.

161 Ibid. S. 201.

162 Ibid. S. 193.

163 Ibid. S. 195.

164 Ibid. S. 199.

165 Ibid. S. 197-201.

166 Ibid. S. 200. 
Siemsen: „Wenn in allerletzter Stunde durch die Beseitigung oder Entmachtung Preußens der Weg freigemacht wird für ein anderes, das wirkliche Deutschland, dann hätte die Sache Europas und der Menschheit einen großen Sieg errungen." 167

\subsection{Neu Beginnen (NB)}

Ähnlich der Sozialistischen Arbeiterpartei verstand sich auch die Gruppe ORG/Neu Beginnen (NB) als „Sammlung aller deutschen Organisationen, die auf dem Boden des Klassenkampfes stehen"168. Folglich definierte auch Neu Beginnen die deutsche Arbeiterklasse als die entscheidende Klasse der europäischen Zukunft ${ }^{169}$. Ihr Gründer Walter Loewenheim, der im Jahre 1933 unter dem Pseudonym Miles die programmatische Schrift Neu Beginnen! veröffentlichte, vertrat eine marxistisch-leninistische Ausrichtung mit der Zielsetzung eines sozialistischen Einparteienstaates ${ }^{170}$. Auch in der Frage nach dem Verhältnis zur Sowjetunion folgte Loewenheim den Grundüberzeugungen der SAP. Er respektierte die UdSSR als ,historisch unentbehrli-

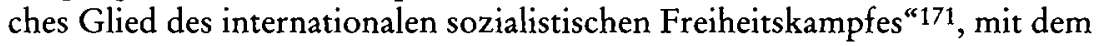
die deutschen Sozialisten trotz einiger insbesondere wirtschaftspolitischer Vorbehalte brüderlich verbunden seien.

Doch legte Miles Wert auf eine klare organisatorische Abgrenzung von der KPD und der Komintern und befürwortete - anders als die SAP - eine sozialistische Einheitsfront unter unbedingtem Ausschluß der Kommunisten, denn: „Unfähig, die Welt anders zu betrachten als durch die Brille ihrer formelhaften, dogmatischen Theorien, existiert für sie die faschistische Wirklichkeit, die diesen Vorstellungen so restlos widerspricht, einfach nicht. "172

Nach dem turbulenten Ausschluß von Miles ${ }^{173} 1935$ vollzogen die beiden führenden NB-Theoretiker Richard Löwenthal und der gerade erst beigetretene Paul Hertz eine dogmatische Kehrtwendung zum demokratischen Sozialismus ${ }^{174}$, den Miles noch vehement abgelehnt hatte ${ }^{175}$. In der Folge ver-

167 Ibid. S. 201.

168 Miles [d. i. Loewenheim], Neu beginnen! Faschismus und Sozialismus 1933, S. 57.

169 Neu Beginnen. Was es will, was es ist und wie es wurde [1939], S. 1.

170 Vgl. z. B. Miles [d. i. Loewenheim], Neu beginnen! Faschismus und Sozialismus 1933, S. 9.

171 lbid. S. 45.

172 Ibid. S. 53 und S. 58.

173 Vgl. das Rundschreiben „Zum Leitungswechsel in der Organisation“ vom 16. 7. 1935, IISG, Coll. Neu Beginnen, M. 48.

174 Neu Beginnen. Was es will, was es ist und wie es wurde [1939], S. 39.

175 Miles hatte sich 1933 noch mit klaren Worten gegen den demokratischen Sozialismus ausgesprochen: „Der Traum von dem ,demokratischen' Sozialismus, also von dem sozialistischen Weg, der, sozialen“ Republik von Weimar ist ausgeträumt. Wir stehen heute vor der nackten, brutalen, faschistischen Wirklichkeit. Jene haben Recht behalten, die schon immer nicht in der Toleranz, in der Unterwerfung, sondern im Kampf die 
suchte die Gruppe, sich als „pressure group“ zwischen der Sopade und der KPD zu etablieren ${ }^{176}$. Dies bedeutete für Löwenthal, Hertz und Karl Frank vor allem vorsichtiges Taktieren. Die elementaren Unterschiede in den Zielsetzungen zwischen Neu Beginnen und der KPD lagen offen. Zwar sprach man noch 1936 von einem „feste[n] Bündnis mit der SU“"177, und auch Löwenthal ließ in demselben Jahr die Überzeugung verlauten, daß „der Sozialist, der die europäische Föderation erstrebt, [...] in der Sowjetunion in der Stunde der Not seine entscheidende Stütze finden" werde ${ }^{178}$. Doch dürften diese Verlautbarungen vorrangig auf den Wunsch einer rein organisatorischen Annäherung an die KPD zurückzuführen sein, um den Brückenschlag zur exilierten Sozialdemokratie in die Wege zu leiten. Spätestens mit der mutmaßlich durch den russischen Geheimdienst NKVD lancierten Ermordung des Neu Beginnen-Mitglieds Mark Rein im spanischen Bürgerkrieg verdüsterten sich die Beziehungen zu den Kommunisten.

Um Kontakt mit sozialdemokratischen Politikern hatte sich die Gruppe Neu Beginnen schon früh bemüht, entsprechend ihrer Politik der personellen Unterwanderung sozialistischer Gruppen. Prominente Mitglieder von Neu Beginnen waren die einflußreichen Sopade-Grenzsekretäre Franz Bögler, Waldemar von Knoeringen und Erwin Schoettle sowie das Exilvorstandsmitglied Paul Hertz. Gerade durch die Kehrtwende zum demokratischen Sozialismus ${ }^{179}$ gestaltete sich die parteipolitische Abgrenzung gegenüber dem sozialdemokratischen Konzept des demokratischen Sozialismus als zunehmend schwierig und künstlich. Daher war der spätere Schritt der Londoner Vertreter von Neu Beginnen, über die Union der deutschen sozialistischen Organisationen in Großbritannien schließlich die Selbstauflösung der Gruppe in der SPD zu deklarieren, letztlich konsequent.

Richard Löwenthal: Europagedanke als Waffe Das zentrale Dokument der Gruppe Neu Beginnen zum Europadiskurs des deutschen Exils ist Richard Löwenthals 1936 in der Zeitschrift für Sozialismus publizierter Artikel „Was ist der Volkssozialismus?" 180 . Zwar handelt es sich dabei nachweislich nicht um das erste Dokument des linkssozialistischen Exils zur Frage der europäi-

Bewegungsform des Sozialismus in der kapitalistischen Gesellschaft sahen."; vgl. MILES [d. i. Loewenheim], Neu beginnen! Faschismus und Sozialismus 1933, S. 55.

176 FoITZIK, Zwischen den Fronten 1986, S. 137.

177 [Neu Beginnen], Protokoll Westkonferenz, 14./15.6. 1936, S. 1, IISG, Coll. Neu Beginnen, M. 55.

178 SERING [d. i. Löwenthal], Was ist der Volkssozialismus?, in: ZfS, 3. Jg., Nr. 36 (September 1936), S. 1105-1136 (1119). •

179 Richard Löwenthal prägte schon früh den Begriff des "freiheitlichen Sozialismus“ in Abgrenzung zur russischen Variante und in krasser Ablehnung der Moskauer Prozesse, die Löwenthal als faschistische Methoden geißelte; vgl. [Neu Beginnen], Protokoll Westkonferenz, 14./15. 6. 1936, S. 48, IISG, Coll. Neu Beginnen, M. 55.

180 SERING [d. i. Löwenthal], Was ist der Volkssozialismus?, in: ZfS, 3. Jg., Nr. 36 (September 1936), S. 1105-1136. 
schen Föderation ${ }^{181}$, doch erkannte der ehemalige KJVD-Funktionär Löwenthal als erster Emigrant das Widerstandspotential der europäischen Idee ${ }^{182}$ : „Der sozialistische Revolutionär wird in der europäischen Entscheidung der Gegenwart [...] den Europagedanken als Waffe einsetzen, um die Front der rücksichtslosen Gegner des Hitlersystems zu stärken."183 Damit war der Nukleus des Europadiskurses im Exil benannt: Planung als Widerstand.

Löwenthal sah schon 1936, daß Europa in dem erwarteten Krieg entscheiden müsse, ob es "mit oder gegen Hitler“ zu kämpfen beabsichtige; eine dritte Verhaltensalternative lehnte er - mit Blick auf den national-sozialistischen Ansatz Otto Strassers - für das politische Exil ab ${ }^{184}$. „Mit oder gegen Hitler" bedeutete für Löwenthal mehr als nur eine vorübergehende Frage der Kriegsstrategie. Vielmehr betonte er den ideologischen Charakter des kommenden Krieges auch für die Frage der europäischen Einigung.

Entsprechend den beiden Verhaltensalternativen boten sich ihm zufolge zwei Gestaltungsalternativen des zukünftigen Europas an: entweder „eine freie Föderation sozialistischer Nationen oder eine unterworfene Militärkolonie des deutschen Faschismus" 185 . Wenngleich der Begriff der freien Föderation sozialistischer Nationen ganz gezielt als Kampfruf gegen den Nationalsozialismus entwickelt und genutzt wurde und Neu Beginnen auf eine intellektuelle Durchdringung des Problems zunächst weitgehend verzichtete, formulierte Richard Löwenthal doch immerhin die wesentlichen Motive einer europäischen Einigung. Neben der ökonomischen und kulturellen $\mathrm{Zu}$ sammenarbeit ${ }^{186}$ werde ein sozialistisches Europa die momentane Tendenz zur Herausbildung internationaler Klassenfronten endgültig überwinden ${ }^{187}$.

181 So aber VoIGT (Hg.), Friedenssicherung 1988, S. 40, erneut S. 203. Das erste Europa-Dokument aus den Reihen der Linkssozialisten stammt - wie schon dargelegt aus der Feder des Revolutionären Sozialisten Alexander SCHIFRIN, Hitler-Deutschland und Europa, in: Sozialistische Revolution, 1. Jg., Nr. 1 (Oktober 1933), S. 24-30. Auch die Beiträge von HilferdING, Das Ende der Völkerbundspolitik, in: ZfS, 2. Jg., H. 20/ 21 (Mai/Juni 1935), S. 625-637, GEYER, Flottenbau und Flottenabkommen, in: NV, Nr. 107 (30.6. 1935), Beilage, S. 1 f. und BIENSTOCK, Kontinentalpolitik oder Weltpolitik?, in: ZfS, 2. Jg., H. 22/23 (Juli/August 1935), S. 697-703 datieren früher als Löwenthals Beitrag.

182 Darin liegt primär die Bedeutung der Überlegungen Löwenthals, die BEHRING, Demokratische Außenpolitik 1999, S. 444, Anm. 7 vernachlässigt, wenn er demgegenüber auf einen SozAk-Artikel aus dem Jahre 1934 verweist. Gleichwohl ist Behring zuzustimmen, daß Löwenthals europapolitische Beiträge auf früher geäußerten Ideen anderer Emigranten basieren und in vielerlei Hinsicht nichts prinzipiell Neues enthalten.

183 SERING [d. i. Löwenthal], Was ist der Volkssozialismus?, in: ZfS, 3. Jg., Nr. 36 (September 1936), S. 1119.

184 Ibid. S. 1136: „Hat er [Strasser] erkannt, daß es im Krieg nur zwei Fronten geben wird - mit Hitler oder gegen Hitler? Es ist an der Zeit, daß wenigstens alle Sozialdemokraten es erkennen."

185 Ibid. S. 1134.

186 Ibid. S. 1118.

187 Ibid. S. 1134. 
Die sozialistische Grundüberzeugung, daß nur ein sozialistisches Europa langfristig den kontinentalen Frieden sichern könne, war Löwenthal zu selbstverständlich, als daß er sie zu verbalisieren gedachte ${ }^{188}$. Wichtiger war ihm die Bildung einer sozialistischen Anti-Hitler-Front, die der Öffentlichkeit aufzeigen müsse, daß allein der Sozialismus als antifaschistische Alternative überzeugen könne. So formulierte er medienwirksam: „Der Weg zum geeinten Europa ist der Weg zum sozialistischen Europa." 189

Das Europabild der meisten Mitglieder von Neu Beginnen beruhte auf der Vorstellung eines umfassenden Sieges des europäischen Sozialismus. Eine Tolerierung oder gar Kooperation mit kapitalistischen Mächten wurde kategorisch abgelehnt. Stattdessen sah Löwenthal in der Idee einer europäischen Föderation eine elementare Forderung des internationalen Sozialismus ${ }^{190}$.

Löwenthals Annäherung an den Europagedanken als antifaschistischen Kampfruf stieß 1936 noch auf keine wesentlichen Hindernisse. Seit 1938 jedoch zeigte die europäische Landkarte ein zunehmend nationalsozialistisches Europa, das im Verlaufe des Zweiten Weltkrieges von der faschistischen Propaganda ausgeschlachtet wurde. Nun war der Europagedanke von den machtpolitisch dominierenden Nationalsozialisten terminologisch besetzt und verlor allein deswegen bei vielen politischen Emigranten an Attraktion und Schlagkraft. Der Europagedanke als Waffe im Kampf gegen Hitler, wie ihn Löwenthal 1936 in den Diskurs einführte, büßte spätestens in den 40er Jahren seine Identität als eo ipso antifaschistischer Widerstand durch Planung ein und mußte von nun an mit dem nationalsozialistischen „Europa aus Rasse und Raum" konkurrieren. Dennoch blieb Löwenthals Ansatz über die Zäsur des Jahres 1938 hinaus für die überwiegende Mehrheit des deutschen politischen Exils von großer Bedeutung.

Paul Hertz: „europäische Planwirtschaft" Zwei weitere Beiträge zum Europadiskurs aus dem Kreis der Gruppe Neu Beginnen wurden in der Sozialistischen Aktion in den Jahren 1934 und 1937 veröffentlicht. Leitlinien einer sozialistischen Außenpolitik wurden in dem 1934 erschienenen Aufsatz "Vom alten zum neuen Europa“ skizziert ${ }^{191}$. Ziel sei die Aufhebung der sozialen und wirtschaftlichen Gegensätze in einem grenzüberschreitenden europäischen Sozialismus. Unbedingte Voraussetzung sei die endgültige

188 Noch im Juni desselben Jahres hatte man sich auf der Westkonferenz der Gruppe Neu Beginnen gegenseitig der sozialistischen Außenpolitik als „einzig wirksame[r] Friedenspolitik ${ }^{*}$ versichert; vgl. [Neu Beginnen], Protokoll Westkonferenz, 14./15.6. 1936, S. 1, IISG, Coll. Neu Beginnen, M. 55.

189 SERING [d. i. Löwenthal], Was ist der Volkssozialismus?, in: ZfS, 3. Jg., Nr. 36 (September 1936), S. 1127.

190 Vgl. etwa ibid. S. 1127.

191 Vom alten zum neuen Europa. Ziele sozialistischer Außenpolitik, in: SozAk (13. 5. 1934), S. 1. 
Niederringung des Kapitalismus, um den Weg für einen „freien, föderativen Bund der sozialistischen Nationen ins Leben zu rufen".

Die Autorenschaft für den 1937 veröffentlichten Artikel „Wo liegen Hitlers nächste Kriegsziele?“ ist zu Recht dem verantwortlichen Redakteur der Sozialistischen Aktion, Paul Hertz, zugeschrieben worden, der das Blatt zunehmend für Stellungnahmen der Gruppe Neu Beginnen öffnete ${ }^{192}$. Hertz, der bis zu seinem Ausschluß Anfang 1938 Parteivorstandsmitglied der Sopade war ${ }^{193}$ und seit 1935 mit Neu Beginnen sympathisiert hatte, forderte ebenfalls „ein freies Deutschland im sozialistischen Europa“194. Dabei wurde der Terminus der europäischen Föderation als zukunftsorientierte Alternative zum Nationalismus alten Stils angedeutet, die als notwendige Vorstufe eines sozialistischen Europas angesehen wurde ${ }^{195}$. Dies hieß jedoch keineswegs eine Kooperation mit kapitalistischen Mächten bis zum endgültigen Sieg des europäischen Sozialismus, wie sie von sozialdemokratischer Seite propagiert wurde. Auch wenn sich der Schluß aufdrängt, die Schaffung einer europäischen Föderation solle der Schaffung der sozialistischen Föderation vorangehen, war hiermit wohl eher ein Gleichlauf der revolutionären Prozesse gemeint: die sozialistische Revolution in möglichst vielen europäischen Staaten würde zugleich die Voraussetzungen einer sich dann nahezu aufdrängenden Föderierung aller sozialistischen Kräfte schaffen. Nur die föderative Zusammenarbeit in einem ,hinreichend großen einheitlichen Wirtschaftsgebiet" könne die Nationalitätenkonflikte etwa in Mittel- und Südosteuropa überwinden und den Sieg des Sozialismus langfristig sichern. Auf diese Weise wäre der Weg frei für eine „europäische Planwirtschaft" ${ }^{196}$. Wie diese europäische Planwirtschaft institutionell zu koordinieren sei, blieb zunächst offen, zumal in der frühen Phase des Europadiskurses Fragen der institutionellen Verankerung überhaupt kaum berührt wurden. Dazu bestand - längst nicht nur bei den Linkssozialisten - noch zuviel Aufklärungsbedarf hinsicht-

192 Für die Autorenschaft von Paul Hertz spricht nicht nur seine die politische Ausrichtung wesentlich prägende Stellung als verantwortlicher Redakteur, sondern auch Duktus und Inhalt des Artikels. Darüber hinaus war Hertz einer der wenigen Autoren der Sozialistischen Aktion, die sich mit europapolitischen Belangen auseinandersetzten. Schließlich handelt es sich bei dem Aufsatz um einen der Leitartikel, die regelmäßig anonym erschienen und zu grundsätzlichen Fragen Stellung bezogen. Für einige dieser Leitartikel kann Hertz mit hoher Wahrscheinlichkeit als Verfasser angesehen werden, so daß nicht ausgeschlossen werden kann, daß er in aller Regel den Leitartikel verfaßte; vgl. z. B. den Hinweis auf den "sicher von Hertz verfaßten Leitartikel" "Jahr IV - die Probe aufs Exempel“ bei LangKau-Alex, Paul Hertz im Exil 90, S. 145.

193 Andere Quellen berichten von einem freiwilligen Ausscheiden. Zur Problematik um die Verkleinerung des Exilparteivorstandes der Sopade von fünf auf vier besoldete Mitglieder und möglichen Ausschluß Paul Hertz' vgl. BuchHOlz, ROTHER (Bearb.), Parteivorstand 1995, S. XXIV, Anm. 72 m.w.N.

194 [HERTZ?], Wo liegen Hitlers nächste Kriegsziele?, in: SozAk (April 1937), S. 1.

195 Ibid.

196 Ibid. 
lich der grundlegenden Motive einer europäischen Einigung und der grundsätzlichen außenpolitischen Leitlinien.

Nur eines war für Neu Beginnen schon früh klar: die unbedingte Ablehnung des Völkerbundes und jeglichen Versuchs, ihn zu reanimieren. So erklärte man im Juni 1936 kategorisch: „[Die Haltung der Arbeiterpartei] verwirft den Pazifismus, die Verherrlichung der Verträge und des Völkerbundes, die die Arbeiterparteien in verschiedener Weise an bürgerlich ideologischen $\mathrm{Maßstäben} \mathrm{orientieren} \mathrm{und} \mathrm{sie} \mathrm{damit} \mathrm{zum} \mathrm{Spielball} \mathrm{imperialistischer} \mathrm{Interes-}$ sen machen." 197 Mit dieser orthodox marxistischen Grundhaltung wandte sich Neu Beginnen zugleich gegen eine Überbewertung des Völkerrechts, das in einem sozialistischen Europa mangels nationaler Konflikte ohnehin überflüssig wäre.

Mit wenigen, aber recht wirkungsvollen Beiträgen bereicherte die Gruppe Neu Beginnen den frühen Europadiskurs des deutschen Exils vor 1938. Gerade vor dem Hintergrund des Selbstverständnisses als Brückenbauer zwischen der KPD und der Sopade ist das Europabild dieser linkssozialistischen Organisation von besonderem Interesse. Löwenthals Entdeckung des aktiven Widerstandspotentials der europäischen Idee spielt für die Funktion des Europadiskurses eine entscheidende Rolle, auch wenn er diese Entdeckung mit anderen teilte. Auch der von Hertz favorisierten Verknüpfung von Sozialismus und Föderalismus auf europäischer Ebene kommt insofern eine strukturelle Bedeutung zu.

\subsection{Internationaler Sozialistischer Kampfbund (ISK)}

Der 1925 gegründete Internationale Sozialistische Kampfbund (ISK) war stark durch die neukantianische Ethik und Friedenslehre ihres Gründers Leonard Nelson geprägt ${ }^{198}$. Der Göttinger Universitätsprofessor hatte in seinen Vorlesungen schon 1914 die Idee der staatlichen Souveränität scharf abgelehnt, da allein dem Recht Souveränität zukomme. Daraus zog der Rechtsphilosoph die für die internationale Ausrichtung des ISK grundlegende Konsequenz, daß das völkerrechtliche Vertragssystem zu einem Staatenbund mit einer internationalen Regierung und einer starken Exekutivgewalt weiterentwickelt werden müsse. Das Regelungswerk eines solchen Staatenbundes müsse unmittelbar auf einem positiven Rechtsgesetz basieren ${ }^{199}$.

197 [Neu Beginnen], Protokoll Westkonferenz, 14./15. 6. 1936, S. 2, IISG, Coll. Neu Beginnen, M. 55.

198 Zur Rechtsphilosophie Leonard NELSONS vgl. insbesondere seine Schriften: Vom Staatenbund. Schlußvorlesung, gehalten am 31.7. 1914, Berlin 1918 und DERS., Die Rechtswissenschaft ohne Recht. Kritische Betrachtungen über die Grundlagen des Staats- und Völkerrechts, insbesondere über die Lehre der Souveränität, Leipzig 1917. 199 Eine vorzügliche Darstellung der politischen Philosophie Nelsons findet sich bei LINK, ISK 1964, S. 3-38. 
Aufbauend auf Nelsons logisch-idealistischer Rechtslehre und seinem nichtmarxistischen Sozialismus arbeitete der ISK auch in der Emigration an der Verwirklichung eines antikapitalistischen Weltbildes. Doch nimmt die Gruppe innerhalb der linkssozialistischen Emigration eine ideologische Sonderposition ein.

Zunächst zeichnet die Grundhaltung des ISK eine dezidierte Ablehnung des historischen Materialismus aus, „der den Sozialismus als das Ergebnis des bloßen Waltens der ökonomischen Verhältnisse [...] hinstellt “200. In ökonomischer Hinsicht propagierte der ISK das Modell einer „sozialistischen Marktwirtschaft ${ }^{\star}$, die das Privateigentum nur insoweit aufhebe, als dadurch die konkrete Gefahr kapitalistischer Ausbeutung drohe, im übrigen aber „die private Initiative und der Wettbewerb, also auch der Markt, erhalten“" bleibe ${ }^{201}$. Diese Position wurde zugleich als Kontrapunkt gegen den marxistischen Kollektivismus verstanden, der „das Recht auf Freiheit, sein Leben innerhalb der Grenzen der Gerechtigkeit selber zu gestalten“, ausschließe202.

Die für den Europadiskurs des Exils wichtigste ideologische Eigenheit des ISK ist jedoch in der herausgehobenen Bedeutung des Verhältnisses von Recht und Sozialismus zu sehen: „Die Regierung dient keiner Willkür - weder der eines Monarchen oder einer anderen Minderheit, noch einer Mehrheit. Sie leitet vielmehr ihre Befugnisse allein aus den Anforderungen des Rechts ab, die mit objektiver Strenge durch die Wissenschaft des Sozialismus begründet werden. "203 Dabei verweigerte der ISK in enger Anlehnung an Nelson nicht nur der Staatssouveränität, sondern auch dem Konzept der Volkssouveränität die Zustimmung und lehnte die Demokratie sowohl auf nationaler als auch auf internationaler Ebene unmißverständlich ab. Somit stimmte er im Ergebnis mit typisch linkssozialistischen Positionen überein und postulierte den revolutionären Sozialismus ${ }^{204}$ : „Die Friedenssicherung ist nur möglich als sozialistische Lösung. "205 Doch ist nicht zu übersehen, $\mathrm{da}$ ß Nelsons Souveränitätstheorie der ISK-Version eines sozialistischen Weltbundes einen vergleichsweise hohen Grad intellektueller Durchdringung verlieh, so daß der ISK insoweit ungeachtet der erschwerten Arbeitsbedingungen im Exil frühzeitig mit konkreten Teilergebnissen ausführlicher Diskussionen aufwarten konnte 206 .

200 Die Sozialistische Republik 1937, S. 12.

201 Ibid. S. $26 \mathrm{f}$.

202 Ibid. S. 26, Anm. 22.

203 Ibid. S. 18.

204 Ibid. S. 15: „Der ISK verwirft [...] alle Ideologien über ein friedliches Hineinwachsen der Klassengesellschaft in eine klassenlose Organisation; er ist eine revolutionäre Partei.“ Dementsprechend wurde die „radikale Säuberung der Beamtenschaft von allen politischen Gegnern der Sozialistischen Republik“ gefordert (ibid. S. 18).

205 Protokoll der Aussprache über "Grundlagen der Politik“ vom 21.9. 1935, S. 2, AsD, Bestand IJB/ISK, Box 8.

206 Dies gilt jedenfalls für die Erörterung einer Völkerbundarmee auf der ISK-Tagung vom 2. 4. 1934 und die Ablehnung eines Staatenbundes unter Beteiligung kapitalisti- 
In dem Bemühen, gemäß Nelsons „Führer-Erziehung“207 eine möglichst internationale Phalanx sozialistischer Kader aufzubauen, unterhielt der ISK auch während der Emigration aktive Verbindungen zu anderen Exilgruppen, etwa zur südfranzösischen Résistance-Gruppe Libérer et Fédérer oder zum italienischen Movimento Federalista Europeo ${ }^{208}$. In Großbritannien übernahm die Socialist Vanguard Group die Rolle einer englischen ISK-Sektion.

Unumstrittene Schlüsselfigur des ISK war der ehemalige Privatsekretär Leonard Nelsons, Willi Eichler. Eichlers Engagement in der europapolitischen Planung fand eine wichtige Stütze in den Beiträgen Hilda Montes, die zwar 1939 aus dem ISK ausgetreten war, ihm aber gerade in den Anschauungen zur internationalen Politik bis zu ihrem tragischen Tod im Frühjahr 1945 nahestand. Zusammen mit Hanna Bartholet nahm Monte im Mai 1944 auf dem von Willem Visser't Hooft organisierten Genfer Föderalistentreffen teil. In der Londoner Zeit des Exils sollte vor allem Walter Fliess einen wichtigen Part der wirtschaftsprogrammatischen Überlegungen übernehmen.

Auf die außenpolitischen Visionen des ISK in der Vorkriegsemigration verweisen neben einigen Veröffentlichungen Eichlers zwei unveröffentlichte Besprechungsprotokolle sowie das Programm von 1937. Allerdings sucht man dort vergebens nach speziell europäischen Konzepten. Dem ISK schwebte zu diesem Zeitpunkt weniger ein europäischer Staatenbund als $\mathrm{Zu}$ kunftsmodell vor, als eher ein sozialistischer Weltbund ${ }^{209}$. Auch das detaillierte Programm von 1937, das den politischen und ökonomischen Aufbau der angestrebten Sozialistischen Republik ebenso vorzeichnet wie die künftige Gestaltung der Sozial-, Bildungs- und Kulturpolitik, enthält keinerlei Hinweis auf einen europaföderalistischen Ansatz ${ }^{210}$. Selbst das Wort „Europa“ oder „europäisch“ ist dort nicht zu finden. Doch ist es für das Verständnis des europäischen Föderationsmodells, dem sich Willi Eichler seit 1938 ausführlicher widmete ${ }^{211}$, unerläßlich, die außenpolitischen Zielkom-

scher Staaten nach einer Besprechung am 21. 9. 1935; vgl. dazu die beiden Protokolle, AsD, Bestand IJB/ISK, Box 8.

207 NELSON, Erziehung zum Führer. Vortrag, gehalten im Zentralinstitut für Erziehung und Unterricht in Berlin am 14. 4. 1920, Leipzig 1920; DERS., Führer-Erziehung als Weg zur Vernunft-Politik. Rede, gehalten auf Einladung des Freybundes in Berlin am 7. 11. 1921, Leipzig 1922.

208 Vgl. VOIGT (Hg.), Friedenssicherung 1988, S. 38.

209 Dieser Umstand kann nicht deutlich genug hervorgehoben werden. Insoweit etwas undifferenziert BEHRING, Demokratische Außenpolitik 1999, S. $423 \mathrm{ff}$.

210 Dagegen erweckt VOIGT (Hg.), Friedenssicherung 1988, S. 38 den Anschein, als sei die von Nelson favorisierte Staatenorganisation eine europäische Föderation, auf deren Konzept das ISK-Programm von 1937 zurückgreife. Tatsächlich finden sich weder bei Nelson noch in den ISK-Quellen der Vorkriegsemigration Anhaltspunkte für eine Reduzierung des völkerrechtlichen Ansatzes auf den europäischen Kontinent. Dies widerspräche auch dem Selbstverständnis des ISK als Teil der weltrevolutionierenden sozialistischen Bewegung.

211 Vgl. dazu Eichlers instruktiven Brief an W. Dierksen [d. i. Auerbach] vom 3. 4. 
ponenten des ISK zu erörtern, wie sie in den ersten Jahren des Exils formuliert wurden.

Sozialistische Föderation mit Völkerbundarmee Das ISK-Programm "Die Sozialistische Republik“ aus dem Jahre 1937 propagierte die Übertragung der innenpolitischen Grundsätze, insbesondere der Symbiose von Recht und Sozialismus, auf die internationale Ebene ${ }^{212}$ und erklärte erneut das Prinzip der Staatssouveränität für unvereinbar mit dem Gedanken des Völkerrechts. Dementsprechend wurde schon 1934 bei einer internen Aussprache eine weitgehende Einschränkung der staatlichen Souveränität und die Unterordnung unter eine internationale Regierung bei Verzicht auf nationale Streitkräfte gefordert ${ }^{213}$.

Aus der übergeordneten Bedeutung des Rechts als internationalem Ordnungsprinzip resultierte für den ISK notwendig die Institutionalisierung des Völkerrechts durch einen sozialistischen Staatenbund. Man zeigte sich überzeugt, daß nur ein solcher Staatenbund den Anforderungen „der Gerechtigkeit im Völkerleben entspricht “214. Damit übernahm der ISK Nelsons Definition des Staatenbundes, die dieser schon 1914 formuliert hatte: „Der Staatenbund ist [...] eine Gemeinschaft von Staaten zum Zweck der Rechtlichkeit ihres Verkehrs. “ ${ }^{215} \mathrm{Da}$ man sich einig war, daß ein freiwilliger Souveränitätsverzicht der imperialistischen Staaten „zunächst nicht wahrscheinlich“ sei, bedurfte es einer explizit „sozialistische[n] Völkerbundspolitik“216, deren Hauptaufgabe in der schrittweise zu vollziehenden Vorbereitung dieses Staatenbundes durch internationale Abkommen bestehe ${ }^{217}$. An diesem Punkt unterscheidet sich der internationale Politikansatz des ISK wesentlich von der Konzeption der SAP. Während die SAP jede organisatorische Anlehnung an den kapitalistisch infiltrierten Völkerbund kategorisch ablehnte, hielt der Kreis um Willi Eichler den bestehenden Völkerbund für die geeignete Basis eines sozialistischen Weltbundes ${ }^{218}$, wenngleich der Völkerbund „so wenig

1938, AsD, Bestand IJB/ISK, Box 35 sowie HART [d. i. Eichler], Furor teutonicus, in: SW, 13. Jg., H. 11 (18. 3. 1938), S. 241-246.

212 Die Sozialistische Republik 1937, S. 23.

213 Gérard, Protokoll der Aussprache vom 2. April 1934 abends. Thema: Internationale Polizei, S. 1, AsD, Bestand IJB/ISK, Box 8.

214 Die Sozialistische Republik 1937, S. 24.

215 Nelson, Vom Staatenbund 1918, S. 4.

216 Gérard, Protokoll der Aussprache vom 2. April 1934 abends. Thema: Internationale Polizei, S. 2, AsD, Bestand IJB/ISK, Box 8.

217 Man dachte dabei zum Beispiel an die „Internationalisierung der Luftfahrt, das Verbot des chemischen und des bakteriologischen Krieges, die Freiheit der Meere, eine internationale Regelung des Arbeiterschutzes“; Die Sozialistische Republik 1937, S. 24. 218 Gérard, Protokoll der Aussprache vom 2. April 1934 abends. Thema: Internationale Polizei, S. 3, AsD, Bestand IJB/ISK, Box 8: „Man kann der sozialistischen Außenpolitik ein Ziel vorzeichnen und man kann zeigen, daß auch bei der heutigen Situation eine wirksame Völkerbundsaktion möglich ist [Hervorhebung im Original, B. S.].“ 
wie irgend eine andere Einrichtung fehlerfrei“"219 sei. Darüber hinaus war die orthodox marxistische Motivation der SAP für den ISK völlig indiskutabel, wenngleich man anfangs in dem formalen Ziel eines sozialistischen Weltbundes unter Auslassung einer selbständigen europäischen Ebene übereinstimmte. Parallelen zeigen sich jedoch zu Eugen Brehms föderalistischem Ansatz, auf den sich Eichler mitunter ausdrücklich bezog 220 .

Dem anzustrebenden Völkerbund, dem in einer deutlich modifizierten und sozialistisch definierten Form die Verbindung des völkerrechtlichen $\mathrm{Ge}$ rechtigkeitsmaßstabs mit dem internationalen Sozialismus vorbehalten sein sollte, wurden im wesentlichen drei Aufgaben zugedacht: Aufbau einer verbindlichen Rechtsordnung für den internationalen Verkehr, effektive Sicherung des Friedens und Aufbau eines sozialistischen Wirtschaftsraumes. Man dachte sich das künftige Europa als sozialistische Einheit unter einer kollegial besetzten, nach elitären Prinzipien auserwählten Regierungsmannschaft und einer internationalen Gerichtsbarkeit ${ }^{221}$. Das Ideal eines sozialistischen (Markt)Wirtschaftsraumes sah die Förderung des internationalen Wettbewerbs vor, indem „unter Bevorzugung der sozialistischen Staaten“ das europäische Schutzzollsystem nivelliert würde ${ }^{222}$. In der Senkung der Außenzölle sah der ISK eine "wichtige Waffe“ der Sozialistischen Republik, um europäischen Produkten den Zugang zu anderen Märkten zu verschaffen ${ }^{223}$. Der Bund war primär als "enges Militär- und Wirtschaftsbündnis" 224 geplant, dem durch eine Erziehung zur „Achtung der Rechte und der Kultur anderer Völker und Rassen“ und durch "Förderung einer internationalen Hilfssprache, Esperanto" 225 , ein internationales Bewußtsein zugrunde gelegt werden sollte.

Das wichtigste Anliegen des ISK war in den frühen Exiljahren die Entwicklung einer starken Exekutive des Staatenbundes ${ }^{226}$, um der internationalen Rechtsordnung zur Durchsetzung zu verhelfen und Friedensstörer zur Rechenschaft zu ziehen, „statt ihnen bloß Wünsche zu überbringen“227. Als

219 HART [d. i. Eichler], Kollektive Sicherheit, in: SW, 12. Jg. (24. 12. 1937), S. 697.

220 Vgl. die Erörterung der Problematik Südosteuropas in Eichlers Brief an Dierksen [d. i. Auerbach] vom 3. 4. 1938, AsD, Bestand IJB/ISK, Box 35. Der dort genannte Name Max Herb war ein Pseudonym des Pazifisten und SAP-Mitglieds Eugen Brehm. $\mathrm{Zu}$ den Übereinstimmungen zwischen Eichler und Brehm siehe das Kapitel „Europa im Exil“, Punkt 2.

221 Die Sozialistische Republik 1937, S. 23.

222 Ibid. S. 30.

223 Ibid. Anm. 28.

224 Ibid. S. 24.

225 Ibid.

226 Inwiefern die Völkerbundarmee ein von der Frage einer starken Exekutive separates "anderes Problem“ darstellen soll, wie BEHRING, Demokratische Außenpolitik 1999, S. 424, meint, bleibt unklar. Insbesondere handelt es sich bei der vom ISK anvisierten internationalen Polizei gerade um einen klassischen Teil der Exekutive.

227 HART [d. i. Eichler], Krieg dem Kriege und der Staaten-Anarchie, in: SW, 9. Jg. (August 1934), S. 97. 
geeignetes Instrument wurde auf einem Themenabend im April 1934 eine „internationale Polizei oder Völkerbundarmee - das heißt eine Armee im Dienste des Völkerbundes"228 angesehen. Ohne näher zwischen den allgemeinen Funktionen von Polizei und Armee zu unterscheiden, hielt das Besprechungsprotokoll fest, daß der Völkerbund zur Sicherung des internationalen Rechts unbedingt eines Machtinstruments bedürfe, „ohne das er auf jeden Fall eine lächerliche Einrichtung ist" ${ }^{229}$. Voraussetzung der Schaffung einer solchen Völkerbundarmee sei die Abrüstung der Nationalarmeen auf die niedrigste Friedenspräsenzstärke. Die Völkerbundarmee selbst sollte nicht aus nationalen Truppenkontingenten bestehen, sondern eine wahrhaft internationale Armee sein, die entsprechend ihrem umfassenden Auftrag über weltweit verstreute Standorte verfügen müsse. Gleichzeitig wurde eine Verpflichtung des Soldaten, gegen sein eigenes Land zu kämpfen, einhellig abgelehnt. Offen blieb in der Diskussion der Verteilungsschlüssel für die von den Mitgliedstaaten zu entsendenden Truppenteile ${ }^{230}$. Einig waren sich die Anwesenden jedoch darüber, daß die militärische Leitung der Völkerbundarmee in die Hand „zuverlässige[r] Pazifisten und gleichzeitig fähige[r] Generäle" gelegt werden sollte ${ }^{231}$, während die politische Leitung in Übereinstimmung mit dem autoritären Führungsverständnis des ISK einem von den Regierungen unabhängigen Komitee mit „rechtlich bekannten hervorragendsten Menschen aller Nationen" zu übertragen sei232. In einem gewissen Widerspruch zu dem dezidiert internationalen Ansatz der geplanten Völkerbundarmee stand die mehrheitlich unterstützte Auffassung, daß jeder Völkerbundsoldat in einem solchen Land zu stationieren sei, „mit dessen Bevölkerung sich sein Volk nicht sehr freundschaftlich steht" ${ }^{233}$. Damit konterkarierte der ISK seine vehemente Ablehnung nationaler Orientierungsmaßstäbe mit einem zutiefst nationalstaatlich verwurzelten Denken, auch wenn der Gedanke der Nation dabei mit einem negativen Vorzeichen versehen wurde.

Wurde auf der internen Besprechung vom April 1934 der Gedanke einer starken Völkerbundarmee recht detailliert diskutiert und auf einen politischen Konsens gebracht, nimmt sich der Ruf des offiziellen ISK-Programms von 1937 nach der „endgültige[n] Abschaffung aller einzelstaatlichen Heere, an deren Stelle eine internationale Gerichtsbarkeit und Polizeitruppe treten soll“234, eher lapidar aus, was teilweise mit der notwendig zugespitzten

228 Gérard, Protokoll der Aussprache vom 2. April 1934 abends. Thema: Internationale Polizei, S. 1, AsD, Bestand IJB/ISK, Box 8.

229 Ibid.

230 Auf den Vorschlag, dem Verteilungsschlüssel die Bevölkerungsstärke der Mitgliedstaaten zugrunde zu legen, konnten sich die Teilnehmer nicht einigen (ibid.).

231 Ibid. S. 2.

232 Ibid.

233 Ibid.

234 Die Sozialistische Republik 1937, S. 23. 
Kürze eines Parteiprogramms zu erklären ist. Dennoch wartete der ISK in den Jahren von 1934 bis 1937 mit einem durchdachten, wissenschaftlich fundierten Konzept eines sozialistischen Weltbundes auf, das sich durch seine antimarxistische, das Völkerrecht hoch haltende Grundlage in wichtigen Bereichen von dem linkssozialistischen Konsens unterschied.

\subsection{Deutsche Volkssozialistische Bewegung (DVB)}

Am 5. Februar 1936 gründeten der ehemalige Kommunist Hans Jaeger, der Sopade-Grenzsekretär Arthur Arzt und der bürgerlich-liberale Journalist Fritz Max Cahén die Deutsche Volkssozialistische Bewegung. Schon das politische Spektrum der Gründer zeigt anschaulich die Zielsetzung dieser Partei: die „Sprengung der Scheidewände zwischen rechts und links“ zugunsten einer „Dritten Front" ${ }^{235}$. Durch die Wiederbelebung nationaler Traditionen ${ }^{236}$ sollte die Arbeiterbewegung gegen künftige nationalistische Verlokkungen des Faschismus gewappnet werden, um so einen erneuten Einbruch des Nationalsozialismus in die Arbeiterschaft zu verhindern. Als linkes Pendant der von Otto Strasser geführten Schwarzen Front wurde die Aufgabe der Volkssozialisten darin gesehen, von der sozialistischen Seite der politischen Parteienlandschaft die Synthese aus nichtmarxistischem Sozialismus und nationalrevolutionärer Bewegung vorzubereiten 237 - nach Jaegers Auffassung „die Synthese, auf die Millionen warten“238. Jaeger zufolge ist der Begriff „Volkssozialismus“ zwar von ihm selbst geprägt, der Öffentlichkeit jedoch erstmals von dem ebenfalls volkssozialistisch inspirierten Sozialdemokraten Wenzel Jaksch vorgestellt worden, der von seinem Freund Otto Strasser in Kenntnis gesetzt worden war ${ }^{239}$. Nicht zufällig bestanden anfänglich enge Kontakte zu Strassers Schwarzer Front, mit der die Volkssozialisten am 10. Januar 1937 ein gemeinsames Manifest der „Deutschen Front gegen

235 Jaeger, Weder links noch rechts, sondern Neue Front!, 17. 11. 1938, S. 8. Es handelt sich hierbei um ein unveröffentlichtes achtseitiges Typoskript eines Beitrages für die von Münzenberg herausgegebene Zeitschrift Die Zukunft. Jaeger schickte den Entwurf mit Datum vom 17.11. 1938 an den Chefredakteur der Zukunft, Werner Thormann. In seinem Begleitschreiben gab Jaeger in Hinblick auf die gemeinsame antinazistische Grundhaltung der DVB und des Kreises um die Zukunft seiner Hoffnung auf eine Veröffentlichung Ausdruck und argumentierte: „Es liegt ja sicher in der Absicht keiner Bewegung oder Gruppe, um sich Chinesische Mauern zu errichten." Typoskript und Begleitbrief finden sich in dem bislang kaum beachteten Redaktionsarchiv der Zukunft in den Archives nationales, $\mathrm{F}^{7} 15123, \mathrm{M}$. I/J.

236 Vgl. RöDER, Sozialistische Exilgruppen ${ }^{2} 1973$, S. 63.

${ }^{237}$ Jaeger, Weder links noch rechts, sondern Neue Front!, 17. 11. 1938, S. 8, ANF, F7 15123, M. I/J: „Diese Dritte Front ist überall im Werden. Für die deutsche Opposition wird sie sichtbar von rechts durch die Schwarze Front, von links durch die Volkssozialisten, die auf nationaler, volksmäßiger und sozialistischer Basis zueinander fanden." 238 Ibid.

239 Vgl. den Verweis auf eine Mitteilung Jaegers vom 30. 3. 1965 bei RöDER, Sozialistische Exilgruppen 21973, S. 64, Anm. 157. 
den Hitlerismus" verabschiedeten ${ }^{240}$. Doch sollte diese Kooperation noch 1937 an internen Überwerfungen und Jaegers dezidiertem Antinationalismus zerbrechen ${ }^{241}$. Nachdem Arzt sich in Großbritannien der Gruppe um Karl Höltermann angeschlossen und Cahén in den USA den Anschluß an die Bewegung verloren hatte, fand Jaeger seit Ende 1939 vor allem in der aktiven Mitarbeit des Pazifisten und SAP-Gründungsmitgliedes Eugen Brehm wertvolle Unterstützung. Verbindungen bestanden auch zu Wilhelm Sollmann in den USA, der innerhalb der Exil-SPD für den volkssozialistischen Gedanken warb und bisweilen in Strassers Organ Die Deutsche Revolution. Europäische Blätter der Dritten Front publizierte ${ }^{242}$.

Auch Karl Otto Paetel verfolgte mit den von ihm selbst herausgegebenen Blättern der Sozialistischen Nation einen volkssozialistischen Ansatz mit dem Ziel einer „Front Deutscher Sozialisten, unbeschadet [...] des differierenden organisatorischen Ursprungs von, rechts" oder, links “"243. Paetel sah sich durch die Annexion Österreichs einer "großdeutsch-faschistischen Realität von heute“ ausgesetzt, der die „Parole des großdeutschen Sozialismus von morgen“ entgegenzustellen sei. Der Anschluß selbst sei ein „absolut progressiver, notwendiger und selbstverständlicher Schritt", der nur dadurch diskreditiert werde, daß er zugleich dem Faschismus eine Frieden gefährdende Erweiterung seiner Machtbasis beschere ${ }^{244}$. Langfristig war Paetels Gruppe Sozialistische Nation jedoch kaum Resonanz gegönnt, während die Volkssozialistische Bewegung recht öffentlichkeitswirksam vorging und mit einigen programmatisch aufschlußreichen Dokumenten aufwartete.

Sozialismus und Abendland Eines der bedeutendsten Dokumente der DVB ist ein Referat zur Frage der europäischen Föderation, das Fritz Max Cahén auf der ordentlichen Sitzung der Volkssozialistischen Bewegung am 19. Juni 1936 vortrug ${ }^{245}$. Darin skizzierte Cahén „das deutsche Zukunftsideal des

240 Vgl. die knappe Darstellung zur anfänglichen Kooperation zwischen Volkssozialisten und Schwarzer Front bei RöDER, Sozialistische Exilgruppen 21973, S. 63-70, hier S. 66 .

${ }^{241}$ Die anfänglich bewußt angestrebte Zusammenarbeit mit dem linken Nationalsozialisten Strasser setzte Jaeger der Kritik anderer Emigranten aus und veranlaßte ihn zu einem ausführlichen Verteidigungsschreiben: Jaeger, Unser Gegensatz zu Otto Strasser, o. D., IfZ, NL Jaeger, ED 210/12.

242 Vgl. z.B. den programmatischen Artikel von SOLLMaNN, Einigung in Etappen, in: Die Deutsche Revolution, Nr. 13 (15. 7. 1937), S. 34-37.

243 Unser Weg, in: Blätter der Sozialistischen Nation, Nr. XV/XVI (Sommer 1939), S. 1-2(1).

244 Großdeutscher Sozialismus, in: Blätter der Sozialistischen Nation, Nr. IX/XII (Spätsommer 1938), S. 2.

245 Cahén, Europäische Föderation. Referat, gehalten am 19.6.1936 in der Sitzung der Volkssozialistischen Bewegung Deutschlands, IfZ, NL Jaeger, ED 210/9. Diese aufschlußreiche Quelle ist $\mathrm{m}$. W. bis dato unbeachtet geblieben, obwohl sie wegen ihrer Ausführlichkeit und in Anbetracht des frühen Zeitpunktes ihrer Entstehung (1936!) erhöhte wissenschaftliche Aufmerksamkeit verdient. Selbst RöDER, Sozialistische Exil- 
Volkssozialismus“, das außenpolitisch dem Nahziel Mitteleuropa und dem Fernziel der „wirtschaftliche[n] Blüte der Europäischen Föderation"246 gewidmet sei. „Im Einverständnis mit den übrigen interessierten Mächten“ sei es die Aufgabe Deutschlands, die konstruktive Idee Mitteleuropa aufzugreifen und zu einem freiwilligen Wirtschaftsverband zu organisieren ${ }^{247}$. Dieser mitteleuropäische Wirtschaftsverband werde dann als Vorstufe zu einer europäischen Großraumpolitik und Großraumwirtschaft fungieren ${ }^{248}$.

Die Aufgaben einer Europäischen Föderation sah Cahén primär in einer Rückbesinnung und Stärkung der abendländischen Kultur in Verbindung mit der Errichtung eines sozialistischen Wirtschaftssystems. Ausgehend von der an Oswald Spenglers "Untergang des Abendlandes" erinnernde These von der Degeneration der Rassen, die "heute im Wesentlichen in ihrer Reinheit nicht mehr vorhanden" seien ${ }^{249}$, schlußfolgerte Cahén, daß Völker und Nationen nunmehr Gegebenheiten seien, „mit denen der Politiker zu rechnen hat" ${ }^{250}$. In offener Ablehnung des nationalsozialistischen Rassenwahns stellte er zugleich klar: „Europa kann nicht an dem Wesen dieser oder jener Lang- oder Kurzschädelrasse genesen, es kann nur genesen, wenn es den Weg zu sich selbst findet, wenn es die Einheitlichkeit des Abendlandes schafft. " 251 Mit dem Stichwort der Einheitlichkeit des Abendlandes schuf Cahén die typisch volkssozialistische Verknüpfung sozialistischer und konservativer Elemente. Der Journalist, der 1932 einige Bürgerlich-Liberale zur Bildung einer antinationalsozialistischen Gruppe zusammengerufen hatte, betonte, daß der europäische Großraum nicht nur eo ipso eine kulturelle Einheit sei, sondern „die Geburtsstätte der gesamten modernen Kultur"252. Hierin sah er eine besondere Verpflichtung des Sozialismus, „dem Abendland durch die Organisierung des Europabundes die wirtschaftliche Blüte und damit seine alte kulturelle Führerstellung" $\mathrm{zu}$ sichern ${ }^{253}$.

Cahén ließ keinen Zweifel an der geographischen Zugehörigkeit Großbritanniens und Rußlands zum europäischen Kontinent, differenzierte aber hinsichtlich der Frage der politischen Zugehörigkeit, die er im Ergebnis unbeantwortet ließ. Beide Staaten seien Vorposten anderer Großräume, Großbritannien für das Commonwealth und die Sowjetunion für den asiatischen Großraum. Anders als Großbritannien sei die Sowjetunion kulturell nicht Europa zuzurechnen. Doch sei auch Großbritannien auf Grund seiner globalen Ausrichtung „schon fast europafern“, zumal es in Ottawa 1932 offen

gruppen 21973, der sich eingehender mit den Volkssozialisten beschäftigt, läßt dieses Dokument unerwähnt.

246 Ibid. S. 7.

247 Ibid. S. 3 f.

248 Ibid. S. 4.

249 Ibid. S. 1.

250 Ibid.

251 Ibid. S. 5 f.

252 Ibid. S. 2.

253 Ibid. S. 6. 
für das Weltreich „und damit in großem Umfang gegen Europa optiert" habe ${ }^{254}$. Dennoch wandte sich das Gründungsmitglied der Volkssozialistischen Bewegung gegen eine antirussische oder antibritische Tendenz des künftigen Staatenbundes und begründete dies in der nachfolgenden Diskussion mit dem Hinweis, daß alle Möglichkeiten offengehalten werden müßten. Man könne nicht so weit gehen, die beiden Länder auszuschließen ${ }^{255}$.

Aus seiner zentralen Position folgte für Cahén eine dreifache Vermittlungsaufgabe Mitteleuropas. Politisch gelte es, das Gleichgewicht zwischen „östlichen Formen der Diktatur und den westlichen Formen der Demokratie" zu finden und zu halten. In wirtschaftlicher Hinsicht stehe vor allem der Ausbau der europäischen Infrastruktur in Vorbereitung auf eine europäische Großraumwirtschaft an. Und schließlich komme Mitteleuropa die soziale Funktion zu, Europa zu neuen Gesellschaftsformen zu verhelfen: „Denn das Hirn der deutschen sozialistischen Wirtschaftsplanung ist berufen, ein zentraler Brennpunkt der europäischen Wirtschaftsplanung überhaupt zu werden. Die Umgestaltung des balkanisierten Europas zu einem einheitlichen Wirtschaftsorganismus kann nicht an der Peripherie einsetzen, sie muß vom Kern her erfolgen. "256 Für die Volkssozialisten sollte der europäische Großraum in konzentrischen Kreisen erschlossen werden - beginnend in der Mitte, das heißt in Deutschland, bis hin zu den Außensphären, die durch Großbritannien und die Sowjetunion gebildet würden. Die auf diese Weise wachsende Europäische Föderation bedürfe des Leitbildes des "guten Europäers", das den überholten marxistischen Internationalismus ablösen und das Bekenntnis „zu Volk und Nation“ sinnvoll ergänzen müsse ${ }^{257}$.

Das wirtschaftliche Ziel des europäischen Sozialismus sah Cahén darüber hinaus in einer engen Verbindung des europäischen mit dem russischen Markt sowie einer „Verquickung zwischen der gesamteuropäischen und der russischen Planung" ${ }^{258}$. Zugleich werde eine europäische Planungskommission für die Beseitigung der Zollmauern und den gerechten Ausgleich zwischen den verschiedenen Wirtschaftsformen Europas sorgen. Damit setzte Cahén gerade kein einheitliches Wirtschaftssystem voraus, so daß für ihn eine Föderation der europäischen Staaten auch mit kapitalistischen Mächten denkbar war. An diesem Punkt setzte in der anschließenden Diskussion die Kritik ein, nur sozialistische Staaten könnten miteinander föderieren ${ }^{259}$. Da-

254 Ibid. S. 2.

255 Protokoll der Versammlung der Volkssozialisten am 19. 6. 1936, IfZ, NL Jaeger, ED 210/9. Cahén hatte sich in seinem Vortrag offen gegen die Konzeption CoudenhoveKalergis ausgesprochen (vgl. S. 5 des Referates), der eine Beteiligung der Sowjetunion ebenso wie Großbritanniens vehement ablehnte.

256 Cahén, Europäische Föderation, 19. 6. 1936, S. 3, IfZ, NL Jaeger, ED 210/9.

257 Ibid. S. 2.

258 Ibid. S. 7.

259 Vgl. Protokoll der Versammlung der Volkssozialisten am 19. 6. 1936, IfZ, NL Jaeger, ED 210/9. An dieser Stelle wurde auch kritisch hinterfragt, wie eine deutsche Planwirtschaft mit einem nicht planwirtschaftlichen Europa kooperieren könne. 
bei handelte es sich um eine kontinuierliche Streitfrage der sozialistischen Emigration, die in enger ideologischer Verbindung zur Auseinandersetzung zwischen den Anhängern des demokratischen und des revolutionären Sozialismus gesehen werden muß. Mit dem zusammenfassenden Ausruf „Frei Deutschland! heißt unsere Parole nach innen. Die Rettung des Abendlandes! lautet sie nach außen. "260 verschob Cahén im letzten Satz seines Vortrages die Parameter seiner Zukunftsvision zugunsten der Rettung der abendländischen Kultur, während der Sozialismus in diesem Kampfruf mit keiner Silbe mehr berücksichtigt wurde.

Mit Blick auf die relativ breite Streuung volkssozialistischen Gedankengutes innerhalb der deutschen Emigration kommt Cahéns Referat eine besondere Bedeutung zu. Als Gründungsmitglied der Volkssozialistischen Bewegung zeichnete er nicht allein im eigenen Namen, sondern gleichsam für die gesamte Partei eine europäische Zukunftsvision, die angesichts des frühen Entstehungszeitpunktes mit konkreten Details erstaunt und sich nicht mit unverbindlichen Schlagworten begnügt. Kennzeichnend für den volkssozialistischen Ansatz ist die Verknüpfung des Sozialismus mit dem AbendlandGedanken konservativer Kreise, die in der Nation verwurzelt und auf der europäischen Ebene zu einem größeren Ganzen zusammengefügt werden sollten. Cahéns Beitrag setzt sich zudem als eine der wenigen Quellen aus der frühen Emigrationszeit mit der Frage der europäischen Grenzen auseinander und bemüht sich um eine differenzierte Annäherung an den ambivalenten Begriff „Europa“.

\subsection{Pazifisten}

Im Gegensatz zu dem in viele mehr oder weniger einflußreiche Gruppen zersplitterten sozialistischen Exil verfügten die exilierten Pazifisten über keine eigene identitätsstiftende Organisationsstruktur. Ihr politisches Engagement war im wesentlichen bestimmt durch die Eigeninitiative Einzelner, die sich mit Ausnahme der Deutschen Freiheitspartei (DFP) - zumeist außerhalb der Exilorganisationen bewegten. Liberale Aktivisten aus dem organisierten $\mathrm{Pa}$ zifismus der Weimarer Republik wie die beiden international renommierten Völkerrechtler Hans Wehberg und Walther Schücking oder der langjährige Vorsitzende der Deutschen Friedensgesellschaft Ludwig Quidde blieben im Exil ihren pazifistischen Idealen ebenso treu wie der Radikalpazifist Friedrich Wilhelm Foerster und die radikalen Linken Otto Lehmann-Russbueldt, Eugen Brehm, Kurt Hiller, Kurt Grossmann und Max Barth. Dennoch war gerade bei den links orientierten Pazifisten die Tendenz zu Beitritt oder Bildung eigener Aktionszirkel ausgeprägter, zumal diesem politischen Spektrum hinsichtlich der Anzahl sozialistischer Gruppierungen deutlich mehr organisatorische Möglichkeiten offenstanden. So bemühten sich Individuali- 
sten wie Hiller und Grossmann um die Sammlung Gleichgesinnter, konnten aber im Ergebnis nur auf einige Vortragsveranstaltungen verweisen, ohne allzu große Resonanz hervorgerufen zu haben ${ }^{261}$.

Aus der pazifistischen Grundüberzeugung, daß eine wirksame Friedenssicherung entscheidend von internationalen Organisationen und Rechtssetzungen abhänge, hatten Pazifisten nach 1918 entscheidende Impulse zur Reform des Völkerrechts und zur Weiterentwicklung des Völkerbundes gegeben und seit 1920 vehement eine Reform des Völkerbundes diskutiert ${ }^{262}$. Dabei handelte es sich regelmäßig um Mitglieder der Deutschen Friedensgesellschaft ${ }^{263}$, der Deutschen Liga für Menschenrechte und der Deutschen Liga für den Völkerbund. Diese Organisationen beeinflußten wiederum Abgeordnete der DDP, später der Deutschen Staatspartei, und der SPD.

$\mathrm{Zu}$ den Europaorganisationen wie der Paneuropa-Bewegung oder dem Verband für europäische Verständigung hatten die auf einen weltweiten Friedensbund konzentrierten pazifistischen Bewegungen zunächst eine kritische Distanz bewahrt, da sie die Friedenssicherung für regional nicht begrenzbar hielten. Später traten auch in den pazifistischen Diskussionen insbesondere die wirtschaftlichen Vorteile einer europäischen (Kon)Föderation in den Vordergrund, jedoch stets als regionale Ergänzung eines reformierten Völkerbundes ${ }^{264}$.

Die pazifistische Kritik an den Schwächen des bestehenden Völkerbundes richtete sich primär gegen den uneingelösten Anspruch der Universalität, die fehlende souveräne Entscheidungsgewalt und die zahnlose Exekutive. Die Pazifisten vermißten die allgemeine Ächtung des Krieges und bemängelten in Verfahrensfragen den Einstimmigkeitszwang in den Entscheidungsgremien ${ }^{265}$. Stattdessen wurden intensive Überlegungen zu einer Demokratisierung und Föderierung des Völkerbunds angestellt.

Aufgrund dieser Vorleistungen mußte die überschaubare Gruppe der exilierten Pazifisten nicht erst mühsame Grundhaltungen entwickeln. Vielmehr blieben „die neue europäische Ordnung und der Völkerbund - symbolisiert durch Versailles und Genf - [...] die wesentlichen Ausgangspunkte aller

261 Dies schmälert keineswegs den Wert einzelner aus diesen Kreisen entstammender Quellen, sondern stellt lediglich auf die Effizienz des politischen Wirkens solcher Gruppen wie Hillers Freiheitsbund Deutscher Sozialisten oder Grossmanns Komitee für einen gerechten Frieden, ein demokratisches Deutschland und ein föderatives Europa ab.

262 Vgl. z.B. VALENTIN, Geschichte des Völkerbundgedankens in Deutschland 1920; QUIDDE, Völkerbund und Demokratie 21922; Harry Graf KESSLER, Richtlinien für einen wahren Völkerbund 21920; SCHÜCKING, WEHBERG (Hg.), Satzung des Völkerbundes 21924 .

$263 \mathrm{Vgl}$. SCHEER, Friedensgesellschaft 21983.

264 Vgl. ibid., S. 381-385.

265 Vgl. die prägnante Kurzdarstellung bei VOIGT (Hg.), Friedenssicherung 1988, S. 126 . 
Überlegungen zur künftigen Neugestaltung der europäischen Verhältnisse" 266 .

Reformierter Völkerbund Heinrich Ströbel hatte schon 1934 ein europäisches System kollektiver Friedenssicherung gefordert, auf das alle Demokratien hinzuwirken verpflichtet seien ${ }^{267}$, nachdem er unmittelbar nach der Machtübernahme der Nationalsozialisten die von Hitler ausgehende akute Kriegsgefahr in klaren Worten aufgezeigt hatte ${ }^{268}$. In diesem Zusammenhang verwies er auf die seit Gründung des Völkerbundes erhobene Forderung nach einer starken Exekutive, der ein Zwangsmaßnahmenkatalog zur Verfügung stehen müsse, um ihre Entscheidungen wirksam umsetzen zu können.

In den Ruf nach einer Stärkung der Exekutive des Völkerbundes stimmten alle politischen Emigranten ein, die nicht die Abschaffung der gesamten Institution forderten. Insbesondere die auf der internen Besprechung des ISK vom Juni 1934 erörterte Idee einer Völkerbundarmee fand bei Hellmut von Gerlach rege Zustimmung ${ }^{269}$. Gerlach, ein Verfechter der deutsch-französischen Verständigung, hatte schon im September 1934 die Internationalisierung der Luftwaffe angeregt, die durch ein Monopol des Völkerbundes für die Militärluftfahrt gewährleistet werden sollte ${ }^{270}$. Auch Ströbel ${ }^{271}$, Lehmann-Russbueldt und Moritz Julius Bonn ${ }^{272}$ beschäftigten sich mit diesem Thema, das in den ersten Jahren des Exils im Vordergrund vieler Europadiskussionen stand ${ }^{273}$. Der Altvordere der pazifistischen Bewegung, Ludwig Quidde, mahnte eine europäische Konföderation an, „die keine nationalen Armeen mehr kennen soll, sondern alle militärische Macht der Bundesgewalt überträgt“ ${ }^{274}$ und proklamierte im Juni 1936 die sofortige Gründung eines neuen Welt-Völkerbundes ${ }^{275}$. Die frappierend klare Begrüßung einer Völkerbundarmee gerade durch Vertreter eines absoluten Pazifismus fand ihre

266 HOLL, Europa des pazifistischen Exils 1992, S. 273.

267 BÜCHNER [d. i. Ströbel], Die Schicksalsfrage Europas, in: Der Aufbau, 15. Jg., Nr. 16 (20.4. 1934), S. $123 \mathrm{f}$.

268 STRÖBEL, Der Nationalsozialismus als Weltgefahr, in: Der Aufbau, 14. Jg., Nr. 11 (17. 3. 1933), S. $81 \mathrm{ff}$.

269 GERLACH, Völkerbundarmee trotz allem, in: Pariser Tageblatt (1. 3. 1935).

270 Gerlach, Neo-Pazifismus, in: Pariser Tageblatt (9. 9. 1934).

${ }^{271}$ STRÖBEL, Programmatisches, in: Der Aufbau, 14. Jg., Nr. 37 (15. 9. 1933), S. 291 ff.; DERS., Wie ist der Krieg noch zu verhüten?, in: Der Aufbau, 16. Jg., Nr. 17 (26. 4. 1935), S. 131-133; DERS., Die Organisation der Friedenssicherung, in: Der Aufbau, 16. Jg. (31. 5.1935), S. $169 \mathrm{ff}$.

272 BONN, Müssen Sanktionen versagen?, in: Pariser Tageszeitung (28. 6. 1936).

273 Andere europäische Fragestellungen wie zum Beispiel die europäische Minderheitenproblematik sollten erst 1938 in den Mittelpunkt des Interesses rücken, insbesondere durch Grossmann und Brehm.

${ }^{274}$ Quidde, Das andere, wahre Deutschland, o. D., S. 22, BAK, NL Quidde, N 1212, Bd. 82.

${ }^{275}$ Ders., Das Schicksal des Völkerbundes, o. D. [Juni 1936], S. 2, BAK, NL Quidde, N 1212 , Bd. 81. 
Fortsetzung in der Ablehnung der Appeasement-Politik. Zu Recht wird in der Literatur darauf hingewiesen, daß „entschiedene Vertreter eines pazifistischen Absolutismus in der Weimarer Republik [...] sich im Laufe der dreißiger Jahre zu ebenso dezidierten ,Anti-Appeasern' und Befürwortern einer glaubwürdigen defensiven Rüstungspolitik Englands und Frankreichs wandelten“ 276 .

Kurt Hiller: logokratische Internationalisierung Einer der engagiertesten Pazifisten des Exils war Kurt Hiller. Der nichtmarxistische Sozialist stand in Verbindung zu Jaegers Volkssozialisten ebenso wie zum ISK, dessen Gründer Leonard Nelson er verehrte. Nelsons engsten Mitarbeiter und Nachfolger Willi Eichler hätte Hiller gerne als Kandidat einer vereinigten Linken für die Reichspräsidentenwahl 1932 gesehen ${ }^{277}$. Hiller war 1920 der Deutschen Friedensgesellschaft beigetreten und hatte dort eng mit Helene Stöcker zusammengearbeitet. Nach harten Auseinandersetzungen mit Fritz Küster und Friedrich Wilhelm Foerster um die politische Ausrichtung der Deutschen Friedensgesellschaft hatte der kompromißlose Pazifist und Sozialist 1926 die letztlich einflußlose Gruppe revolutionärer Pazifisten ins Leben gerufen, und Ende 1939 sollte er den Freiheitsbund Deutscher Sozialisten (FDS) gründen. Bis dahin aber äußerte er sich vornehmlich als extremer Individualist, ohne sich einer bestimmten politischen Gruppierung zuordnen zu wollen. In engem Kontakt mit Hiller stand der zunächst nach Skandinavien geflüchtete Journalist Max Barth, der wiederum in Briefkontakt mit Ludwig Quidde stand.

Der Nonkonformist Hiller verweigerte sich bewußt jeder Weltanschauung, denn "nur die Idee des Lebens selbst ist wert, das Leben kämpfend für sie einzusetzen“. Seine Aufgabe sah er darin, im Exil die „Flagge der Autonomie des Geistes"278 hochzuhalten und bekannte sich zum Pazifismus als einem Teil seiner „Welt-Wollung“, die er terminologisch scharf von der Weltanschauung zu trennen wußte ${ }^{279}$. Deutschland fehle „die riesige Waage, inmitten alles Volks errichtet, auf der die nationalen Werte gegeneinander abgewogen werden. Sie fehlt, weil, von Afterphilosophen genährt, das herrscht, was Immanuel Kant genannt hat: ,Misologie, das heißt $\mathrm{Haß}$ der Vernunft'. "280 Seine Schlußfolgerung hatte er schon 1921 in seinem Buch „Logo-

276 HOLL, Europa des pazifistischen Exils 1992, S. 276.

277 Vgl. STUHLManN, Hiller im Exil 1998, S. 47.

278 HILlER in einer Einführung zu einem Vortrag der Gruppe Unabhängiger Deutscher Autoren (GUDA), die Hiller 1939 als Gegenpart zu dem kommunistisch dominierten Freien Deutschen Kulturbund gegründet hatte; abgedruckt in: DERS., Leben gegen die Zeit 1969, S. 324.

279 Hiller, Heroismus und Pazifismus. Aus einer Diskussion mit Nationalisten (Berlin, Anfang 1933, vor dem Reichstagsbrand), in: DERS., Ratioaktiv 1966, S. 99-105 (99). 280 Ibid. S. 102. Bezeichnenderweise erschien dieser Beitrag in der letzten Ausgabe der Weltbühne am 7.3. 1933, nur wenige Stunden vor dem Verbot dieser Zeitschrift und dem Beginn der Verfolgung Hillers durch die Nationalsozialisten. 
kratie“ dargelegt und kam nun erneut darauf zurück ${ }^{281}$. Statt der kantianischen Misologie müsse gerade die Vernunft zum nationalen Maßstab erhoben werden. In diesem Sinne setzte er sich unermüdlich für einen sozialistischen Idealstaat unter der Herrschaft des Geistes ein, dessen Parameter schon dem gegenwärtigen Klassenstaat abgefordert werden müßten: „Und wir haben ihm [dem Klassenstaat] das Maß von Vernunft, das Maß von Humanität, von Rücksicht gegen seine eignen Kinder, das Maß von Menschenschutzpolitik zuzumuten, das wir vom sozialistischen Idealstaat erwarten, für dessen Verwirklichung wir arbeiten." 282

Als ein „Wahrheitssucher von unbezweifelbarem Ernst “283 kämpfte Hiller für eine Internationalisierung der Konfliktbewältigung, sah aber keine Chance, dabei das nationale Sentiment übergehen zu können. In seiner beiBend ironischen Diktion stellte er Anfang 1933 klar: „Die Nationen sind eine gegebene Tatsache und übrigens eine liebenswerte. [...] Deshalb ist die Frivolität gegenüber dem Nationalen eine Lästerung der Natur und, daß die Nationen verschwinden mögen, ein unfrommer Wunsch. "284 Ohne sich diesen unfrommen Wunsch auf die Fahne zu schreiben, forderte der sozialistische Pazifist eine Substitution der Kriege durch internationale Prozesse. Der Krieg sei nicht unumgänglich, sondern liege in der schlechten intellektuellen und moralischen Erziehung begründet ${ }^{285}$. Jeder Krieg schwäche die Substanz der Nation, wohingegen die Unterwerfung unter eine internationale Gerichtsbarkeit der Nation deutlich weniger schade ${ }^{286}$. Deshalb sei „schon dem Staat von heute das Aufgeben seiner, Souveränität', die Einordnung in ein System zwischenstaatlicher oder überstaatlicher Rechtsordnung zuzumuten, die Unterwerfung unter Sprüche eines internationalen Gerichts"287. Als entschiedener Gegner des bestehenden Völkerbundes wünschte sich auch Hiller eine internationale Organisation mit einer möglichst starken Exekutive, die auf der internationalen Ebene die Idee der Logokratie, der Herrschaft des Geistes und der Vernunft fortsetzen müsse. Allerdings ließ Hiller offen, ob dieses Staatensystem international oder supranational zu gestalten sei.

281 Hiller, Logokratie, Berlin 1921 sowie Ders., Geist werde Herr, Berlin 1920.

282 Ders., Heroismus und Pazifismus 1933, in: Ders., Ratioaktiv 1966, S. 99-105 (101).

283 So das Verdikt Rudolf Oldens in einem Referenzschreiben an den Präsidenten der American Guild for German Cultural Freedom, Hubertus Prinz zu Löwenstein, abgedruckt in: BERTHOLD, ECKERT, WENDE (Hg.), Deutsche Intellektuelle im Exil 1993,

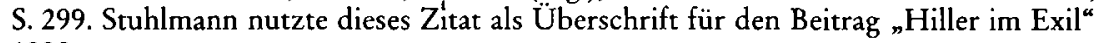
1998.

284 Hiller, Heroismus und Pazifismus 1933, in: Ders., Ratioaktiv 1966, S. 100.

285 Ibid. S. 100 f. Gegen die militaristische Heroisierung fand Hiller ebenfalls deutliche Worte: „Weil einer stirbt, ist er kein Held. [...] Weil er durch eine krepierende Granate krepiert, ist er kein Held. Weil einem das Vögelchen eines Maschinengewehrs ins Auge pickt, ist er kein Held. Weil giftiges Gas jemandem die Gewebe zerätzt und das Atmen verschlägt, bis er allmählich verreckt, ist er kein Held.“ (ibid.).

286 Ibid. S. 101: „An den Schwindel vom ,Stahlbad" glaubt heute ja doch niemand mehr."

287 Ibid. 
Otto Lehmann-Russbueldt: „Schafft die Eidgenossenschaft Europa!" Ein auf seine Weise ebenfalls radikal linker Pazifist war der Schriftsteller Otto Lehmann-Russbueldt, der trotz grundsätzlicher parteipolitischer Abstinenz sowohl zu Hillers FDS als auch zu Jaegers Volkssozialisten in Kontakt stand und sich 1941 der Parlamentarier-Gruppe um Karl Höltermann anschloß. Der ehemalige Generalsekretär der Deutschen Liga für Menschenrechte war in der Weimarer Zeit mit zahlreichen pazifistischen Publikationen an die Öffentlichkeit getreten und hatte sich insbesondere für die deutsch-französische Verständigung eingesetzt.

Im Exil gehörte er zu denjenigen Pazifisten, die der Appeasement-Politik zunehmend kritisch gegenüberstanden und vor diesem Hintergrund vor einer „Deform des Völkerbundes" warnte288. Gerade Großbritannien warf er vor, das Wort von der Reform des Völkerbundes zwar auf den Lippen zu führen, tatsächlich aber das europäische Schicksal rücksichtslos den eigenen Nationalinteressen zu opfern ${ }^{289}$. Doch sparte er auch nicht mit Kritik an den im Ersten Weltkrieg neutral gebliebenen Ländern. Denn insbesondere der Schweiz und den skandinavischen Staaten wollte Lehmann-Russbueldt die Wahrung der europäischen Idee anvertrauen, befürchtete aber für den erwarteten nächsten Krieg eine erneute Flucht dieser Länder in die Neutralität. Er forderte sie auf, sich über eine Abwehr des bevorstehenden deutschen Angriffs hinaus zu vergegenwärtigen, "daß nicht Deutschland allein das Problem ist, sondern daß die Ursachen zur Kriegsmöglichkeit vor allem auch in wirtschaftlicher Hinsicht aufgehoben werden müssen "290. Wie viele Emigranten von der europäischen Vorbildfunktion des schweizerischen Staatsmodells überzeugt, rief er den kleinen Staaten nahezu flehentlich zu: „Schafft die Eidgenossenschaft Europa!"291 In der eidgenössischen Schweiz erkannte Lehmann-Russbueldt das „lebendige Symbol jenes Zustandes in Europa [...], der den sicheren Ausweg aus der drohenden Kriegskatastrophe eröffnet ${ }^{\alpha 292}$. Über die gegenwärtige Bedrohung durch das Dritte Reich hinaus projizierte er auf das eidgenössische Europamodell nicht nur die Zielsetzung langfristiger Friedenssicherung, sondern auch die wirtschaftliche Prosperität, derer jede Friedensplanung als unbedingte Voraussetzung bedürfe.

Als drittes Moment ist Lehmann-Russbueldts Äußerungen der kulturelle Aspekt der christlich-humanistischen Tradition zu entnehmen. Dies wird deutlich in seiner als rhetorische Frage verkleideten Aufforderung an diejeni-

288 So der Titel eines Beitrages in der Pariser Tageszeitung: LeHManN-RussbueldT, Reform oder Deform des Völkerbundes?, in: Pariser Tageszeitung (28. 6. 1936), S. 1.

289 Ibid: „Es besteht die Gefahr, daß die englische Politik unter Wahrung des schönen Scheines einer Reform dieses Zerstörungswerk vollendet, um wenigstens das britische Weltreich aus dem befürchteten Europakrieg mit unvermeidlich folgendem ,Bolschewismus" herauszuhalten."

290 LEHMANN-RUSSBUELDT, Wer rettet Europa? 1936, S. 43.

291 Ibid.

292 Ibid. 
gen europäischen Staaten, die sich im Ersten Weltkrieg durch die Flucht in die Neutralität selbst der Verwirklichung der europäischen Idee beraubt hätten: „Habt ihr dadurch nicht den Ruf eures Landes als christliches Land, als Länder des Humanismus und der Kultur wieder gutzumachen?"293

Entgegen dem mehrheitlichen Trend der deutschen Emigration wandte Lehmann-Russbueldt gerade in den Jahren ab 1937/38 dem Europadiskurs desillusioniert den Rücken zu und widmete sich stärker der Mitarbeit in diversen politischen Diskussionszirkeln sowie der Publikation eigener Bücher, hauptsächlich zur deutschen Rüstungspolitik, zum preußischen Militarismus und zum Nationalsozialismus als gesellschaftlichem Phänomen ${ }^{294}$. Erst mit seinem 1948 erschienenen Werk „Europa den Europäern“ schöpfte er wieder Hoffnung für eine europäische Einigung 295 .

Friedrich W. Foerster: Föderalismus und Christentum In der geistigen Nachfolge des Föderalisten Constantin Frantz, der wie Proudhon den Föderalismus als durchgängiges Ordnungsprinzip verstanden hatte ${ }^{296}$, stand Friedrich Wilhelm Foerster. In seinem 1937 publizierten fundamentalen Werk „Europa und die deutsche Frage“297 sprach sich der Hochschullehrer für eine „Neuerweckung des Föderalismus als organisatorisches Völkerprinzip" 298 aus, um ihn dann mit den Grundaussagen des christlichen Glaubens $\mathrm{zu}$ verbinden ${ }^{299}$, denn: „Daß das politische Völkerproblem in der letzten Tiefe ein religiöses und ein kirchliches ist, das ist die Schlußfolgerung all unserer Schlußfolgerungen. "300 Der christliche Glaube sei die eigentliche Geistesgrundlage des europäischen Völkerlebens, deren Neubelebung nun anstehe $^{301}$. Der Nationalismus dagegen stehe der christlichen Idee diametral entgegen: „Es ist der entgeistigte, auf den Kopf gestellte, entchristlichte Mensch, der das Völkerchaos hervorgebracht hat. “302

Anknüpfend an universalgeschichtliche Modellvorstellungen der Mystik und des Joachimismus, bemühte sich Foerster, der europäischen Geschichte in übersteigert religiösen und historisch verquasten Wendungen ein wiederkehrendes Moment zu verpassen: „Hitler ist der wiedererstandene Ferdinand

293 Ibid. S. 42.

294 Vgl. z. B. Lehmann-Russbueldt, Hitlers Wings of Death 1936; DeRS., Landesverteidigung ohne Profit 1936; Ders., Der Krieg als Geschäft 1938; DerS., Neues Deutschtum 1939; sowie Ders., Aggression. The Origin of Germany's War Machine 1942.

295 LEHMANN-RuSSBUELDT, Europa den Europäern 1948.

296 Vgl. Bülck, Föderalismus 1964, S. 14, Anm. 34 a. E.

297 Bei Holl, Europa des pazifistischen Exils 1992, S. 281 findet sich die Angabe, Foersters Buch sei schon 1935 publiziert worden. Meines Wissens ist jedoch eine frühere Ausgabe als die des Jahres 1937 nicht bekannt.

298 FoERSTER, Europa und die deutsche Frage 1937, S. 76.

299 Ibid. S. 509: „, Ego sum Vita!' Christus ist der Staatengründer, Christus ist der Organisator: ,Wer nicht mit mir sammelt, der zerstreuet'.“

300 Ibid. S. 507.

301 Ibid. S. 80.

302 Ibid. S. 509. 
II., der hoch in den Lüften den Kampf gegen Richelieu wieder aufnimmt, aber in einer neuen Phase, wo Ferdinand, wiederauferweckt, sich seinerseits mit dem nördlichen Protestantismus verbündet, um den Westen endgültig niederzuwerfen; Hitler begründet den neuen dreißigjährigen Krieg, will dessen Schutthaufen zum europäischen Schutthaufen erweitern. Der dreißigjährige Krieg wurde ja nicht entsühnt, der Weltkrieg wurde nicht entsühnt, alles geht weiter - bis dereinst der lebendige Christus dazwischen treten und die innerste geistige Überwindung des Vergangenen verwirklichen wird. “303 Aus diesem christlich-historischen Blickwinkel sah Foerster die Rettung Europas allein in einer Rückbesinnung auf die christliche Tradition: „Was fehlt und was allein retten kann, das ist das ganz Universale, Mütterliche, Zusammenfassende, Allgerechte, Allgütige, es ist die menschgewordene Gottheit, es ist die ,mater gloriosa', wie sie im letzten Teile des ,Faust' erscheint und der schuldbefleckten, nur auf sich selbst gestellten Manneskraft die Lösung aller Lösungen zeigt. Noch schweigt diese höchste rettende Macht.“304

Für Foerster stellte der Föderalismus ein vielseitig verwendbares Lösungsmodell mit elementaren Scharnierfunktionen dar, insbesondere als Verbindungselement zwischen der nationalen und der internationalen Handlungsebene. Die Probleme des bestehenden Völkerbundes, den Foerster reformieren, aber nicht abschaffen wollte, seien darauf zurückzuführen, daß bislang der Übergang zwischen dem geschlossenen Nationalstaat mit seinem starren Souveränitätsbegriff und der offenen Weltföderation nicht gelungen sei ${ }^{305}$. In Übereinstimmung etwa mit Hilferding, Geyer und Stampfer vertrat auch der Pädagoge Foerster die Auffassung, daß nicht der Völkerbund versagt habe, sondern die auf ihr nationales Interesse fixierten Mitgliedstaaten - „und sie werden weiter versagen, weil in ihrer Mitte ein übernationales Wesen fehlt, das ein Gegengewicht gegen die Starrheit des Nationalkrampfes bilden und die Brücke zu übernationalen Organisationen schlagen könnte"306. Ein solches übernationales Wesen wäre in der Lage, die Nation mit dem Völkerbundgedanken zu versöhnen und ein übernationales Bewußtsein für die gemeinsamen Interessen wach zu halten ${ }^{307}$.

Der föderale Gedanke, den das britische Commonwealth auf der globalen Ebene entwickelt habe, konnte nach Foersters Überzeugung ebenso auf die europäische Dimension übertragen werden. Als ,einzig mögliche Synthese zwischen Eigengesetz und Gesamtgesetz" ${ }^{308}$ sei das föderalistische Ordnungsprinzip in der Lage, Europa langfristig den Frieden zu sichern. Der gläubige Christ vertrat die Auffassung, daß der Niedergang Europas nur aufgehalten werden könne, indem seine christlich-abendländische Schlüsselpo-

303 Ibid. S. 499.

304 Ibid. S. 507.

305 Ibid. S. 78.

306 Ibid.

307 Ibid. S. 80.

308 Ibid. S. 77. 
sition für die Welt neu entdeckt würde. In scharfer Wendung gegen den Nationalismus, in dem er "die Verstaatlichung des Wahnsinns, das rasende kollektive Ich" 309 erblickte, rief Foerster nach der sofortigen Heilung dieser europäischen „Krankheit". Er verlangte ein "göttliches Opfer", um die „abendländische Auflösung" aufzuhalten, die seines Erachtens der Kern des allgemeinen Weltübels sei ${ }^{310}$. Coudenhoves Paneuropa-Idee stimmte Foerster nur im Ansatz zu. Zwar seien kontinentale Föderationen notwendig als Vorbedingung für eine Weltföderation, doch sei für jede Föderation eine organische Entwicklung unumgänglich. Im Gegensatz zu Coudenhoves eher abstraktem Europabegriff müsse sich die europäische Föderation „von einem bestimmten Zentrum aus langsam wachsend ausbreiten"311. Aus einem antithetischen Denken heraus erblickte Foerster in Deutschland das für dieses Projekt geeignete Zentrum. Denn die deutsche Frage sei eine wesentlich europäische Frage, und die Entwicklung einer föderalen Ordnung müsse gerade dort beginnen, wo der Nationalismus seine stärkste Ausprägung zeige „ist doch Deutschland der ausgewachsenste Ausdruck dieses Chaos, dieser Entgeistigung, dieses Ich-Wahns der Einzelnen und der Kollektivitäten “312. Allerdings begab sich Foerster in einen Widerspruch, wenn er an anderer Stelle desselben Werkes Österreich zur „Erweiterung des Zusammenschlusses der südosteuropäischen Völker und damit [...] Reorganisation Europas“ aufforderte und ein „föderatives System der Donauvölker" anregte ${ }^{313}$.

Friedrich Foersters christlich-abendländische Vision einer Rettung des nationalistisch gespaltenen Europas beruhte auf dem Axiom einer fortschreitend dekadenten, entchristlichten Welt und entsprach insoweit einer zum damaligen Zeitpunkt in bürgerlichen Kreisen weit verbreiteten Angst vor dem Untergang des Abendlandes. Aus diesem Denken heraus kam er in zunehmend antikommunistischer Diktion zu dem Schluß, daß Faschismus und Bolschewismus prinzipiell gleichzusetzen seien. Den Stalinismus dagegen meinte er als Rettung der Sowjetunion vor dem "Gift des westlichen Marxismus" definieren zu können, wenngleich sich sein christlich-abendländischer Pazifismus ideologisch von Grund auf unterschied ${ }^{314}$. Foerster formulierte stellvertretend für viele bürgerliche Emigranten ein pessimistisches Menschenbild, dem die Hoffnung auf christliche Erlösung entgegengehalten werden müsse. In Übereinstimmung mit dem politischen Linkskatholizismus er-

309 Ibid. S. 509.

310 Ibid: „Die Krankheit ist eine allgemeine und im besonderen Sinne, soweit es sich um ihren politischen Ausdruck handelt, eine europäische und muß europäisch geheilt werden. Sie muß es, weil ohne das auch die übrige Welt nicht genesen wird, die durch die abendländische Auflösung selber in fortschreitende Zersetzung geworfen ist. Nur im Geheimnis des göttlichen Opfers, das das Geheimnis der Selbsterhaltung für die Einzelnen und die Staaten ist, kann die europäische Selbstvernichtung ihr Ende finden.“

311 Ibid. S. 80.

312 Ibid. S. 507.

313 Ibid. S. $464 \mathrm{f}$.

314 Ibid. S. 502. 
kannte der individualistische Pazifist das allein Halt versprechende Ordnungsprinzip im christlichen Glauben, dem in staatsrechtlicher und völkerrechtlicher Perspektive der Föderalgedanke entspreche. Mit dieser logischen Verknüpfung zwischen Christentum und Föderalismus setzte Foerster einen ideengeschichtlich bedeutenden Meilenstein in der Genesis europäischer $\mathrm{Zu}$ kunftspläne des Exils.

\subsection{Liberale und Bürgerlich-Konservative}

Viele Gedanken des Pazifisten Foerster finden sich in den liberalen und bürgerlich-konservativen Kreisen der deutschen Emigration wieder. Hierzu zählt sowohl das ausgeprägte christlich-abendländische Bewußtsein als auch der nicht minder ausgeprägte Antikommunismus. Doch Foersters vehementen Antinationalismus vermochte zumindest in der ersten Phase des Europadiskurses kaum ein Liberaler oder gar Konservativer zu teilen. In einem Aufruf der Anfang 1936 in Paris gegründeten Deutschen Freiheitspartei, die als Sammelbecken für Liberale, Pazifisten, Katholiken und Konservative gedacht war ${ }^{315}$, hieß es: „Wir haben als nationale Deutsche mit dem Kommunismus nichts gemein und lehnen den roten Bolschewismus mit derselben Entschiedenheit ab, mit der wir uns aus der Umklammerung der braunen befreien wollen. "316 In treffender Selbstcharakterisierung bekannte man weiter: „Wappnen wir uns für den Tag, an dem wir die unwürdige, entehrende Tyrannenherrschaft brechen werden! Heil Deutschland!"317 Sicherlich fand sich in solchen Formulierungen längst nicht jeder Liberale wieder. Doch war auch den linksliberalen Emigranten ein engeres Verhältnis zur deutschen Nation und ein stärkerer Glaube an die Idee des christlichen Abendlandes zu eigen ${ }^{318}$. Jedenfalls in ihren Europavorstellungen wiesen Linksliberale, Rechtsliberale, Bürgerlich-Konservative und der politische Katholizismus einige grundlegende Übereinstimmungen auf, so daß eine gemeinsame Darstellung an dieser Stelle vertretbar ist.

Das einzige bedeutende Organisationsforum der exilierten Pazifisten war die Deutsche Freiheitspartei (DFP), die jedoch schon kurz nach der durch

315 Zur Organisationsgeschichte der DFP vgl. BOuvIER, Deutsche Freiheitspartei 1969. 316 Aufruf der Deutschen Freiheitspartei, o. D. [1936/37]. Anlage zu einem Brief Warendorfs an Schwarzschild vom 19. 7. 1937, BAB, NL Schwarzschild, N 2277/4, Bl. 5, VS.

317 Ibid.

318 Dies belegt unter anderem der konservative Sprachgebrauch, der sich auch bei unabhängigen Linksliberalen wie Leopold Schwarzschild, einem kritischen Querdenker des Exils, wiederfindet: „Es gibt, politisch, keine Emigration. Es gibt nur eine Zusammenhäufung einzelner Emigranten, deren keiner etwas vom anderen weiß, keiner etwas vom anderen wissen will, und die politisch, wie im Vergrößerungsspiegel, nur den $\mathrm{Zu}$ stand der traurigen Zerweichung und Entmännlichung des Landes, aus dem sie kamen, konterfeien. “; SCHWARZSCHILD, Das Bedürfnis nach Seeschlangen, in: NTB, 2. Jg., H. 1 (6. 1. 1934), S. 10-13 (12). 
die Besetzung Frankreichs erzwungenen Sitzverlegung nach London 1940 ihre Aktivitäten einstellte ${ }^{319}$. Ihr hoch gestecktes Ziel, ein eigenes Widerstandsnetz aufzubauen und eine nichtsozialistische Volksfront zu bilden, wurde weit verfehlt. Doch ist es vor allem dem ehemaligen Sonderbeauftragten für die Bekämpfung des Nationalsozialismus, Carl Spiecker, zu verdanken, daß mit den zumeist wohl von ihm verfaßten Deutschen Freibeitsbriefen sowie der ab Januar 1938 herausgegebenen Zeitschrift Das Wabre Deutschland einige erwähnenswerte Gedanken dieses Kreises an die Öffentlichkeit gelangten.

Beeinflußt durch Spieckers konservativen Kurs vertrat die DFP trotz ihres breit gestreuten Adressatenkreises in den Jahren 1933 bis 1937 ein primär nationales Programm. Im Vordergrund stand die Selbstversicherung national orientierter Wertvorstellungen: „Die Demokratie, der sie [die DFP] dienen will, muß und wird eine Demokratie der eisernen Selbstbehauptung, der Manneszucht, der nationalen Disziplin, der sozialen Gerechtigkeit und des gerechten Friedens sein. [...] Sie verlangt ein deutsches Reich auf dem tragenden Fundament der Gerechtigkeit und der Freiheit. " ${ }^{320}$ Möglicherweise unbewußt knüpfte man mit den beiden letztgenannten Schlagworten an das Parteiprogramm der DDP aus dem Jahre 1919 an, in dem „Gerechtigkeit und Freiheit" auch als Grundlage der völkerrechtlichen Beziehungen angestrebt worden war, ohne jedoch das Selbstbestimmungsrecht der Völker in Frage zu stellen. Stattdessen sollte gerade das Selbstbestimmungsrecht dem „Zusammenschluß aller deutschen Stämme“ den Weg ebnen. Dementsprechend dachte man sich den Völkerbund als Plattform einer internationalen Kooperation, die das Ausmaß einer "internationalen Arbeitsgemeinschaft" nicht sprengen sollte $\mathrm{B}^{321}$.

Hatte die liberale DDP 1919 den Völkerbundgedanken gerade einmal erwähnt, den Europagedanken dagegen völlig ignoriert, behielten die exilierten Liberalen diese national definierte Grundhaltung vorerst bei und beteiligten sich erst ab Herbst 1938 allmählich am Europadiskurs des deutschen Exils ${ }^{322}$. Nur wenige bürgerlich-liberale Emigranten bemühten sich schon früher um die europäische Frage, unter ihnen die Schriftsteller Heinrich Mann und Leopold Schwarzschild.

Heinrich Mann: Souveränitätsverzicht zugunsten eines europäischen Gesamtstaates Heinrich Mann hatte sich im französischen Exil zeitweilig klar zum Sozialismus bekannt. Doch kann er vor dem Hintergrund seiner Biographie und der späteren Abkehr von sozialistischen Grundaussagen nicht als

319 Vgl. Bouvier, Deutsche Freiheitspartei 1969, S. 27-38.

320 O. T., in: Deutscher Freiheitsbrief, Nr. 16, Bl. 2 RS.

321 Programm der Deutschen Demokratischen Partei vom Dezember 1919, abgedruckt in: MOMMSEN (Hg.), Parteiprogramme 1961, S. 508-514 (510).

$322 \mathrm{Vgl}$. den Beitrag: Europas schwarzer Tag, in: Das Wahre Deutschland (Oktober 1938), S. 1-3. 
überzeugter Sozialist im eigentlichen Sinn bezeichnet werden. Vielmehr ergaben sich seine Sympathien für den Sozialismus aus seinem kompromißlosen Antifaschismus und einem allgemeinen Gerechtigkeitsstreben, das politisch eher als linksliberal kategorisiert werden kann. Mann selbst charakterisierte sich selbst als antifaschistischer Radikaldemokrat ${ }^{323}$ und „revolutio-

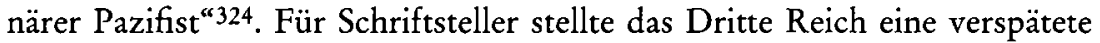
Auflehnung der Deutschen gegen Europa dar ${ }^{325}$. Daher forderte der Vorsitzende des Vorläufigen Ausschusses zur Vorbereitung einer deutschen Volksfront in seinen Ergänzungsvorschlägen für ein von Emil Julius Gumbel erarbeitetes Programm der deutschen Volksfront: „Republik, Sozialismus, Selbstregierung des Volkes werden niemals in Frage gestellt: besonders aber nicht die internationale Einordnung des Deutschen Volksstaates. Bei hoher Strafe soll niemand sich, national' oder ,deutsch' nennen dürfen zum Zweck eines Angriffes auf den Staat oder seine Angehörigen." 326 Hier wird Manns strikter Antinationalismus deutlich, der durch seine sozialistische Annäherung in dieser Zeit noch verstärkt wurde. Der antinationalistischen Haltung entsprang die Forderung nach dem obligatorischen Beitritt Deutschlands zu einem europäischen Staatenbund, der als Regionalorganisation wiederum dem Völkerbund untergeordnet sein müsse ${ }^{327}$. Dabei hoffte der renommierte Schriftsteller auf einen Völkerbund der "gesammelte[n] Weltdemokratie" 328 , den er sich - in gewissem Widerspruch zu seinem dezidierten Antinationalismus - als freies, unabhängiges „Parlament der Nationen“ vorstellte, statt als Versammlung der Regierungen ${ }^{329}$. In Ergänzung zu Gumbels Minimalprogramm einer deutschen Volksfront, das in außenpolitischer Hinsicht lediglich den Wiedereintritt Deutschlands in den Völkerbund vorsah ${ }^{330}$, ging Mann auch auf die europäische Frage ein. Er befürwortete eine „Synchroni-

323 Vgl. z. B. H. MANN, Es kommt der Tag, o. D. [Mai 1936], in: DERs., Verteidigung der Kultur 21973, S. 179-187 (186): „Der Sturz des Dritten Reiches ist gewiß. Feststehen muß im voraus das Grundgesetz der revolutionären Demokratie. Hier ist es. Sie folgt auf eine Pöbelherrschaft, sie wird ein Regime der sittlichen Erziehung sein."

324 DERS., Das Friedenstreffen, o. D. [Juli 1936], in: DERS., Verteidigung der Kultur 21973 , S. 197-202 (202).

325 DERS., Es kommt der Tag, o. D. [Mai 1936], in: Ders., Verteidigung der Kultur 21973, S. 187.

326 Ders., Vorschlag für Ergänzungen des Gumbel'schen Minimalprogramms der Deutschen Volksfront, o. D. [1936], S. 1, AsD, Bestand PV-Emigration Sopade, M. 194; auch abgedruckt bei LANGKAU-ALEX, Volksfront 1977, S. 180-182.

327 Ibid.

328 H. MAnN, Es kommt der Tag, o. D. [Mai 1936], in: Ders., Verteidigung der Kultur 21973, S. 187.

329 DERS., Wehrt euch!, o. D. [Mai 1939], in: Ders., Verteidigung der Kultur 21973, S. 350 .

330 Gumbel, Minimal-Programm der Deutschen Volksfront, o. D. [1936], Punkt 19, AsD, Bestand PV-Emigration Sopade, M. 194. 
sierung“ der europäischen Regime ${ }^{331}$ und die anschließende Gründung eines europäischen Gesamtstaates mit einer übernationalen Regierung. Nach der erfolgreichen Etablierung hätten die Mitgliedstaaten in vollem Umfang auf ihre Souveränität zu verzichten ${ }^{332}$. Dies entsprach Manns allgemeiner Wahrnehmung der internationalen Beziehungen, die „in Fluß gekommen" seien. Hoffnungsfroh meinte er feststellen zu können, daß die Staaten sich ohnehin „dem Interesse der Gesamtheit zu fügen haben, und auch internationale Beschlüsse werden nur noch kollektiv gefaßt werden"333.

Für den Präsidenten der Deutschen Freiheitsbibliothek war die ,irgend erreichbare Vereinheitlichung Europas" die sicherste Gewähr für die Bewahrung des kollektiven Friedens ${ }^{334}$. Staatliches Aggressionspotential sollte frühzeitig durch die konsequente Umsetzung des Volksfrontgedankens gebrochen werden können: in jedem Land eine nationale Volksfront „und alle zusammen nur eine einzige Welt-Volksfront" 335 . Darüber hinaus erkannte Mann die identitätsfördernde Funktion einer vereinigten Wirtschaft: Besser als auf dem Papier einer Verfassung könne die Freiheit des Menschen „durch die „Normalisierung der Wirtschaft" gesichert werden ${ }^{336}$. Dies umso mehr als das Hauptmotiv der aggressiven nationalsozialistischen Außenpolitik die „Unfähigkeit und der böse Wille angesichts der Wirtschaftsfragen des Landes" 337 sei.

Leopold Schwarzschild: Bund europäischer Nationen statt Völkerbund Eine herausragende Rolle in der liberalen Vorkriegsemigration spielte der linksliberale Publizist Leopold Schwarzschild, der die bis 1940 erschienene, politisch einflußreiche Zeitschrift Das Neue Tage-Buch herausgab und selbst zahlreiche ihrer Beiträge verfaßte. Schwarzschilds publizistisches Hauptanliegen war die eindringliche Warnung vor der seitens des Dritten Reiches drohenden Kriegsgefahr, die allein durch eine willensstarke und kompromißlose Opposition der europäischen Staaten abgewendet werden könne. Früh hatte er den

331 H. MANN, Das Friedenstreffen, o. D. [Juli 1936], in: DERS., Verteidigung der Kultur 21973 , S. 201.

332 Ders., Vorschlag für Ergänzungen des Gumbel'schen Minimalprogramms der Deutschen Volksfront [1936], S. 1, AsD, Bestand PV-Emigration Sopade, M. 194: „Nachdem das Ziel einer überstaatlichen Leitung Europas erreicht ist, begibt sich der Deutsche Volksstaat ausdrücklich seiner Souveränität zugunsten des europäischen Gesamtstaates."

333 Ders., Der Wert des Friedens, o. D. [Januar 1936], in: Ders., Verteidigung der Kultur 21973, S. 188-190 (190).

334 Ders., Vorschlag für Ergänzungen des Gumbel'schen Minimalprogramms der Deutschen Volksfront [1936], AsD, Bestand PV-Emigration Sopade, M. 194, S. 1.

335 DerS., Der Wert des Friedens, o. D. [Januar 1936], in: DERS., Verteidigung der Kultur 21973, S. 190.

336 Ders., Es kommt der Tag, o. D. [Mai 1936], in: Ders., Verteidigung der Kultur 21973, S. 186.

337 DERS., Das Friedenstreffen, o. D. [Juli 1936], in: DERS., Verteidigung der Kultur 21973, S. 200. 
synergetischen Effekt eines geeinten antifaschistischen Exils erkannt, wenngleich er etwas zu optimistisch meinte, ihn auf alle europäischen Staaten ausdehnen zu können ${ }^{338}$. Schwarzschilds Kriegswarnungen wiesen zugleich auf die zu befürchtenden Auseinandersetzungen um die europäische Hegemonie hin, die ein bisher ungekanntes Ausmaß anzunehmen und die europäische Idee endgültig zu begraben drohten. In seiner radikalen Reduzierung des internationalen Geschehens auf die europäische Machtfrage verlangte Schwarzschild eine breite antifaschistische Solidarität jenseits aller ideologischen Trennlinien. Die blutige Niederschlagung des österreichischen Arbeiteraufstandes am 6. Februar 1934 war ihm ein typisches Zeichen der Zeit, das ihn zu dem erbitterten Ausruf veranlaßte: „Es ist Krieg! Das ist es, was nicht begriffen wird. Was seit Jahren nicht begriffen wird. Ein Krieg um die Herrschaft über Europa!"“339

Sein auf den europäischen Kontinent fixierter Blickwinkel führte dazu, daß Schwarzschild sich kaum mit dem Völkerbundgedanken auseinandersetzte, dessen ersten Realisierungsversuch er mit der gängigen Kritik als schwach und unzuverlässig verurteilte. In dem „vagen Nebel des Völkerbund-Vertrages" fehle eine verbindliche Definition des Angriffskrieges als Bündnisfall ebenso wie ein Katalog möglicher Sanktionsmaßnahmen ${ }^{340}$. Daher setzte er sich vorzugsweise mit den konkreten Möglichkeiten einer europäischen Einigung auseinander, die er anstelle des „papiernen Welt-Völkerbundes“ implementiert sehen wollte. Im Gegensatz zu Heinrich Mann lehnte Schwarzschild einen europäischen Einheitsstaat $a b$ und propagierte stattdessen einen „konkret verklammerte[n] Bund der europäischen Nationen“, dessen Gründung nach dem Ende des Ersten Weltkrieges versäumt worden $\operatorname{se}^{341}$. Die Funktion der Nationalstaaten würde sich innerhalb dieses europäischen Bundes auf die autonome, aber souveränitätslose Selbstverwaltung reduzieren ${ }^{342}$. Als wichtigste Bundesaufgabe sah auch Schwarzschild die Erhaltung des bundesinternen Friedens und die Bündelung der ökonomischen Kräfte. In seinem Verfassungsentwurf, den er auftragsgemäß im Februar 1936 dem Vorläufigen Ausschuß zur Vorbereitung einer Deutschen Volksfront vorlegte, postulierte er: „Jede Außenpolitik, die auf Krieg abzielt, ist schon aus diesem Grund ein Verbrechen." 343 Wie sich der Publizist den Umgang mit Angreiferstaaten in den eigenen Reihen des europäischen Bundes

338 Schwarzschild, Die Parole Pan-Europa, in: NTB, 3. Jg., H. 20 (18. 5. 1935), S. 465-467 (466): „In der Tat ist der Kontinent seit einigen Monaten in einen Zusammenschluß-Prozeß geraten, der noch vor kurzem ganz undenkbar gewesen wäre. Europa vollzieht eine ,Gleichschaltung" gegen Hitler."

339 DERS., Österreich, in: NTB, 2. Jg., H. 8 (24. 2. 1934), S. 176-179 (177).

340 DERS., Stresa, in: NTB, 3. Jg., H. 15 (13. 4. 1935), S. 345-349 (346).

341 DERS., Die Parole Pan-Europa, in: NTB, 3. Jg., H. 20 (18. 5. 1935), S. 467.

342 Ibid.

343 Schwarzschild, Verfassungsentwurf für Deutschland, o. D. [1936], BAB, NL Schwarzschild,

N 2277/6, Bl. 26-28 (26). 
vorstellte, wird in einer Stellungnahme zur Stresa-Konferenz 1935 deutlich $^{344}$. Dort wurden die Minister aufgefordert, alternativ ein einziges Bündnis oder eine lückenlose Kette von Individualbündnissen „rings um den Angriffs-Drohenden ${ }^{“}$ zu errichten. Insofern war für den linksliberalen Emigranten nicht die Friedensüberzeugung der Pazifisten oder Sozialisten entscheidend, sondern allein das tatsächliche Friedensergebnis. Hierfür reichte grundsätzlich ein erzwungener Friede aus ${ }^{345}$. In demselben Artikel findet sich auch ein Vorschlag für die geographische Zusammensetzung eines solchen Total-Bündnisses, das sich auf Frankreich, Belgien, England, Italien, Rußland, die baltischen Staaten, die Kleine Entente und den Balkanbund erstrecken sollte. Die geographische Ausweitung der hilfsweise zu bildenden Regionalbündnisse dagegen müßte sich vornehmlich an den europäischen Gefahrenzonen orientieren ${ }^{346}$. Von dieser geographischen Grundkonstellation, die noch die Sowjetunion als wichtigen Machtblock berücksichtigte, sollte Schwarzschild im Gefolge der Moskauer Prozesse und des deutschsowjetischen Nichtangriffspaktes wieder abrücken, um einem dezidiert antibolschewistischen Europabild Raum zu geben.

Die zweite Bundesaufgabe lag in der Bündelung der europäischen Wirtschaftsmacht. Schwarzschild, der dem Lutetia-Komitee als Vertreter der bürgerlichen Emigration angehörte, sah in seinem Verfassungsentwurf auch insoweit die Verwirklichung der Vereinigten Staaten von Europa vor, um den Wohlstand zu fördern und „die verschiedenen Sonder-Aspirationen einzelner Länder" endgültig dem Wohl der Allgemeinheit unterzuordnen ${ }^{347} .1935$ resümierte er: „Von Paneuropa heute zu reden, darüber nachzudenken, Kräfte dafür zu sammeln und Pläne zu systematisieren, ist Vorbereitung für eine der positivsten Unternehmungen, die im Laufe der Geschichte je möglich waren." 348

In einer ausführlichen Auseinandersetzung mit dem Paneuropagedanken verhehlte Schwarzschild nicht seine grundsätzliche Sympathie, gab dem Projekt jedoch kaum eine Chance auf Realisierung. Erst in ferner Zukunft sei es denkbar, daß sich ein europäisches Zusammengehörigkeitsgefühl herausgebildet haben werde, mit dessen Initialkraft das momentan nur politisch-militärisch definierte, gegen Deutschland gerichtete Europa sich zu einem „staatsrechtlich-wirtschaftlichen Pan-Europa“" werde entwickeln können ${ }^{349}$.

Für das Verständnis seines Europabildes ist Schwarzschilds Haltung zur UdSSR elementar. Von Beginn an betrachtete er die Sowjetunion als eine Diktatur, die dem nationalsozialistischen Regime in Deutschland geistesver-

344 DeRS., Stresa, in: N'TB, 3. Jg., H. 15 (13. 4. 1935), S. 345-349.

345 Ibid. S. 345.

346 Ibid. S. 346.

347 Schwarzschild, Verfassungsentwurf für Deutschland, o. D. [1936], Punkt 4, BAB, NL Schwarzschild, N 2277/6, Bl. 26-28 (27f.).

348 Ders., Die Parole Pan-Europa, in: N'TB, 3. Jg., H. 20 (18. 5. 1935), S. 465.

349 Ibid. S. 466. 
wandt sei. Vor diesem Hintergrund beobachtete Schwarzschild mit großer Beunruhigung die Entwicklung in Österreich. Ein Sieg des Austrofaschismus würde Österreich seiner europäischen Funktion als Keil zwischen der deutschen und der sowjetischen Diktatur entheben und Westeuropa der Gefahr aussetzen, unter sowjetischen Einfluß zu geraten ${ }^{350}$. Rußland gehöre nicht zu Europa, so daß die Frage, ob es zu Paneuropa gehören solle oder nicht, letztlich eine rein "religiöse Debatte“ sei351. Es gebe auch für die Sowjetunion keine Veranlassung, ,an den komplizierten Verein des alten Kontinents angeschlossen zu werden". Dennoch schloß Schwarzschild eine spätere Integration der UdSSR nicht aus ${ }^{352}$. Unabhängig von der Frage der Integration in einen europäischen Staatenverband unterstrich Schwarzschild die eminent wichtige Bedeutung einer strategischen Einbindung dieses internationalen Machtfaktors in die antinationalsozialistische Abwehrfront. Dabei erkannte er, daß der internationale Faktor Sowjetunion auf die ,geistige und materielle Verfassung Europas und der Europäer" großen Einfluß ausübte ${ }^{353}$.

Diese rein machtpolitische Betrachtung der sowjetischen Position im internationalen Staatengefüge wich ab 1937 einem harschen Antikommunismus ${ }^{354}$. Zutiefst erschüttert nahm Schwarzschild die Nachrichten über die Moskauer Prozesse entgegen und konstatierte: „Das Erlebnis schien zunächst nur zerstören zu können. Der Glaube und die Hoffnung von Millionen wurden erschüttert. Gute Freundschaften wurden zersprengt, hohes Ansehen wurde vertan. "355 In der Folge beobachtete Schwarzschild „ein tiefes Nachdenken“, das nicht zuletzt ihn selbst zu der grundlegenden Revision seines rein machtpolitisch definierten Verhältnisses zur UdSSR zwang: „Gewissen erforschen sich selbst, Ideologien werden nachgeprüft, das Erlebnis wirkt wie ein Licht, das viel Dunkles neu beleuchtet - und zögernd noch, aber allerwärts beginnen Begriffe wieder zum Leben zu erwachen, die verblaßt erschienen waren, formalistische Schablonen, fragwürdige Postulate einer illusionären Welt. Ja, es ist wahr: Worte wie Freiheit, Recht, Demokratie klingen für viele infolge des Moskauer Lehrgangs plötzlich wieder mit neuem Klang." 356 Sicherlich auch aus Enttäuschung über den Kommunismus, den er 1935 noch als eine der beiden „Positivitäten“ für Europa bezeichnet hatte, steigerte sich Schwarzschilds Haltung zum Sowjetregime zu einer

350 SCHWARZSCHILD, Österreich, in: NTB, 2. Jg., H. 8 (24. 2. 1934), S. 178.

351 Ders., Die Parole Pan-Europa, in: NTB, 3.Jg., H. 20 (18. 5. 1935), S. 466.

352 Ibid.

353 DERS., Hinrichtung, in: NTB, 5. Jg., H. 25 (19.6. 1937), S. 584-588 (585).

354 Eine gut recherchierte Darstellung des antikommunistischen Denkens bei Schwarzschild bietet Brousseau, Das Neue Tage-Buch 1999, S. 47-62. Brousseaus Analyse verdient auch deshalb Beachtung, weil er durchgängig und aufschlußreich das Thema des Sammelbandes, „Der Europadiskurs in den deutschen Zeitschriften" bedient. Ein Vorzug, den leider nicht jeder der Beiträge dieses Sammelbandes aufweist.

355 SCHWARZSCHILD, Die alte Wahrheit, in: NTB, 5. Jg., H. 7 (13.2. 1937), S. 155-157 (155).

356 Ibid. 
tiefen Verachtung ${ }^{357}$, die letztlich jegliche Unterschiede zwischen dem Nationalsozialismus und dem Bolschewismus nivellierte. Beide Ideologien seien "derselbe Dreck, derselbe Stank, dieselbe Lepra“, die „in dieselbe Niedrigkeit und auf denselben Schindanger" führten wie jede andere Diktatur ${ }^{358}$.

Während die liberale Vorkriegsemigration zumindest mit Heinrich Mann und Leopold Schwarzschild zwei engagierte Teilnehmer des Europadiskurses aufweisen konnte, sind aus konservativen Kreisen oder dem Umfeld des politischen Katholizismus kaum europarelevante Quellen bekannt - sieht man von Emigranten wie Friedrich Wilhelm Foerster ab, die ihre (christlich-) konservative Grundeinstellung mit einem aktiven pazifistischen Engagement verbanden und deshalb an anderer Stelle zu behandeln sind.

Für den politischen Linkskatholizismus stritten insbesondere die emigrierten Publizisten Werner Thormann, Hubertus Prinz zu Löwenstein und Walter Dirks, wobei vor allem die beiden Erstgenannten ab 1938 zu europapolitischen Fragen Stellung bezogen ${ }^{359}$. Für den rechten Flügel des politischen Katholizismus kann insbesondere auf die ehemaligen Zentrumspolitiker und Reichskanzler Heinrich Brüning und Josef Wirth verwiesen werden. Doch während sich der in die Schweiz emigrierte Wirth im Rahmen des Arbeitskreises Das Demokratische Deutschland hin und wieder auch mit der europäischen Frage auseinandersetzte, zog sich Brüning in der Emigration völlig aus dem politischen Leben zurück und verweigerte bis zum Schluß jede Mitarbeit.

Zur Einschätzung der Exilforschung, aus dem konservativ-katholischen Exil seien wegen des kleinen Personenkreises und der fehlenden Kommunikationsstruktur nur vereinzelt Stellungnahmen zur internationalen Nachkriegsordnung abgegeben worden ${ }^{360}$, ist ergänzend zu bemerken, daß sicherlich auch die betont nationale Ausrichtung in der Außenpolitik eine intensive Beschäftigung mit einem geeinten Europa verhindert hat. Selbst ein Jahr nach dem Abschluß des Locarno-Paktes war der Vizepräsident des Reichstages und Zentrumsabgeordnete Johannes Bell außer Stande gewesen, in einem Grundsatzartikel zur deutschen Außenpolitik die Europaidee auch nur zu

357 Zur Entwicklung der antikommunistischen Haltung Schwarzschilds vgl. auch SCHWARZSCHILD, Zwei Despotien, in: NTB, 5. Jg., H. 34 (21. 8. 1937), S. 800-805 und H. 35 (28. 8. 1937), S. 825-831 sowie Ders., Die Pandorabüchse, in: NTB, 5. Jg., H. 46 (13.11. 1937), S. 1089-1094.

${ }^{358}$ SChwarzSCHILD, Hinrichtung, in: NTB, 5. Jg., H. 25 (19. 6. 1937), S. 585. Der KPD warf er die sarkastische Bemerkung hinterher: „Es scheint, als ob viele es diesmal schon einsähen, und das wäre wahrlich kein geringer Gewinn. Für die, deren Augen sich auch jetzt noch nicht öffnen, bleibt nichts übrig, als weiter auf Stalin zu vertrauen.“

359 Thormann war seit 1939 Chefredakteur der von Willi Münzenberg herausgegebenen Zeitschrift Die Zukunft. Sein erster europapolitischer Beitrag erschien unter dem Titel: Umgrenzung der Aufgabe, in: Die Zukunft (21. 10. 1938), S. 6 f. Löwenstein meldete sich im August 1939 mit einem aufschlußreichen Artikel in der Neuen Weltbühne zu Wort: LöWENSTEIN, Nach Hitlers Fall, in: Die Neue Weltbühne, XXXV. Jg., Nr. 31 (3. 8. 1939), S. 958-962.

360 Vgl. VoIGT (Hg.), Friedenssicherung 1988, S. 181. 
erwähnen ${ }^{361}$. Erst 1927 wurde in einem Manifest der Zentrumsfraktion die Rückkehr des deutschen Volkes „in eine europäische zwischenstaatliche [sic!] Rechtsordnung" angeregt ${ }^{362}$. Doch war damit nicht mehr als die Retablierung der europäischen balance of power gemeint, denn eines stand fest: „In der Einordnung in die gegebene Solidarität der Völker darf und soll das Wesen unserer eignen Nation nicht verdunkelt werden. ${ }^{\text {"363 }}$

\subsection{Nationalkonservative}

Es bedarf kaum einer Erwähnung, daß nur äußerst wenige Nationalkonservative den Weg ins Exil suchten, da sie sich entweder der nationalsozialistischen Bewegung angeschlossen hatten oder zumindest eine Kooperation mit dem Hitler-Regime anstrebten. $\mathrm{Zu}$ Recht ist darauf hingewiesen worden, daß selbst nach der Röhm-Affäre die nationalkonservative Emigration kaum Zuwachs erhielt ${ }^{364}$. Gerade bei einer Untersuchung des Europadiskurses im Exil jedoch stößt man unweigerlich auf zwei Emigranten, die schon aufgrund ihrer erklärten nationalsozialistischen Vergangenheit die Aufmerksamkeit ihrer exilierten Schicksalsgenossen erregten: Otto Strasser und Hermann Rauschning. Beide, einst überzeugte Parteigänger Hitlers, teilten eine betont nationale, antidemokratisch-konservative Grundhaltung. Doch während sich der ehemalige Danziger Senatspräsident Rauschning im Exil endgültig vom Nationalsozialismus lossagte ${ }^{365}$, bemühte sich Strasser, den linken $\mathrm{Na}$ tionalsozialismus seines 1934 ermordeten Bruders Gregor zu neuem Leben zu erwecken. Zu diesem Zweck hatte er schon im September 1931 die Schwarze Front (SF) gegründet, die er im Prager Exil neu gründete. Unter Verwertung jungkonservativen, nationalsozialistischen und sozialistischen Gedankengutes bemühte sich Strasser, eine neue, nationalrevolutionäre Richtung vorzugeben ${ }^{366}$.

Otto Strasser: Europa zwischen Faschismus und Bolschewismus Als eine der schillerndsten Gestalten des deutschen Exils schieden sich an Otto Strasser die politischen Geister. Die von der SAP herausgegebene Zeitschrift Neue

361 BELL, Zentrumsgedanken zur deutschen Außenpolitik, in: Europäische Gespräche, H. IV (April 1926), S. 175-182.

362 Nationalpolitisches und Sozialpolitisches Manifest der Zentrumsfraktion des Reichstages vom 21. 1. 1927, abgedruckt in: MOMMSEN (Hg.), Parteiprogramme 1961, S. 493-498 (495). Vgl. ferner die skizzenhaften Stichworte bei JoOs, Die politische Ideenwelt des Zentrums 1928, insb. S. 10, 23, 56-60.

363 Nationalpolitisches und Sozialpolitisches Manifest der Zentrumsfraktion des Reichstages vom 21. 1. 1927, abgedruckt in: MOMMSEN (Hg.), Parteiprogramme 1961, S. 493-498 (495).

364 Vgl. VOIGT (Hg.), Friedenssicherung 1988, S. 188.

365 Vgl. seine Abrechnung mit Hitler: RAusCHNING, Revolution des Nihilismus ${ }^{2} 1939$.

366 Vgl. z.B. STRASSER, Unsere Außenpolitik, in: Die Deutsche Revolution 9, Nr. 3 (27. 5. 1934), S. 1-2 (2). 
Front charakterisierte Strasser in einer Rezension seines Buches „Deutsche Bartholomäusnacht “ als „ein Unikum: ein Nationalist, der Antifaschist zugleich, ein Antimarxist, der gleichzeitig Antikapitalist, ein Konservativer, der Revolutionär ist“" ${ }^{367}$. Die Gruppe Neu Beginnen sprach der Schwarzen Front Strassers jegliche langfristige Bedeutung $a b$, warnte aber zugleich vor dem drohenden Einbruch solch volkssozialistischer Strömungen in die Arbeiterbewegung, wie sie die sudetendeutsche Sozialdemokratie unter Wenzel Jaksch schon propagiere ${ }^{368}$. Der sozialdemokratische Pazifist Kurt Grossmann verurteilte 1949 in der Zeitschrift Jewish Frontiers die Schwarze Front als ein „adventurous and dangerous movement" und Strassers politische Philosophie als "weird combination of nationalism and Bolshevism" 369 . Vor dem Hintergrund erster Meldungen über ein Wiedererstarken des Nationalismus in Deutschland befürchtete Grossmann: „Should his sixth or seventh application for a passport to the Fatherland be one day approved, Otto Strasser might become the rallying figure for the Neo-nazism prevalent in an alarming degree in Germany - only three years after its 'unconditional surrender'." 370 Der Sozialist und Querdenker Kurt Hiller dagegen veröffentlichte zusammen mit Otto Strasser am 30. Januar 1938 eine gemeinsame Erklärung gegen das Hitler-Regime und einigte sich mit ihm auf einen Grundkonsens für die Neuordnung Deutschlands nach Hitler ${ }^{371}$.

Strasser selbst sah sich in der geistigen Nachfolge Mazzinis, der den nationalen Sozialismus als vierte Variante des Sozialismus neben Marxismus, Bolschewismus und religiösem Sozialismus begründet habe ${ }^{372}$. Vorbildfunktion hatte für den emigrierten National-Sozialisten der tschechoslowakische Präsident Thomas Masaryk, den er überaus verehrte und zum Führer eines neuen Europas stilisierte ${ }^{373}$. Inhaltlich stand Strasser mit der Schwarzen Front mitten im Kampf gegen das Hitlersystem und berief sich dabei auf

367 DERS., „Deutsche Bartholomäusnacht", in: Die Neue Front 3, Nr. 21 (Anfang November 1935), S. 2.

368 Parteivorstand an „Werte Genossen!“, Rundschreiben, 29.9. 1936, IISG, NL Hertz, S11, M. Q, Bl. 6 sowie die möglicherweise von Paul Hertz verfaßte Denkschrift: Arbeitersozialismus oder Nationaler Sozialismus? Zur Auseinandersetzung mit Otto Strasser, 1937, IISG, NL Hertz, S11, M. R, Nr. 2,

Bl. $1-4$, insb. Bl. $2 \mathrm{ff}$.

369 GrossmanN, The Career of Otto Strasser, in: Jewish Frontiers (June 1949), S. 20-25 (21f.).

370 Ibid. S. 25.

371 Die Erklärung ist zum Beispiel abgedruckt bei HLLER, Zum Thema Otto Strasser, in: Ders., Köpfe und Tröpfe 1950, S. 143-152 (144-148).

372 STRASSER, Masaryk 1938, S. 203.

${ }^{373}$ Mit einem bedingungslosen Ita est beschwor Strasser, ibid. S. 274, die Weisheit Masaryks: „Wir hören die klagenden, anklagenden Worte des weisen Lehrers - und nach jedem Satz spricht die Stimme unseres Gewissens tonlos und schuldbewußt: ,so ist es "“" Am Ende des Werkes findet sich ein jubilierendes „So war dieser T. G. Masaryk! Das lehrte dieser T. G. Masaryk! Dazu forderte er uns auf, dieser T. G. Masaryk!“; ibid. S. 280. 
zwei ideologische Stützen: den Deutschen Sozialismus und die „Überzeugung, daß die Politik Hitlers eine Gefahr für die nationale Existenz Deutschlands und für die Zukunft Europas darstellt und auch bei vorübergehenden Siegen nicht geeignet ist, eine dauerhafte Neuordnung Europas zu begründen “374. Entsprechend seinem autoritär-elitären Gesellschaftsverständnis verstand Strasser die Schwarze Front als intellektuelle Vorhut einer „Dritten Front" zwischen Faschismus und Bolschewismus ${ }^{375}$. Innenpolitisch finde sich die „Dritte Front" zwischen der „liberal-marxistisch-bolschewistische[n] Volksfront" und der "konservativ-national-sozialistische[n] Deutsche[n] Front" wieder, ohne dabei wie die "sozialdemokratisch-gewerkschaftliche Gruppe hin und her zu schwanken" ${ }^{376}$. Im Gleichklang mit der politischen Position seiner Schwarzen Front formulierte der agile Nationalsozialist den dreifachen Schlachtruf: „Nationale Freiheit! Soziale Gerechtigkeit! Europäische Zusammenarbeit! " 377 , den er seinen Anhängern in den Jahren von 1934 bis 1937 in ständiger Wiederholung zurief. Diesen drei politischen Schlagworten wurde ein Verhaltenskodex der kämpferischen Disziplin, der ritterlichen Haltung und einer „neuen religiösen und wahrhaft konservativen Weltanschauung" zugeordnet ${ }^{378}$.

Im Gegensatz zu Hermann Rauschning, der sich erst ab 1938 aktiv in die Europadebatten des Exils einschaltete, formulierte Strasser gerade in den frühen Jahren der Emigration wesentliche Grundzüge seines Europabildes. Er setzte sich zunächst in Prag, später in Paris und schließlich in Lateinamerika für eine den ganzen europäischen Kontinent erfassende, wörtlich verstanden national-sozialistische Revolution ein. Als deren Vorkämpfer heroisierte er Thomas Masaryk und ab Juni 1934 seinen beim sogenannten Röhm-Putsch ermordeten Bruder Gregor Strasser als Bannerträger des wahren, unverfälschten Nationalsozialismus ${ }^{379}$. Diese revolutionäre Bewegung sollte nach seinen Vorstellungen in ein - nicht näher spezifiziertes - gemeinsames Europa münden, dessen gemeinsame Wurzeln in den „völkischen, geopoli-

374 KAP, Denkschrift über den Kampf der Schwarzen Front nach dem Anschluß Österreichs, o. D. [Mitte März 1938], S. 1, NL Strasser, IfZ, ED 118/20.

375 STRASSER, Die Dritte Front, in: Die Deutsche Revolution, 11. Jg., Nr. 39 (25. 10. 1936), S. 1 f. (2).

376 Ders., Aufgaben und Möglichkeiten, in: Die Deutsche Revolution, 12. Jg., Nr. 13 (15. 7. 1937),

S. 38-41 (38).

377 Z. B. STRASSER, Unsere Außenpolitik, in: Die Deutsche Revolution, 9. Jg., Nr. 3 (27. 5. 1934), S. 2; Ders., Die Dritte Front, in: Die Deutsche Revolution, 11. Jg., Nr. 39 (25. 10. 1936), S. 2; DERS., Aufgaben und Möglichkeiten, in: Die Deutsche Revolution, 12. Jg., Nr. 13 (15. 7. 1937), S. 40.

378 DERS., Wird Europa gerettet? Ein hoffnungsvoller Ausblick, in: Die Deutsche Revolution, 12. Jg., Nr. 9 (Mai 1937), S. 1.

$379 \mathrm{Vgl}$. z. B. [STRASSER], Gregor Strasser - der deutsche Sozialist, in: Die Deutsche Revolution, 9. Jg., Nr. 9 (8.7.1934). 
tischen, wirtschaftlichen, geschichtlichen und kulturellen Gegebenheiten“ der "große[n] Gemeinsamkeit des Abendlandes" zu sehen seien ${ }^{380}$.

Strassers Abendland-Begriff ist zunächst ebenso durch die kulturhistorische Identifikation geprägt wie die (christlich-)abendländische Vorstellung der Liberalen und Bürgerlich-Konservativen ${ }^{381}$. Doch erhält er eine besondere Konnotation durch die Verknüpfung mit der völkischen Idee, die nach Strassers Interpretation die verschiedenen Völker zwar als gleichrangig ansieht, jeder "Völkerfamilie" aber einen anderen göttlichen Auftrag zuweist $^{382}$. In dem sichtlichen Bemühen, sich von dem Antisemitismus des Hitlerregimes abzugrenzen, rief Strasser den Lesern seiner Zeitschrift Die Deutsche Revolution 1934 zu: „Der Antisemitismus ist tot - Es lebe die Völkische Idee!" ${ }^{383}$ Dahinter stand die wenig überzeugende Taktik, sein Verständnis der völkischen Idee als die eigentlich deutsche Version darzustellen, während Julius Streichers Antisemitismus diese Idee verfälsche und schände. In Verbindung mit seinem Selbstverständnis als Repräsentant des wahren Nationalsozialismus ergab sich daraus ein gewagter Spagat: „Der Nationalsozialismus aber hat mit dieser unvölkischen, undeutschen, unmenschlichen Lüge dieses antisemitischen Kampfes nichts zu tun. ${ }^{\text {384 }}$

Strassers Nationalsozialismus liegt neben dem Abendlandgedanken und der völkischen Idee als dritte Komponente der sogenannte Deutsche Sozialismus zugrunde - einem Zusammenspiel des kapitalistischen Prinzips der Privatinitiative und des marxistischen Prinzips der Vergesellschaftung der

380 STRAsSER, Unsere Außenpolitik, in: Die Deutsche Revolution, 9. Jg., Nr. 3 (27. 5. 1934), S. 1.

381 Vgl. etwa den pragmatischen Vorschlag des SF-Mitarbeiters JANESCHITZ, Garantien für den Völkerfrieden, in: Die Deutsche Revolution, 11. Jg., Nr. 41 (8. 11. 1936), S. 2: „Statt imperialistisches Mobilisierungsmaterial soll man auf den Hochschulen Europas lieber eine Literatur über fremde Völker, Sprachen, Sitten, Lebensgewohnheiten usw. in lebendiger dynamischer Sprache, leicht für jedermann faßlich, bringen. Dadurch wird die eigene Stellung innerhalb des eigenen Raumes begriffen und hierdurch auch die Stellung anderer Völker. Sind diese geistigen und seelischen Grundlagen geschaffen, dann werden auch alle anderen Fragen, die heute Europa so arg bedrängen, gelöst werden können."

382 [STRASSER], (Leitartikel), in: Die Deutsche Revolution, 9. Jg., Nr. 5 (10.6. 1934), S. 1. Der anonym publizierte Beitrag ist mit hoher Wahrscheinlichkeit von Strasser selbst verfaßt worden, der nicht nur in der Bewegung der Schwarzen Front die unumstrittene Führerpersönlichkeit war, sondern auch die inhaltlichen Vorgaben für Die Deutsche Revolution ersann. Gerade der Leitartikel war regelmäßig ihm selbst vorbehalten. Dafür sprechen auch die stilistischen Anlehnungen an den von Strasser gezeichneten Artikel: Unsere Außenpolitik, in: Die Deutsche Revolution, 9. Jg., Nr. 3 (27. 5. 1934), S. 1 f., der in anderem Zusammenhang ebenfalls die alte französische Formel für die Verkündigung des geblütsrechtlichen Herrschaftsübergangs nach dem Tod des Königs benutzt. Dort findet sich auch eine korrespondierende Darstellung der völkischen Idee, die die Welt in koexistierende, zueinander sich unorganisch verhaltende Völkerfamilien einteilt.

383 Ibid.

384 Ibid. 
Monopolgüter, dessen Aufgabe die „Entproletarisierung des einzelnen Menschen und die gesicherte Bedarfsdeckung für die Gemeinschaft ${ }^{* 385}$ sei. Ziel des Deutschen Sozialismus sei eine nationale sozialistische Revolution, die eine „völlige Abkehr vom Geist des Imperialismus und Kapitalismus, offenbar gemacht im Aufbau eines sozialistischen Wirtschaftssystems und eines Volksstaates der Selbstverwaltung", herbeiführen werde ${ }^{386}$. Im Gegensatz zur gängigen sozialistischen Revolutionsideologie verzichtete Strasser also auf eine Weltrevolution, sondern berief sich auf das seiner Ansicht nach antiimperialistisch strukturierte Selbstbestimmungsrecht der Völker, das jeden Übergriff auf andere Völker verbiete ${ }^{387}$.

Aus der völkischen Fokussierung seiner Sicht folgte für Strasser: „Nicht Völkerbund - sondern Europabund" 388 . Ein Weltbund komme als Grundlage der internationalen Ordnung schon deshalb nicht in Betracht, weil dort verschiedene Völkerfamilien zusammenträfen, die lediglich einen der völkischen Idee widersprechenden „unorganischen“ Formalbund eingehen könn$\operatorname{ten}^{389}$. Sinnvoll sei allein die Zusammenfassung von Gliedern ein und derselben Völkerfamilie. Daher sei ein vereinigtes Europa nur anstelle des Völkerbundes denkbar ${ }^{390}$. Da von der Frage der europäischen Einigung zugleich die Rolle Europas in der Welt abhänge, sei die Einigung unbedingt notwendig ${ }^{391}$. Vorrangig auf die wirtschaftliche Perspektive abstellend, konstatierte der eigenwillige Einzelkämpfer, daß nur ein Europabund in der Lage sei, den angestammten Platz des alten Kontinents als fünfter Weltwirtschaftsblock neben Rußland, dem Commonwealth, Amerika und Ostasien ("Japan-China“) einzunehmen ${ }^{392}$.

Der Jurist und Ökonom wähnte Europas geistige Entwicklung in einer Übergangsphase, die es als „Geburtswehen einer neuen Ordnung“ zu erken-

385 STRASSER, Die Dritte Front, in: Die Deutsche Revolution, 11. Jg., Nr. 39 (25. 10. 1936), S. 1 f. Die Vision eines Wirtschaftssystems mit kollektivistischen und individualistischen Elementen weist einige bemerkenswerte Parallelen zu den ökonomischen Neuordnungsplänen des bürgerlich-konservativen Journalisten Edgar Stern-Rubarth auf, der in einem 1940 veröffentlichten Verfassungsentwurf für eine europäische Föderation eine Monopolisierung und Verstaatlichung aller das Existenzminimum gewährleistenden Güterproduktionen (Lebensmittel, Textilien, Energie, Unterkunft und medizinische Versorgung) anregte; vgl. STERN-RuBARTH, Exit Prussia 1940, insb. S. $214 \mathrm{f}$. 386 STRASSER, Unsere Außenpolitik, in: Die Deutsche Revolution, 9. Jg., Nr. 3 (27. 5. 1934), S. 2.

387 Strasser formulierte eine „leidenschaftliche Absage an den Imperialismus“ und versicherte: "Die sozialistische Revolution gibt auch dem eingefleischtesten Argwohn die Gewähr, daß dieses neue Deutschland niemals an die nationale Freiheit und innere Unabhängigkeit eines anderen Volkes rührt, sondern in Theorie und Praxis das Selbstbestimmungsrecht der Völker anerkennt. “ (ibid.).

388 Ibid.

389 Ibid.

390 Euphorisch rief Strasser, ibid.: „Der Völkerbund ist tot - Es lebe die Europäische Föderation! ${ }^{\prime}$

391 Ibid.

392 Ibid. 
nen gelte ${ }^{393}$. Diese neue Ordnung sei ebenso notwendig wie unausweichlich und werde die momentane ideologische Verwirrung zwischen Faschismus und Bolschewismus zugunsten einer synthetisierenden Dritten Front des wohlverstandenen Nationalsozialismus aufheben. Aus einer erklärtermaßen antiliberalen, antikapitalistischen und antiimperialistischen Haltung heraus forderte der "Gegenführer im Exil“394 eine europäische Einigung auf der Grundlage nationaler Freiheit und planwirtschaftlicher Kooperation ${ }^{395}$. Auch in geostrategischer Hinsicht sei ein Umdenken notwendig. Die von Hitler angestrebte "London-Berlin-Rom-Linie“ spalte den Kontinent und bedürfe daher einer strukturellen Substitution durch die kontinental zusammenfassende Linie „Paris-Berlin-Prag-Belgrad-Bukarest“396.

Auch wenn Strasser die "endliche Befriedung Europas"397 beschwor, so war sein eigentliches Motiv wohl weniger der Frieden als Selbstzweck, sondern die machtvolle Stärkung Europas in zumindest ökonomischer Frontstellung gegen die anderen vier Weltreiche. Daher legte er - im Unterschied zu seiner Nachkriegsposition - großen Wert auf eine „Rückversicherung bei der Sowjetunion“398, deren weltweite Machtfülle er klar erkannte ${ }^{399}$.

Ordnungspolitisch wählte auch Strasser das Vorbild der Schweiz und befürwortete eine Europäische Föderation nach Schweizer Muster. Damit sei insbesondere dem krisengeschüttelten Südosteuropa eine Zukunft als Kornkammer Europas und Impulsgeber einer neuen abendländischen Blüte gesichert ${ }^{400}$. Mit einem gewagten Spiel der Begriffe steigerte sich der SF-Mitarbeiter Johann von Buch zu der These: „Faschismus gleich Imperialismus Nationalsozialismus gleich Föderalismus “401. Erneut wird die strikte Ab-

393 STRASSER, Wird Europa gerettet?, in: Die Deutsche Revolution, 12. Jg., Nr. 9 (Mai 1937), S. 1.

394 So der treffende Titel eines Aufsatzes von ZuR MüHLEN, Der "Gegen-Führer“ im Exil. Die Otto-Strasser-Bewegung in Lateinamerika 1985.

395 STRASSER, Unsere Außenpolitik, in: Die Deutsche Revolution, 9. Jg., Nr. 3 (27. 5. 1934), S. 2.

396 Ibid.

397 Ibid.

398 STRASSER, Alfred Rosenberg und das neue Europa. Der Leiter des Außenpolitischen Amtes der NSDAP als ,Realpolitiker", in: Die Deutsche Revolution, 9. Jg., Nr. 25 (18. 10. 1934).

399 DERS., Unsere Außenpolitik, in: Die Deutsche Revolution, 9. Jg., Nr. 3 (27. 5. 1934), S. 2: „Wer zweifelt daran, daß diese Europäische Föderation, für deren Möglichkeit und Aufbau die Schweiz ein geradezu klassisches Muster darstellt, es ermöglicht, Europa noch einmal gleichberechtigt in die Reihe der gewaltigen Welt-Wirtschafts-Reiche zu setzen, deren Bildung deutlich sichtbar ist?! Wer zweifelt andererseits daran, daß ohne diese Europäische Föderation nicht nur machtpolitisch die Rolle Europas ausgespielt ist, sondern auch der Lebensstandard seiner Bevölkerung und die Höhe seiner Kultur hoffnungslos verloren sind?!“

400 Ibid.

401 BuCH, Der Faschismus und die Neugeburt Europas. Faschismus gleich Imperialismus - Nationalsozialismus gleich Föderalismus, in: Die Deutsche Revolution, 9. Jg., Nr. 11 (22.7. 1934). 
grenzung des eigenen nationalsozialistischen Verständnisses von Hitlers Faschismus deutlich, wobei sich Strasser mit seinem föderalistischen Anspruch in einen kaum zu überwindenden Widerspruch zu der gleichzeitig geforderten strikten Einhaltung des Nichteinmischungsprinzips und der Verweigerung jeglichen nationalen Souveränitätsverzichts begab ${ }^{402}$.

Keinen Zweifel ließ der Gründer der Schwarzen Front an der Schlüsselposition Deutschlands, ohne dessen Freiheit eine europäische Zukunft undenkbar sei. Seinen Lesern wurde die Schwarze Front als „Avantgarde einer Wiedergeburt Europas durch die Wiedergeburt Deutschlands" präsentiert „eine Wiedergeburt aus dem Geist des Abendlandes, der sich in der Deutschen Revolution erneuert unter den Parolen: nationale Freiheit, soziale Gerechtigkeit, europäische Zusammenarbeit! " ${ }^{403}$ Deutschland müsse im Zeichen sozialistischer Wiedergeburt den Weg in die Gemeinschaft der abendländischen Nationen suchen ${ }^{404}$. Erst dann werde die Dritte Front das Ziel ihres Kampfes erreicht haben: „Das neue Deutschland im neuen Europa!“405

Strasser war kein Gegner des Nationalsozialismus, sondern ein persönlicher Gegner Hitlers, den er als „,Kork' der [deutschen] Revolution“, "Pseudo-Führer" und „Barometer des Kleinbürgertums" verachtete ${ }^{406}$ und dem er den Tod seines Bruders nie verzeihen konnte. Ein Außenseiter im Exil, vertrat Strasser ein Europabild, das europäischen Föderalismus mit jungkonservativem Nationalismus und revolutionären Sozialismus mit völkischem Rassismus zu verbinden suchte ${ }^{407}$. Dieser ideelle Drahtseilakt entbehrte der nötigen Stringenz und litt an einer überschießenden Innentendenz theoretisierender Konzeptionalisierung. Strassers im Ergebnis sehr vage gehaltenes Europakonzept unterlag im Laufe des Exils mehrfachen Modifikationen, deren Abgrenzung zu einem schlicht machtpolitisch definierten Europa unter dem Hakenkreuz spätestens seit 1938 zunehmend schwieriger werden sollte ${ }^{408}$.

402 Insbesondere in STRASSERS Veröffentlichung Europäische Föderation 1936 findet sich die Bejahung einer europäischen Föderation unter Einschränkung der nationalen Souveränität.

403 STRASSER, Aufgaben und Möglichkeiten, in: Die Deutsche Revolution, 12. Jg., Nr. 13 (15. 7. 1937), S. 39 f.

404 STRASSER, Volk ans Gewehr. Die Parole des neuen Jahres, in: Deutsche Revolution (Januar 1937), abgedruckt in: BaRTSCH, Zwischen drei Stühlen 1990, S. 241.

405 Strasser, Aufgaben und Möglichkeiten, in: Die Deutsche Revolution, 12. Jg., Nr. 13 (15. 7. 1937), S. 41.

406 STRASSER, Volk ans Gewehr, in: Deutsche Revolution (Januar 1937), abgedruckt in: BARTSCH, Zwischen drei Stühlen 1990, S. 239.

407 Dies verkennt VoIGT (Hg.), Friedenssicherung 1988, S. 190, wenn er urteilt, Strasser habe sich vom völkischen Nationalisten zum europäischen Föderalisten gewandelt. Strasser versuchte vielmehr eine Verschmelzung beider Ansätze.

408 Vgl. etwa Strassers unveröffentlichte Denkschrift über den Kampf der Schwarzen Front nach dem Anschluß Österreichs, o. D. [Mitte März 1938], S. 1, NL Strasser, IfZ, ED 118/20, in der er trotz aller persönlichen Vorbehalte gegen Hitler anerkannte: „[...] 


\section{Zwischenergebnisse}

Stellvertretend für viele deutsche Emigranten stellte August Siemsen noch 1937 fest: „Europa ist ein geographischer, aber kein politischer Begriff, wenigstens keiner mit positivem Inhalt. Es gibt die Sowjetunion, es gibt das englische Weltreich, es gibt die Vereinigten Staaten von Amerika, - aber es gibt keine Vereinigten Staaten von Europa. “409

Auf den ersten Blick erscheint Siemsens Urteil überzogen angesichts der nicht zu unterschätzenden europapolitischen Bemühungen des politischen Exils zwischen 1933 und 1937. Wenngleich die bis 1937 entwickelten Gedanken zu einer Neuordnung des europäischen Kontinents der wünschenswerten Tiefe und Präzision entbehrten, wurden in diesen ersten Jahren der Emigration doch einige wesentliche Grundzüge herausgearbeitet, die ab 1938 wieder aufgenommen und im Detail erörtert wurden. Drei wesentliche Ergebnisse stehen am Ende dieser frühen Phase des Europadiskurses:

Zunächst ist festzuhalten, daß mit Ausnahme der Kommunisten Vertreter nahezu aller politischen Gruppierungen des deutschen Exils bis 1937 zur Frage der europäischen Zukunft Stellung nahmen und die europapolitische Debatte in unterschiedlicher Intensität aufrechterhielten. Darüber hinaus wurde in den ersten Jahren des Exils durch die tagespolitischen Impulse der europäischen Entwicklung und die persönliche Betroffenheit der Emigranten ein europäisches Krisenbewußtsein gefördert, das schon bald in eine zögerliche, aber nachhaltige innereuropäische Rückbesinnung mündete. Man erinnerte sich des Europagedankens als politischem Kampfbegriff und erkannte frühzeitig dessen Widerstandspotential.

Das Selbstverständnis des politischen Exils als Aktivposten des deutschen Widerstandes gegen das Hitler-Regime erfuhr eine weitere Dimension mit der Erkenntnis, daß die Entwicklung von Neuordnungsplänen für Deutschland und Europa die Anleitung des innerdeutschen Widerstandes sinnvoll ergänzen könne. Dieser Widerstand durch Planung hatte zudem den Vorteil, daß er unmittelbar aus dem Exil heraus geleistet werden konnte und nicht auf die breite Basis der Mitglieder und Wähler angewiesen war, der die Exilorganisationen verlustig gegangen waren.

Schließlich wurden während der frühen Diskursphase ideologische Grundlagen für ein vereintes Europa hergeleitet oder aus den Weimarer Debatten aktualisiert. Auf diese Weise offenbarten die Gruppen des politischen Exils ihre Motive für eine europäische Einigung und boten oft erste Begründungsansätze. Mehrheitlich wurde das Interesse an einer gemeinsam gestalteten europäischen Zukunft mit der Überwindung Hitlers, der wirksamen Bekämpfung künftiger Aggressoren und dem allgemeinen Wunsch nach Besei-

der Anschluß Österreichs stellt einen historischen Erfolg für die Nation selbst dar, den wir weder leugnen, noch verkleinern dürfen".

409 Siemsen (Hg.), Preußen. Die Gefahr Europas 1937, S. 193. 
tigung der Kriegsgefahr durch eine effektive Friedenssicherung begründet. Auch lassen sich erste, häufig noch vage Überlegungen zur Neugestaltung internationaler Ordnungsprinzipien durch den Föderalismusgedanken oder ein stärkeres Völkerrecht erkennen. Der Ruf nach einer Überwindung des Nationalstaatsprinzips und der damit verbundenen Doktrin absoluter Staatssouveränität sollte in den Jahren ab 1938 eine Schlüsselfunktion des Europadiskurses übernehmen. Zudem spielten welt- und binnenwirtschaftliche Überlegungen eine zentrale Rolle. Doch handelte es sich bei der Forderung nach einem europäischen Wirtschaftsbündnis um geistiges Allgemeingut aus Weimarer Diskussionen, das weniger ideologischen Kontroversen als vielmehr der Einsicht in ökonomische Notwendigkeiten entsprang. Mithin sind die zwischen 1933 und 1937 erarbeiteten Einsichten und Impulse für das Verständnis des weiteren Europadiskurses grundlegend und weisen eine strukturelle Nachhaltigkeit auf.

Dennoch darf nicht übersehen werden, daß August Siemsens enttäuschende Bilanz nicht völlig unberechtigt ist. Jedenfalls ist ihm insoweit zuzustimmen, als die Überlegungen zu einem vereinten Europa als selbständigem, in sich selbst legitimiertem Ziel bis 1937 noch nicht allzu weit gediehen waren. Die meisten Ansätze blieben dort stehen, wo eine Konkretisierung des politischen Gehaltes einer europäischen Staatengemeinschaft angestanden hätte: die Position und die künftigen Aufgaben eines vereinten Europas in der Welt, die Institutionalisierung der Friedenssicherung und Wirtschaftskooperation sowie eine genauere Betrachtung des Verhältnisses zum Völkerbund wurden in der frühen Phase des Europadiskurses nur selten mit der gebotenen Ausführlichkeit erörtert.

Für dieses Versäumnis können mehrere Gründe angeführt werden. Die Hauptursache ist in der Tatsache zu sehen, daß das aktuelle Zeitgeschehen von den Emigranten anfangs eine andere Prioritätensetzung forderte. Exiltypische Probleme beanspruchten das politische Engagement in hohem Maße. Es galt, ein neues Selbstverständnis als Partei im Exil, als Widerstandsorganisation ohne Basis und individuell als Persönlichkeit im fremden Land zu entwickeln. Fragen der politischen Legitimation und persönliche Zwistigkeiten ließen die intensiven Volksfrontbestrebungen zeitweilig an die Arbeiten des Sisyphos erinnern. Die persönliche und organisatorische Ausnahmesituation des Exils bedurfte einer längeren Gewöhnungsphase. Auch nahm der Aufbau einer neuen geistigen Heimat, insbesondere in den Exilzentren Prag und Paris, viel Zeit in Anspruch, zumal die politische Emigration zu Beginn mehrheitlich eine rasche Überwindung des Hitler-Regimes und eine dementsprechend baldige Rückkehr erwartet hatten. Gerade in dieser Hinsicht dienten die intellektuellen Diskurse als Substitut des heimatlichen sozialen Umfeldes. Umso mehr gilt dies für den Europadiskurs, der in besonderer Weise geeignet war, durch die kontroverse Erörterung eines im Grundsatz allseits bejahten Zieles eine gewisse Solidarität des geistigen Disputes im Exil zu schaffen. 
Daher blieb die Konkretisierung des politischen Begriffs „Europa“, zu der Siemsen aufforderte, den detaillierten Europadiskussionen ab 1938 vorbehalten. Es offenbart sich eine gewisse Tragik in der Tatsache, daß die exilierten Europäer in dem Augenblick, in dem sie sich anschickten, Siemsens Aufforderung nachzukommen, von der Wirklichkeit eines nationalsozialistisch definierten, zum politischen Faktum heranwachsenden Europas überholt wurden. 
